NASA/TM-2012-217678

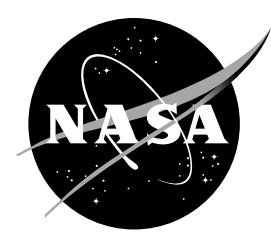

Optical and Scanning Electron Microscopy of the Materials International Space Station Experiment (MISSE) Spacecraft Silicone Experiment

Ching-cheh Hung and Kim K. de Groh

Glenn Research Center, Cleveland, Ohio

Bruce A. Banks

Alphaport, Inc., Cleveland, Ohio 


\section{NASA STI Program . . . in Profile}

Since its founding, NASA has been dedicated to the advancement of aeronautics and space science. The NASA Scientific and Technical Information (STI) program plays a key part in helping NASA maintain this important role.

The NASA STI Program operates under the auspices of the Agency Chief Information Officer. It collects, organizes, provides for archiving, and disseminates NASA's STI. The NASA STI program provides access to the NASA Aeronautics and Space Database and its public interface, the NASA Technical Reports Server, thus providing one of the largest collections of aeronautical and space science STI in the world. Results are published in both non-NASA channels and by NASA in the NASA STI Report Series, which includes the following report types:

- TECHNICAL PUBLICATION. Reports of completed research or a major significant phase of research that present the results of NASA programs and include extensive data or theoretical analysis. Includes compilations of significant scientific and technical data and information deemed to be of continuing reference value. NASA counterpart of peer-reviewed formal professional papers but has less stringent limitations on manuscript length and extent of graphic presentations.

- TECHNICAL MEMORANDUM. Scientific and technical findings that are preliminary or of specialized interest, e.g., quick release reports, working papers, and bibliographies that contain minimal annotation. Does not contain extensive analysis.

- CONTRACTOR REPORT. Scientific and technical findings by NASA-sponsored contractors and grantees.
- CONFERENCE PUBLICATION. Collected papers from scientific and technical conferences, symposia, seminars, or other meetings sponsored or cosponsored by NASA.

- SPECIAL PUBLICATION. Scientific, technical, or historical information from NASA programs, projects, and missions, often concerned with subjects having substantial public interest.

- TECHNICAL TRANSLATION. Englishlanguage translations of foreign scientific and technical material pertinent to NASA's mission.

Specialized services also include creating custom thesauri, building customized databases, organizing and publishing research results.

For more information about the NASA STI program, see the following:

- Access the NASA STI program home page at http://www.sti.nasa.gov

- E-mail your question to help@sti.nasa.gov

- Fax your question to the NASA STI Information Desk at 443-757-5803

- Phone the NASA STI Information Desk at 443-757-5802

- Write to: STI Information Desk NASA Center for AeroSpace Information 7115 Standard Drive Hanover, MD 21076-1320 
NASA/TM-2012-217678

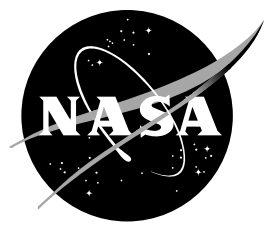

\section{Optical and Scanning Electron Microscopy of the Materials International Space Station Experiment (MISSE) Spacecraft Silicone Experiment}

Ching-cheh Hung and Kim K. de Groh

Glenn Research Center, Cleveland, Ohio

Bruce A. Banks

Alphaport, Inc., Cleveland, Ohio

Prepared for the

10th International Space Conference on Protection of Materials and Structures From the Space

Environment (ICPMSE-10J)

cosponsored by ITL, MDA, CSA, JAXA, Kobe University Graduate School of Engineering, and the Society for Promotion of Space Science

Bankoku-Shinryokan, Okinawa, Japan, June 12-17, 2011

National Aeronautics and

Space Administration

Glenn Research Center

Cleveland, Ohio 44135 
Trade names and trademarks are used in this report for identification only. Their usage does not constitute an official endorsement, either expressed or implied, by the National Aeronautics and Space Administration.

Level of Review: This material has been technically reviewed by technical management.

Available from

NASA Center for Aerospace Information 7115 Standard Drive

Hanover, MD 21076-1320
National Technical Information Service 5301 Shawnee Road Alexandria, VA 22312

Available electronically at http://www.sti.nasa.gov 


\title{
Optical and Scanning Electron Microscopy of the Materials International Space Station Experiment (MISSE) Spacecraft Silicone Experiment
}

\author{
Ching-cheh Hung and Kim K. de Groh \\ National Aeronautics and Space Administration \\ Glenn Research Center \\ Cleveland, Ohio 44135 \\ Bruce A. Banks \\ Alphaport, Inc. \\ Cleveland, Ohio 44135
}

\begin{abstract}
Summary
Under a microscope, atomic oxygen (AO) exposed silicone surfaces are crazed and seen as "islands" separated by numerous crack lines, much analogous to mud-tile cracks. This research characterized and compared the degree of $\mathrm{AO}$ degradation of silicones by analyzing optical microscope images of samples exposed to low Earth orbit (LEO) AO as part of the Spacecraft Silicone Experiment. The Spacecraft Silicone Experiment consisted of eight DC 93-500 silicone samples exposed to eight different AO fluence levels (ranged from 1.46 to $8.43 \times 10^{21}$ atoms $/ \mathrm{cm}^{2}$ ) during two different Materials International Space Station Experiment (MISSE) missions. Image analysis software was used to analyze images taken using a digital camera. To describe the morphological degradation of each $\mathrm{AO}$ exposed flight sample, three different parameters were selected and estimated: (1) average area of islands was determined and found to be in the 1000 to $3100 \mu \mathrm{m}^{2}$ range; (2) total length of crack lines per unit area of the sample surface were determined and found to be in the range of 27 to $59 \mathrm{~mm}$ of crack length per $\mathrm{mm}^{2}$ of sample surface; and (3) the fraction of sample surface area that is occupied by crack lines was determined and found to be in the 25 to 56 percent range. In addition, average crack width can be estimated from crack length and crack area measurements and was calculated to be about $10 \mu \mathrm{m}$. Among the parameters studied, the fraction of sample surface area that is occupied by crack lines is believed to be most useful in characterizing the degree of silicone conversion to silicates by AO because its value steadily increases with increasing fluence over the entire fluence range. A series of SEM images from the eight samples exposed to different AO fluences suggest a complex sequence of surface stress due to surface shrinkage and crack formation, followed by re-distribution of stress and shrinking rate on the sample surface. Energy dispersive spectra (EDS) indicated that upon AO exposure, carbon content on the surface decreased relatively quickly at the beginning, to 32 percent of the pristine value for the least exposed sample in this set of experiments $\left(1.46 \times 10^{21}\right.$ atoms $\left./ \mathrm{cm}^{2}\right)$, but then decreased slowly, to 22 percent of the pristine value for the most exposed sample in this set of experiment $\left(8.43 \times 10^{21}\right.$ atoms $\left./ \mathrm{cm}^{2}\right)$. The oxygen content appears to increase at a slower rate. The least and most $\mathrm{AO}$ exposed samples were, respectively, 52 and 150 percent above the pristine values. The silicone samples with the greater AO exposure $\left(7.75 \times 10^{21}\right.$ atoms $/ \mathrm{cm}^{2}$ and higher $)$ appear to have a surface layer which contains $\mathrm{SiO}_{2}$ with perhaps small amounts of unreacted silicone, $\mathrm{CO}$ and $\mathrm{CO}_{2}$ sealed inside.
\end{abstract}




\section{Introduction}

In LEO, the AO environment causes silicones to shrink at the surface as the AO exposed surface converts to a glassy brittle silicate layer, which then cracks due to shrinkage giving the surface a crazed, or mud-tile cracked, appearance (Ref. 1). Because silicone is a commonly used pliable spacecraft material use for applications such as the use of DC 93-500 to bond cover glasses to solar cells for the ISS photovoltaic array blankets or as protective coatings on the back of solar arrays, characterization of its degradation during space exposure is essential for this material to be used properly.

Because AO exposure typically does not cause silicones to lose mass, its AO degradation is better characterized by other changes that can be more accurately measured than mass loss (which is used for the majority of other hydrocarbon based materials) (Ref. 2). For example, changes in surface hardness have been measured for silicone samples exposed to both ground-laboratory and space AO using nanoindentation techniques (Ref. 3). Silicone degradation in AO can also be characterized by changes in optical properties. This study was accomplished by measuring surface cracks in silicone samples exposed to LEO AO on the exterior of the International Space Station as part of the Spacecraft Silicones Experiment flown on both Materials International Space Station Experiment 2 and 4 (MISSE 2 \& 4) (Ref. 4).

This research characterized and compared the degree of AO degradation of silicones by analyzing optical microscope images of samples exposed to LEO AO as part of the Spacecraft Silicone Experiment. The Spacecraft Silicone Experiment consisted of eight DC 93-500 silicone samples exposed to eight different AO fluence levels (ranged from 1.46 to $8.43 \times 10^{21}$ atoms $/ \mathrm{cm}^{2}$ ) during two different Materials International Space Station Experiment (MISSE) missions.

The most obvious effect observed for silicones during AO environment exposure are changes in surface morphology. Under optical microscopy, all space exposed silicone surfaces contain "islands" separated by numerous crack lines (as shown in Fig. 1, Ref. 5) after they have been exposed to relatively low AO fluence exposures. Surface morphology changes, however, have not been used in the past to characterize silicone degradation during AO exposure. This is because of the difficulty in developing a standard method that can quickly, accurately and quantitatively be used to analyze changes in surface morphology. The problem of using numbers to characterize changes in pictures, however, is greatly alleviated due to the recent advancement of imaging analysis computer software. Consequently, using morphology changes to characterize silicone degradation due to AO exposure has become feasible. In this study, the morphology of retrieved MISSE $2 \& 4$ silicone samples were examined and quantified. Commercially available image analysis software was used to analyze images of the samples taken by an optical microscope. Scanning electron microscope (SEM) was also used to examine features that were beyond the capability of the optical microscope. No attempts were made to use the image analysis software to analyze the SEM images.

Images from the optical microscope were analyzed using commercially available software to determine the average area of "islands", the density of crack lines, and the percent of total area that is occupied by the crack lines. Relationships between these morphological parameters and the AO fluences were then examined and discussed. SEM was used to analyze smaller features of the samples exposed to the LEO environment over several different fluence levels. Development of individual cracks as a function of fluence was examined. In addition, energy dispersive spectrum (EDS) was used to semiquantitatively analyze the relative concentrations of silicon, oxygen and carbon. Results of the SEM investigation were used to infer the kinetics of atomic oxygen-silicone reactions. 


\section{Methods}

\section{Silicone Samples and LEO Exposure}

Eight DC 93-500 samples were exposed to LEO ram exposure during 2 different MISSE missions (MISSE $2 \& 4$ ) such that each sample received a different AO fluence level. Four samples were exposed during each of the MISSE missions. Three of the four samples in each mission were covered with different thickness layers of Kapton $\mathrm{H}$ film in order for each of the samples in the same mission to receive a different $\mathrm{AO}$ fluence, as the $\mathrm{AO}$ needs to erode through the cover-laying Kapton before attacking the underlying silicone. The samples were $0.025 \mathrm{~cm}(10 \mathrm{mil})$ thick and were placed on $0.16 \mathrm{~cm}(1 / 16 \mathrm{in}$.) thick fused silica slides to keep the samples from bending and hence inducing cracking in the glassy oxidized layer (Ref. 4). The samples in the experiment trays were photographed prior to, and after, space exposure as shown in Figures 2 and 3. Post-flight photos of the eight samples are shown in Figure 4 along with the sample ID, the Kapton H cover thickness and the resulting AO fluences. It should be noted that MISSE 4 sample 4-E22-2 was flown with an aluminum washer (with a 0.44 in. diameter opening), thus the exposed area is a smaller area than the other seven flight samples, as indicated in Figure 4. The edges of the samples are protected from AO exposure during flight, and hence the Kapton covers are still present at the edges of the six samples that contained Kapton covers. The sample space exposures are summarized in Table 1. The sunlight and temperature history and the detailed results of previous studies of these samples are summarized elsewhere (Refs. 4, 6 to 8 ).

\section{Optical Microscope}

\section{Instruments}

The stereomicroscope used in this study was a MZ 16 by Leica Microsystems. It has a magnification power range of $x 7$ to $x 110$. The silicone samples were placed on a motorized microscope stage (by Semprex) which is operated by a controller (OASIS-4i with computer software by Objective Imaging Ltd). The controller precisely controls the movement of microscope stage in a simple, repeatable manner for reproducible results. This eliminates the need to manually adjust sample positions. Images of the samples are taken by a digital color camera (TRV3.3 by MicroPublisher). The camera is controlled by computer software (Image Pro Plus by Media Cybernetics), which acquires, processes, analyzes and measure the images from the camera. Image analysis used in this study is described in detail in the following sections.

\section{Image Description and Characterization}

The Leica Microsystems camera receives white light reflected from the sample surface. Since the crack region is less transparent and more reflective than the rest of the sample surface, the image obtained from the camera shows a network of white crack lines and black "island" areas. Figure 5(a) is an example of an optical microscope image This picture is from the MISSE sample exposed to the highest AO fluence (sample 2-E5-1, which did not contain a Kapton H cover and received an AO fluence of $8.43 \times 10^{21}$ atoms $/ \mathrm{cm}^{2}$ during the MISSE 2 mission). In this report, all the optical microscope images were taken from an $1110 \times 830 \mu \mathrm{m}$ area at the center of the sample surface. This is equivalent to $100 \mathrm{x}$ magnification.

Various parameters to characterize the optical microscope images were analyzed and compared. Specifically, three parameters were obtained from the image analysis software and studied in this research. These include: (1) the average area of the islands, (2) the fraction of sample surface area that is occupied by crack lines, and (3) the total length of crack lines per unit area of the sample surface. 


\section{Image Analysis}

The above three parameters were obtained using image analysis software. This was done by first modifying the original pictures so that the modified picture was compatible with the software, and then by actually doing the analysis measurement. Details of this process are described below using Figure 5 as the illustrating example.

The original picture (Fig. 5(a)) was at first modified by removing the shades of grey, so that the region occupied by crack lines became 100 percent white and the rest of the areas became 100 percent black. The black and white in this picture was then inverted to give Figure 5(b), which can be used by the software to calculate individual and total white (island) areas. The black thick lines (crack lines) in Figure 5(b) were then reduced to thin lines by the software to result in Figure 5(c), from which the perimeter of individual areas as well as sum of perimeters of all areas in the picture can be calculated by the software. The total length of the crack lines in the picture were then calculated as half of the sum of perimeters of all areas in the picture. Individual, total and average island areas were also calculated from Figure 5(c).

Noise reduction and signal enhancement were applied throughout the process. These were done in the same way to all samples, and were carried out by the computer software. When enhancing the very faint crack lines, the image enhancement process may erroneously create fabricated lines and many very small "islands" from two crack lines that are in very close proximity to each other. The effects of this type of error will be discussed later in this report.

\section{Scanning Electron Microscopes}

\section{Sample Preparation}

A Hitachi S-3100 was used to take 350x pictures. A Hitachi S-4700II was used to take 1000x and higher magnification pictures. All silicone samples in this research are electrical insulators. A path of electricity from the sample holder to the sample surface is needed for the purpose of examining the sample by SEM. For this purpose, two sections of copper tape were taped to every sample to electrically connect the bottom of the sample (i.e., the fused silica slides used to protect the silicone sample) to the sample surface. The surfaces of samples were then coated with thin layers of 40 percent Pd-60 percent $\mathrm{Au}$. During coating, half of the sample surface was protected by a piece of paper. Therefore, only half of the surface of every sample was coated. A small spot of carbon paint was then placed on the area between the copper tape and the coated surface. In this situation, the electron beam from the SEM travels to the surface, the carbon dot, the copper tape, the sample holder at the bottom of the sample, and then back to the instrument.

\section{Examination}

Morphologies of all AO exposed silicone surfaces were examined. Pictures of every sample were taken at three different magnifications: 350x, 1000x, and 5000x. From these images, the kinetics of shrink-crack interaction can be examined.

EDS spectra of all AO exposed silicone surfaces, and a pristine sample surface, were also obtained and analyzed. All spectra were taken with the same instrument settings of $6 \mathrm{kV}$ and $10 \mu \mathrm{A}$. From each spectrum, the ratios of $\mathrm{C}$ to Si peak height and $\mathrm{O}$ to Si peak height were measured and calculated. The peak height ratios of $\mathrm{AO}$ exposed samples were then compared to those of the pristine sample. From these results, a semi-quantitative analysis can be made to measure the changes of the chemical composition of silicone resulting from $\mathrm{AO}$ exposure over a long period of time. 


\section{Results and Discussions}

\section{Optical Microscope}

\section{Pictures}

The original and processed optical microscopy images of all eight samples examined in this research are presented in Appendix A.

It was observed that the silicone sample with the lowest AO fluence (sample 4-E22-5) has a large amount of debris material on it, seen primarily as white spots and clusters (Fig. A8 in Appendix A). These are residual fragments of the Kapton $\mathrm{H}$ cover layer placed on top of the silicone for the purpose of adjusting AO exposure of the under-laying silicone to a lower level. Since the residue resulted in strong interference during image analysis, optical microscope data obtained from this sample was not further examined. This sample, however, was further examined by SEM which will be described later in this report.

All of the samples had some debris on them also. These particles were examined using EDS, and will be described at the final part of the Scanning Electron Microscope Image Analysis Section. These particles also contribute to the interference of signals, especially during the process of signal enhancement. During this process a large number of very small "islands" were created around these particles at the same time when the very faint crack lines were enhanced and therefore preserved. The error cause by this interference will be discussed in Section "Possible error".

\section{General Trend of Parameters to Characterize AO Exposure}

The three different characterization parameters (the average area of the islands, the fraction of sample surface area that is occupied by crack lines, and the total length of crack lines per unit area of the sample surface) for the samples that were degraded by AO exposure to seven different fluence levels are summarized in Table 2. Since average crack widths can be estimated from crack length and crack area described above, they were calculated and also shown in Table 2. Figure 6 contains plots and corresponding trend lines of these morphological parameters plotted against the AO fluence. Exponential equations were used to represent the trend lines because of the observation that changes of the morphological parameters were fast at the beginning, but slowed down continuously as the total fluence increased.

\section{Possible Error}

A review of Table 2 and Figure 6 revealed that, among the three morphological parameter-fluence relations, the fraction of sample surface area that is occupied by crack lines seems to have the least data scattering and most consistent trend, as shown in Figure 6(b). The other two plots had larger data scattering. These large data scattering may be an artificial effect resulting from the data processing.

The data scattering for the average area of the islands-fluence relation may be an error resulting from the creation of a large number of very small "islands" during the process of image enhancement. Adding many small fabricated islands into the picture significantly reduces the average island area.

The data scattering of the total crack line length per unit area is more difficult to explain. It may also be an artificial effect resulting from the image processing.

Data scattering of the fraction of sample surface area that is occupied by crack lines is the least among these three. This may possibly be a result of it being the simplest data processing method, as it was calculated from images of crack areas (see picture (b) in all Figures in Appendix A), while the other two parameters were calculated from images where crack areas needed to be reduced to thin lines (picture (c) from all Figures in Appendix A). Regardless of the reason why some trends appears to be more complicated than others, the above results suggest that the best morphological parameter to characterize the degradation of silicone under AO exposure would be the crack line area as a percent of the total sample surface area because it has the least data scatter. 


\section{Possible Kinetics of Crack Line Development}

Figure 7 is a plot of crack length per area versus crack area per total area. It shows the surface area increases almost linearly with crack length, indicating that crack width does not change much. Newly formed cracks continue to have the same width as the old ones until the fluence reached a very high level. This suggests that crack propagation is mostly either by growth of new cracks or by lengthening of the old cracks until the island areas become thick, glassy, and small.

As described previously, the image of AO exposed silicone samples obtained from reflected light shows white crack lines and black "island" areas. This illustrates that the island areas transmit light, and the crack areas are more reflective. A consequence of the growth of crack area would therefore be a loss of specular transmittance with fluence. This would be a problem for Fresnel concentrators made of DC 93-500, or similar behaving silicones, which could represent large losses for concentrator-based photovoltaic systems. Light can be specularly transmitted through the islands that are free of cracks, however, the bottom of cracks are not parallel to the pristine surface of the DC 93-500 and thus cause the light passing through them to be diffusely scattered. Assuming the specular transmittance (1) is zero at the crack area and (2) does not change due to AO exposure at the island area, then the percent of specular transmittance loss would be the same as the percent of crack area, or the y axis of Figure 6(b). From this point of view crack area as a percent of total surface area seems to be a more relevant parameter to characterize the transmittance loss due to $\mathrm{AO}$ exposure.

For the AO fluence level studied here $\left(1.72-8.43 \times 10^{21}\right.$ atom $\left./ \mathrm{cm}^{2}\right)$, adding island area as percent of total area to crack area as percent of total area would result in 100 percent. Therefore, for the plot of percent island area (A) as a function of fluence (F), the data fit (Fig. 8) an exponential equation

$$
\begin{gathered}
A=100-\left(26.071 \mathrm{~F}^{0.3218}\right) \quad \mathrm{F} \geq 1.72 \\
A=100-(26.071) 1.72^{0.3218}(\mathrm{~F} / 1.72) \quad \mathrm{F} \leq 1.72
\end{gathered}
$$

The first equation is from the data fit in Figure 6(b). The second equation assumes a linear relation at a fluence level from zero to $1.72 \times 10^{21}$ atom $/ \mathrm{cm}^{2}$, the lowest fluence examined in this research.

Then, if the specular transmittance at the crack area is not zero, the predicted specular transmittance of the sample relative to initial transmittance as a function of $\mathrm{AO}$ fluence would be the area-based average of the specular transmittance at the crack and the specular transmittance at the island. It is calculated to be approximately

$$
\begin{gathered}
\mathrm{ST} / \mathrm{ST}_{\mathrm{p}}=1-0.26\left(1-\left(\mathrm{ST}_{\mathrm{c}} / \mathrm{ST}_{\mathrm{p}}\right)\right) \mathrm{F}^{1 / 3} \text { for } \mathrm{F} \geq 1.72 \\
\mathrm{ST} / \mathrm{ST}_{\mathrm{p}}=1-0.26\left(1-\left(\mathrm{ST}_{\mathrm{c}} / \mathrm{ST}_{\mathrm{p}}\right)\right) 1.72^{1 / 3}(\mathrm{~F} / 1.72) \text { for } \mathrm{F} \leq 1.72
\end{gathered}
$$

where

$\mathrm{F}$ is the total AO fluence to which the silicone sample is exposed (in $10^{21}$ atom $/ \mathrm{cm}^{2}$ ). ST is specular transmittance of the AO exposed sample $\left(0<\mathrm{ST}<\mathrm{ST}_{\mathrm{p}}\right), \mathrm{ST}_{\mathrm{c}}$ is specular transmittance of the AO exposed sample at the crack area $\left(0<\mathrm{ST}_{\mathrm{c}}<\mathrm{ST}_{\mathrm{p}}\right)$, and $\mathrm{ST}_{\mathrm{p}}$ is specular transmittance of the pristine sample.

The above empirical equation suggests the specular transmittance loss would be proportional to AO fluence when the fluence is low, and proportional to AO fluence's one-third power (i.e., $F^{1 / 3}$ ) when the fluence is high.

The specular transmittance of the pristine and AO exposed samples were measured to be $\mathrm{ST}_{\mathrm{p}}=0.911$ for the pristine sample, $\mathrm{ST}=0.644-0.666$ for MISSE 2 samples, and ST $=0.788-0.864$ for MISSE 4 samples (Ref. 8). Using these values with the known AO fluences for these samples, the specular transmittance at the crack areas $\left(\mathrm{ST}_{\mathrm{c}}\right)$ can be calculated from the above equations. The calculated value 
for the four high AO fluence MISSE 2 samples was in 0.40 to 0.44 range. Using the average value of 0.42 and the above equation for high fluence, the specular transmittance of DC93-500 samples after long LEO exposures can be simplified to

$$
\mathrm{ST}=0.91-0.13 \mathrm{~F}^{1 / 3}
$$

Both the high fluence equation and the low fluence equation give the four MISSE 4 samples $\mathrm{ST}_{\mathrm{c}}$ values in 0.45 to 0.78 range. Because of the debris on some of the MISSE 4 samples, the true $\mathrm{ST}_{\mathrm{c}}$ is believed to be near the high end of this range. Using $\mathrm{ST}_{\mathrm{c}}=0.78$ and the above equation for low fluence, the specular transmittance of a debris-free DC93-500 samples after short LEO exposures can be simplified to

$$
\mathrm{ST}=0.91-0.024 \mathrm{~F}
$$

\section{Scanning Electron Microscope Image Analysis}

\section{Pictures}

The representative SEM images of silicone samples exposed to different AO fluences are presented in Figures 9(a) to (d). It can be seen that at lower AO exposure levels (Fig. 9(a) and (b)), the cracks are relatively simple and can be understood as the result of shrinkage of a thin layer of silicone surface due to silicone-AO reactions.

It can also be seen that new crack lines split old crack lines, and some old crack lines seem to stop cracking after some time, as many new crack lines become wider and deeper than the old crack lines. This data suggests that the oldest and first cracks, which are narrow, occur on surfaces that are under only small tensile stress. After the event of a crack, there will be a re-distribution of stress and tensile stress parallel to the crack becomes reduced. However, in directions approximately perpendicular to the initial cracks, stress builds up to accumulate to greater than that at the time of the initial cracks. This causes the newest cracks to open wider and deeper than the initial cracks. In general, the process continues to cause the newest branch cracks to be wider and deeper than older cracks. Consequently, some of the old crack lines diminish their cracking because the stress on them decreases. The more mud tiled the surface becomes, the deeper the thickness of silicone oxidation, which grows slower with fluence because the atomic oxygen has a more difficult time migrating deep to unoxidized silicone. Although the surface gradually becomes very cracked, the islands remain well adhered because their surface layer is a gradual transition from completely oxidized silica to unoxidized silicone interior. It would only be for very thin surface layer where oxidation could occur through the full thickness causing the silicone to be significantly converted to silica that the mud tiles could break apart. This may be a durability threat for silicone Fresnel lenses, inflatable structures, or silicone coatings in low Earth orbit.

In the case of dimishing stress, after long AO exposure, the part of the surface that has not yet cracked develops a thick glassy layer, which is structurally stronger than a newly formed very thin oxide layer. Under stress, this newly formed layer will crack first to release the stress, and, further cracking of the thick glassy layer can be prevented. In the case of intensifying stress, the cycle of brittle surface formation-shrink-crack will continue until the stress is reduced, or the cracks become too deep for AO to reach. There are also observed cases where part of the cracked surface become increasingly glassy and thick, but the rest of the cracked surface continues to crack into greater depth due to the cycles of forming thin oxide layers causing high stress-cracking (Fig. 10).

The results give a complex overall picture of the morphology change of silicone surfaces during silicone-AO reactions. Shrinkage causes stress. Thin AO exposed silicone is brittle. After long AO exposure, the part of the surface that has not yet cracked develops a thick glassy layer, which is structurally stronger than a newly formed very thin oxide layer. Shrinkage and stress of thin AO exposed layers cause cracks. Cracks then cause sudden surface movements, which cause stress on the surface to 
re-distribute, which result in a new shrink rate on the surface and new crack rate at the crack lines. The activity of cracking increases for some crack lines, but diminishes for some others. Above all of these, the $\mathrm{AO}$ continues to react with the entire silicone surface, most likely at a higher rate at the stressed crack lines because those are places where some interior silicone is newly exposed to AO. The result is the newly formed thin oxide layer which is more inclined to crack under stress.

Figure 11(a) to (c) are pictures of the complex crack morphology from the highest AO fluence exposed sample in this research (fluence $=8.43 \times 10^{21}$ atom $/ \mathrm{cm}^{2}$ ).

The representative SEM images of all eight flight samples are presented in Appendix B (1000x) and $\mathrm{C}(5000 \mathrm{x})$.

\section{Energy Dispersive Spectrum}

Representative EDS spectra of all eight AO exposed flight samples at "island" regions are provided in Appendix D. The EDS of the pristine sample (Fig. D9) was taken from the part of sample 4-E22-2

(Fig. 4) that was covered by the aluminum spacer. From these spectra, the semi-quantitative atomic $\mathrm{C} / \mathrm{Si}$ and $\mathrm{O} / \mathrm{Si}$ concentrations of the flight samples relative to the pristine sample can be calculated. Results are shown in Table 3. It was estimated that the C/Si ratio dropped to 28 to 35 percent and 16 to 22 percent of the pristine value when the AO fluences are 1.46 to $2.14 \times 10^{21}$ (MISSE 4) and 7.75 to $8.43 \times 10^{21}$

(MISSE 2), respectively. The O/Si ratio, on the other hand, increased to 152 to 195 percent and 206 to 258 percent of the pristine value, respectively. The carbon content decreased relatively quickly at the beginning when the fluence level was lower than the MISSE 4 value, but leveled to 20 percent of the pristine value at the MISSE 2's fluence. The oxygen content appears to increase at a slower rate.

Assuming the pristine DC93-500 has a $\mathrm{C} / \mathrm{Si}$ and $\mathrm{O} / \mathrm{Si}$ values of 2 and 1, respectively, the above numbers would suggest the highest $\mathrm{AO}$ fluence exposed silicone has $\mathrm{C} / \mathrm{Si}$ and $\mathrm{O} / \mathrm{Si}$ values of about 0.4 and 2.3, respectively. From these numbers, it is theorized that the AO exposed silicone will eventually become $\mathrm{SiO}_{2}$ with small amounts of unreacted silicone, $\mathrm{CO}$ and $\mathrm{CO}_{2}$ sealed inside.

The regions occupied by the crack lines were also examined by EDS. In general these areas contain less oxygen and more carbon than their neighboring islands do. This is expected, as the cracks result in the opening of the sample interior that was not exposed to $\mathrm{AO}$ at the beginning of the experiments.

The $2.2 \mathrm{keV}$ peaks in all EDS spectra are believed to be aluminum contamination, as all samples were near aluminum when they were exposed to AO. This includes the pristine sample, which was well protected by aluminum during the time of $\mathrm{AO}$ exposure.

SEM pictures of the residual Kapton, $\mathrm{SiO}_{\mathrm{X}}$ nano-particles and contaminants on the sample surfaces are shown in Figures 12 and 13. These materials were also examined by EDS. In Figure 12 the EDS spectra of the MISSE flight sample with the lowest AO fluence exposure $\left(1.46 \times 10^{21}\right.$ atoms $\left./ \mathrm{cm}^{2}\right)$ indicates more carbon and oxygen than the pristine material. This is consistent with the belief that the debris is residual fragments of the Kapton $\mathrm{H}$ cover layer placed on top of the sample at the beginning of the experiment. In Figure 13 the numerous nano-sized particles were found to be $\mathrm{SiO}_{\mathrm{X}}$. They were observed to be only on the samples that were covered by the over-laying Kapton. It is believed that during AO exposure, small particles of silicone were ejected from the samples, trapped by the over-laying Kapton, and eventually oxidized by the AO to form the nano-sized particles. Other particles such as the one shown in Figure 13(b) contain mostly $\mathrm{C}$ and $\mathrm{O}$, but also contains numerous elements that include $\mathrm{Na}, \mathrm{Mg}, \mathrm{Al}, \mathrm{Si}$, $\mathrm{S}, \mathrm{P}, \mathrm{Cl}$. These are believed to be organic contaminations. 


\section{Conclusions}

Eight DC 93-500 samples exposed to eight different AO fluence levels (that ranged from 1.46 to $8.43 \times 10^{21}$ atoms $/ \mathrm{cm}^{2}$ ) during two different MISSE missions (MISSE 2 and 4) were examined using optical microscopy, scanning electron microscopy and energy dispersive spectroscopy. Three morphological parameters were obtained for each image using computer image analysis software. These parameters were then used to characterize the morphological degradation of the AO exposed samples:

1. The average area of the islands was found to range from 1000 to $3100 \mu \mathrm{m}^{2}$. Average island area is under-estimated because the software created a large number of small islands during image processing.

2. The total length of crack lines per unit area of the sample surface was found to range from 27 to $59 \mathrm{~mm}$ crack length per $\mathrm{mm}^{2}$ of sample surface. The total crack length was observed to increase with increasing AO fluence until the AO fluence reached a high level where the glassy islands on the surface may become sufficient hard, thick and small to inhibit further length propagation.

3. The fraction of sample surface area that is occupied by crack lines was found to range from 25 to 56 percent for the fluence levels tested. This value increases steadily during the entire fluence range tested in this research.

4. Average crack width can be estimated from crack length and crack area described above, and was calculated to be about $10 \mu \mathrm{m}$.

The fraction of sample surface area that is occupied by crack lines was found to be most useful morphological parameter in characterizing the degree of silicone degradation caused by AO exposure.

The series of SEM images from the eight MISSE flight samples exposed to different AO fluences suggest a complex sequence of surface stress due to shrinkage, cracking, and then re-distribution of stress and shrinking on the sample surface. The data suggests that the oldest cracks, which are narrow, occur on surfaces that are under only small tensile stress. After a "crack event" there is a re-distribution of stress and the tensile stress parallel to the crack becomes reduced. However, in directions approximately perpendicular to the initial cracks, stress builds, which causes the newest cracks to be wider and deeper than the initial cracks. This cycle of shrinkage and cracking may be slowed in some areas if there is near area cracking sufficient to reduce the local stress. Then they will experience sufficient oxidation to develop a thick glassy layer, which not only significantly shields further oxidation, but also is structurally stronger than a newly formed very thin oxide layer. In that instance the reactions to AO will move to the stressed crack lines because those are places where some interior silicone is newly exposed to AO, resulting in a new thin oxide layer which is more inclined to crack again under stress. The energy dispersive spectra (EDS) indicated that upon AO exposure, carbon content decreased to 32 percent of the pristine value for the least exposed sample in this set of experiments $\left(1.46 \times 10^{21}\right.$ atoms $\left./ \mathrm{cm}^{2}\right)$, but leveled to 20 percent of the pristine value for the most exposed sample in this set of experiments $\left(8.43 \times 10^{21}\right.$ atoms $\left./ \mathrm{cm}^{2}\right)$. The oxygen content appears to increase at a slower rate. The least and most AO exposed samples were, respectively, 52 and 150 percent above the pristine values. The highest AO fluence exposed flight sample appears to have a surface layer which contains $\mathrm{SiO}_{2}$ with perhaps some unreacted silicone, $\mathrm{CO}$ and $\mathrm{CO}_{2}$ sealed in the $\mathrm{SiO}_{2}$ layer.

\section{References}

1. K.K. de Groh and T.A. McCollum, "Low Earth Orbit Durability of Protected Silicone for Refractive Photovoltaic Concentrator Arrays," Journal of Spacecraft and Rockets, vol. 32, no. 1, Jan-Feb 1995, pp. 103-109.

2. Ching-cheh Hung and Gidget Cantrell, "Reaction and protection of electrical wire insulators in atomic-oxygen environments," NASA TM 1067671994. 
3. K.K. de Groh, B.A. Banks and D. Ma, "Ground-to-Space Effective Atomic Oxygen Fluence Correlation for DC 93-500 Silicone," (Special Section: Space Environmental Effects on Materials) Journal of Spacecraft and Rockets, vol. 43, no. 2, March-April 2006, 414-420.

4. de Groh K., Banks B., Dever J., Jaworske D., Miller S., Sechkar E., Panko S. 2008. "NASA Glenn Research Center's Materials International Space Station Experiments (MISSE 1-7)," NASA/TM2008-215482.

5. de Groh K. and McCollum T.1995 "Low Earth Orbit Durability of Protected Silicone for Refractive Photovoltaic Concentrator Arrays," Journal of Spacecraft and Rockets, Volume 32 Number 1, Page 103-109.

6. Pippin G. 2008 "Summary Status of MISSE-1 \& MISSE-2 Experiments and Details of Estimated Environmental Exposures for MISSE-1 \& MISSE-2," Final Report Air Force Contract 02-S470-011C1.

7. Pippin G. 2008 "Summary Status of MISSE-3 \& MISSE-4 Experiments and Details of Estimated Environmental Exposures for MISSE-3 \& MISSE-4," Final Report Universal Technology Corporation Contract 07-S568-030-C1-R1 (Government Prime Contract FA8650-050D-5807).

8. D.L. Waters, K.K. de Groh, B.A. Banks, and K.C. Cameron, "Changes in Optical and Thermal Properties of the MISSE 2 PEACE Polymers and Spacecraft Silicones," Proceedings of the International Symposium on Materials in a Space Environment (ISMSE-11), September 15-18, 2009, Aix-en-Provence, France, 2009.

TABLE 1.-MISSE 1 AND 2 MISSION AND SPACE EXPOSURE SUMMARY

\begin{tabular}{|c|c|c|c|c|c|c|c|}
\hline $\begin{array}{c}\text { MISSE } \\
\text { PEC }\end{array}$ & $\begin{array}{c}\text { Launch } \\
\text { Mission }\end{array}$ & $\begin{array}{c}\text { Date placed } \\
\text { outside ISS }\end{array}$ & Location on ISS & Orientation & $\begin{array}{c}\text { Retrieval } \\
\text { mission }\end{array}$ & $\begin{array}{c}\text { Date } \\
\text { retrieved } \\
\text { from ISS }\end{array}$ & $\begin{array}{c}\text { LEO } \\
\text { exposure } \\
\text { duration }\end{array}$ \\
\hline $1 \& 2$ & STS-105 & $8 / 16 / 2001$ & $\begin{array}{c}\text { PEC 1: High pressure } \\
\text { gas tank } \\
\text { PEC 2: Quest airlock }\end{array}$ & Ram \& Wake & STS-114 & $7 / 30 / 2005$ & 3.95 years \\
\hline $3 \& 4$ & STS-121 & $8 / 3 / 2006$ & $\begin{array}{c}\text { PEC 3: High pressure } \\
\text { gas tank } \\
\text { PEC 4: Quest airlock }\end{array}$ & Ram \& Wake & STS-118 & $8 / 18 / 2007$ & 1 year \\
\hline
\end{tabular}

TABLE 2.-MORPHOLOGICAL PARAMETERS OF SILICONE SAMPLES EXPOSED TO DIFFERENT AO FLUENCES DURING MISSE 2 AND 4 MISSIONS

\begin{tabular}{|c|c|c|c|c|}
\hline $\begin{array}{c}\text { Fluence } \\
\text { xE21 }\end{array}$ & $\begin{array}{c}\text { Total crack length in } \\
1 \mathrm{~mm}^{2} \text { of sample, } \\
\mathrm{mm}\end{array}$ & $\begin{array}{c}\text { Crack area to } \\
\text { sample surface area ratio }\end{array}$ & $\begin{array}{c}\text { Average island } \\
\text { area, } \\
\mu \mathrm{m}^{2}\end{array}$ & $\begin{array}{c}\text { Approx. crack } \\
\text { width, } \\
\mu \mathrm{m}\end{array}$ \\
\hline 8.43 & 52 & 0.56 & 979 & 11 \\
\hline 8.18 & 59 & 0.53 & 696 & 9 \\
\hline 8.01 & 46 & 0.45 & 1191 & 10 \\
\hline 7.75 & 48 & 0.49 & 1146 & 10 \\
\hline 2.14 & 42 & 0.38 & 1234 & 9 \\
\hline 1.89 & 41 & 0.35 & 1472 & 9 \\
\hline 1.72 & 27 & 0.25 & 3089 & 9 \\
\hline
\end{tabular}

TABLE 3.-CALCULATED VALUES OF THE SEMI-QUANTITATIVE ATOMIC C/Si AND O/Si CONCENTRATION OF THE AO EXPOSED SAMPLE RELATIVE TO THE PRISTINE SAMPLE

\begin{tabular}{|c|c|c|}
\hline $\begin{array}{c}\text { AO fluence } \\
\mathrm{X} 10^{21} \text { atom } / \mathrm{cm}^{2}\end{array}$ & $(\mathrm{O} / \mathrm{Si}) /(\mathrm{O} / \mathrm{Si}) \mathrm{p}$ & $(\mathrm{C} / \mathrm{Si}) /(\mathrm{C} / \mathrm{Si}) \mathrm{p}$ \\
\hline 1.46 & 1.52 & 0.32 \\
\hline 1.72 & 1.73 & 0.28 \\
\hline 1.89 & 1.65 & 0.35 \\
\hline 2.14 & 1.95 & 0.34 \\
\hline 7.75 & 2.58 & 0.16 \\
\hline 8.01 & 2.47 & 0.21 \\
\hline 8.18 & 2.06 & 0.17 \\
\hline 8.43 & 2.50 & 0.22 \\
\hline
\end{tabular}




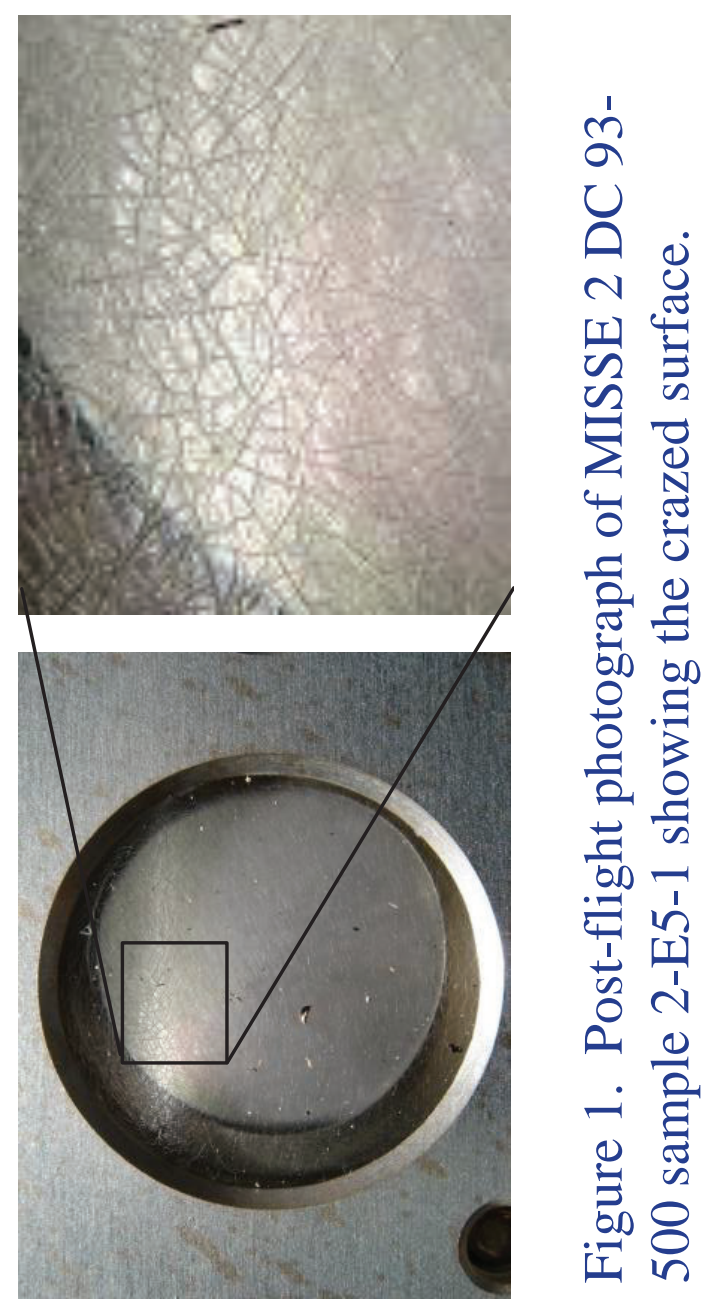



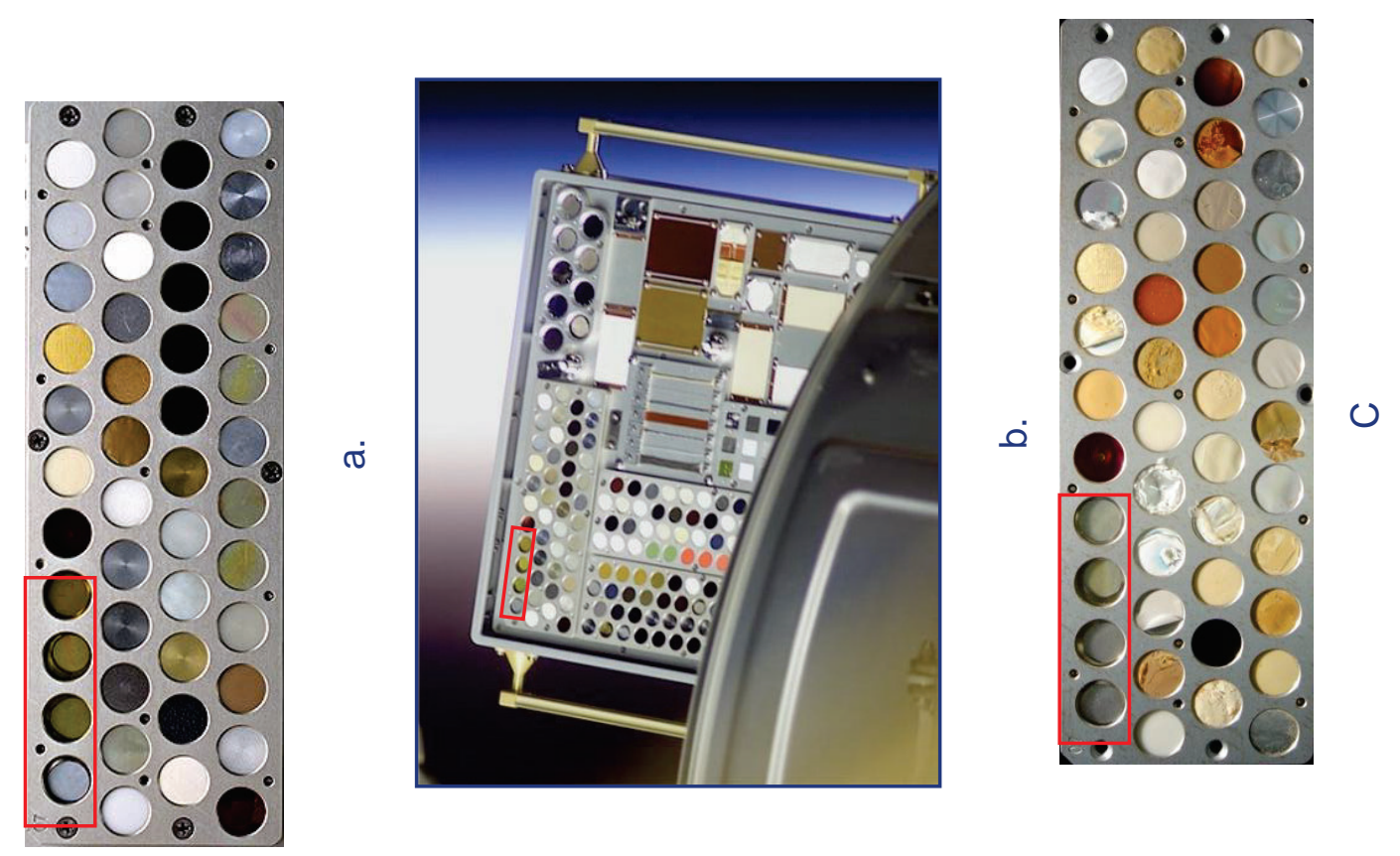

ज

() ฏ

जิ

宁

जิ

议

जิ จิ

Ð

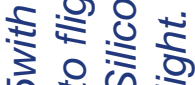

เी

出

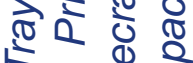

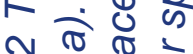

山ें ज选

ज)

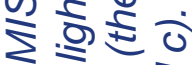

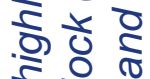

ข ब

(1)

ปริ 


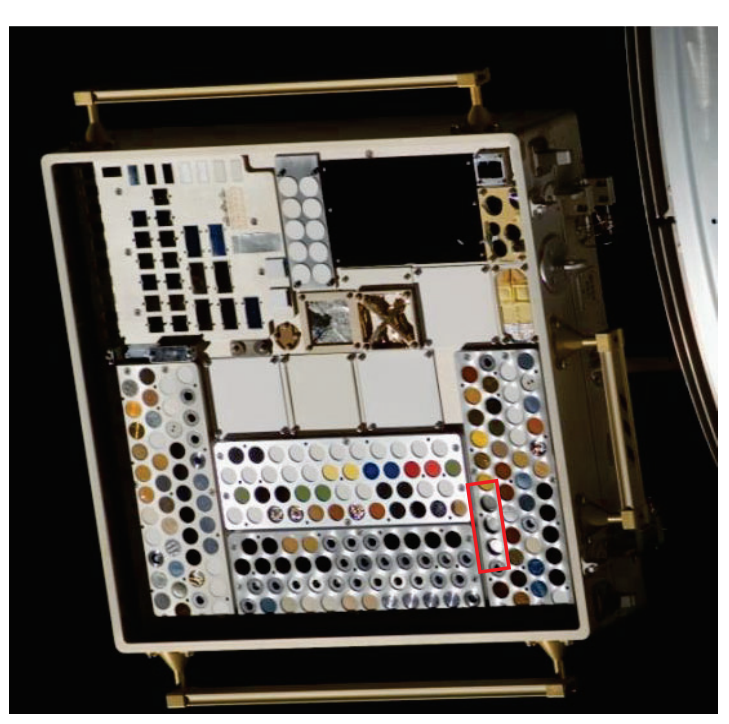

ఏ.

๙ิ

¿

.5

은

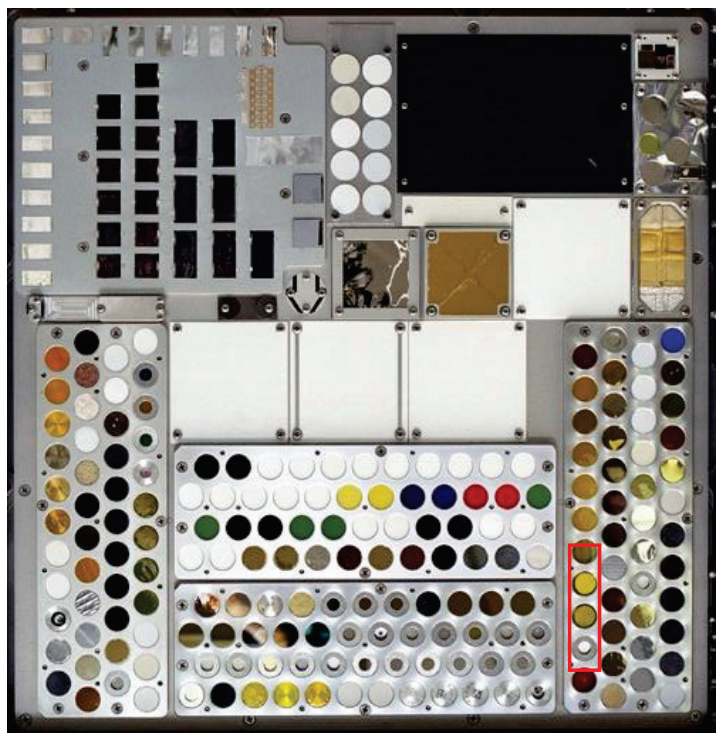

$\tau$

है

ฮิ

ह

बे

ㅇำ

(1) $\mathbb{8}$

$\frac{1}{\sigma}$

()

(⿻)

券

$\div 2$

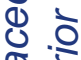

ชิ 은

जิ

Q.

政

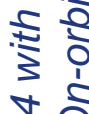

岁

जे

$\sum \frac{1}{\Sigma}$

i)

高

i⿺辶 


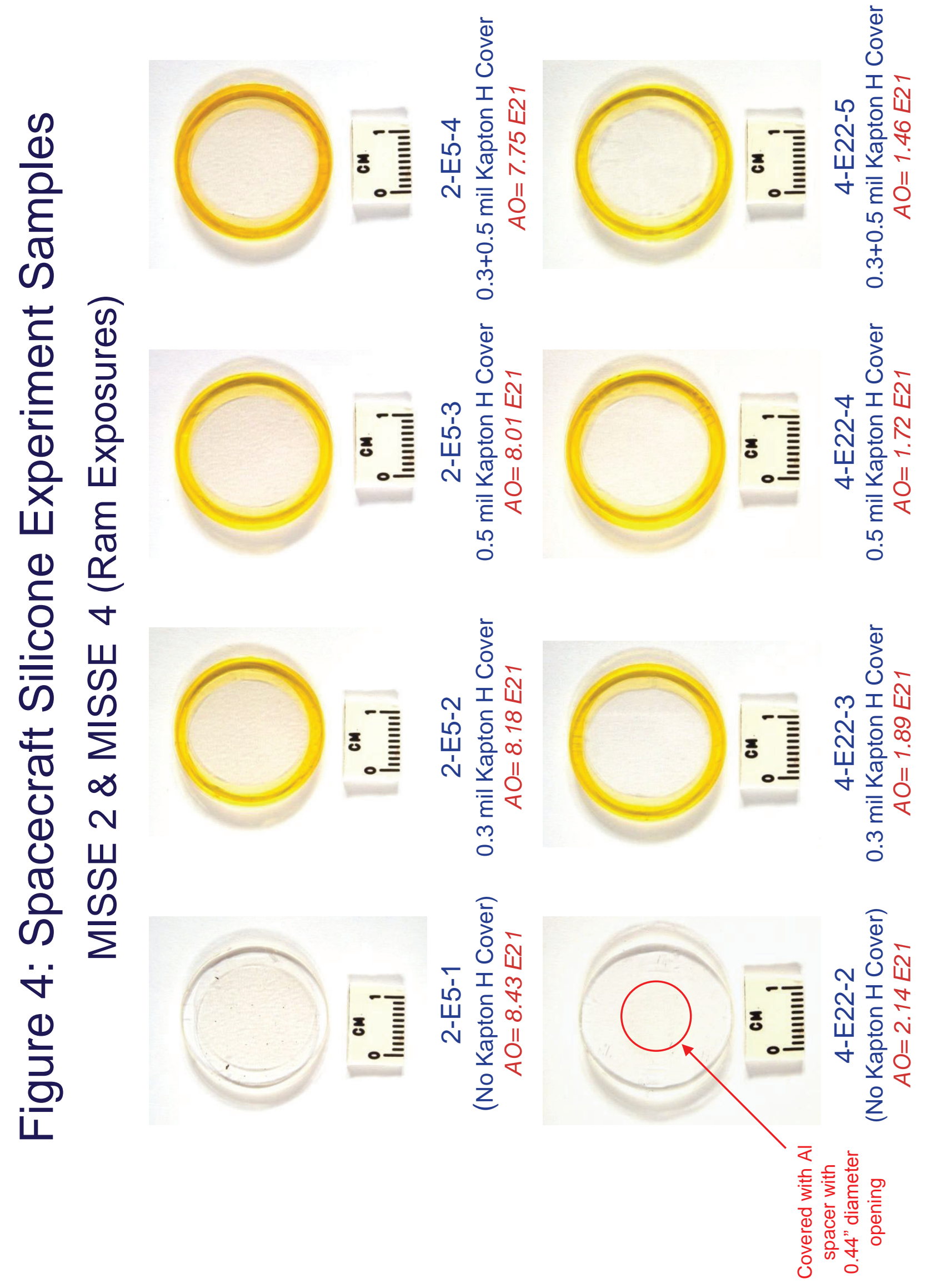



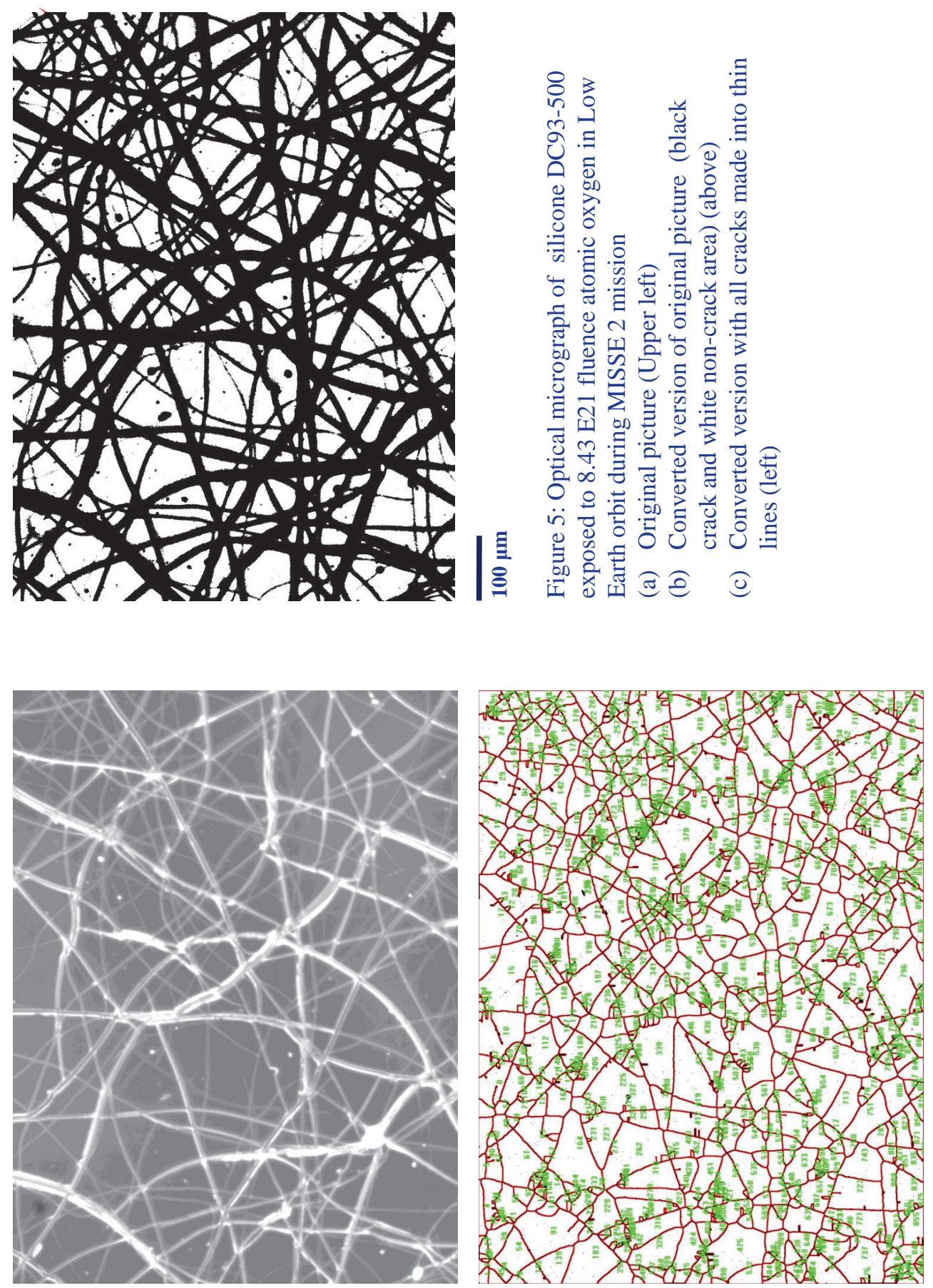

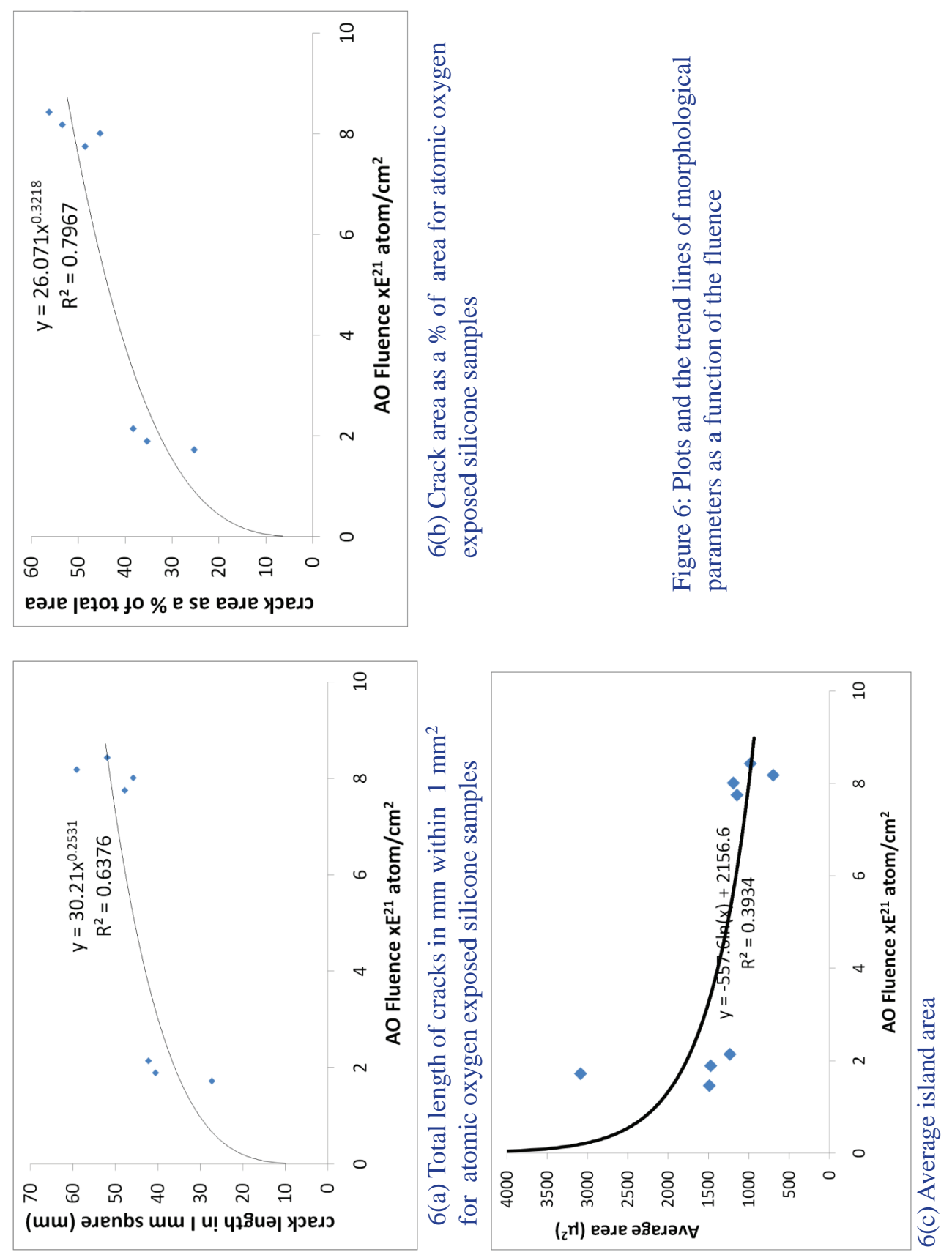


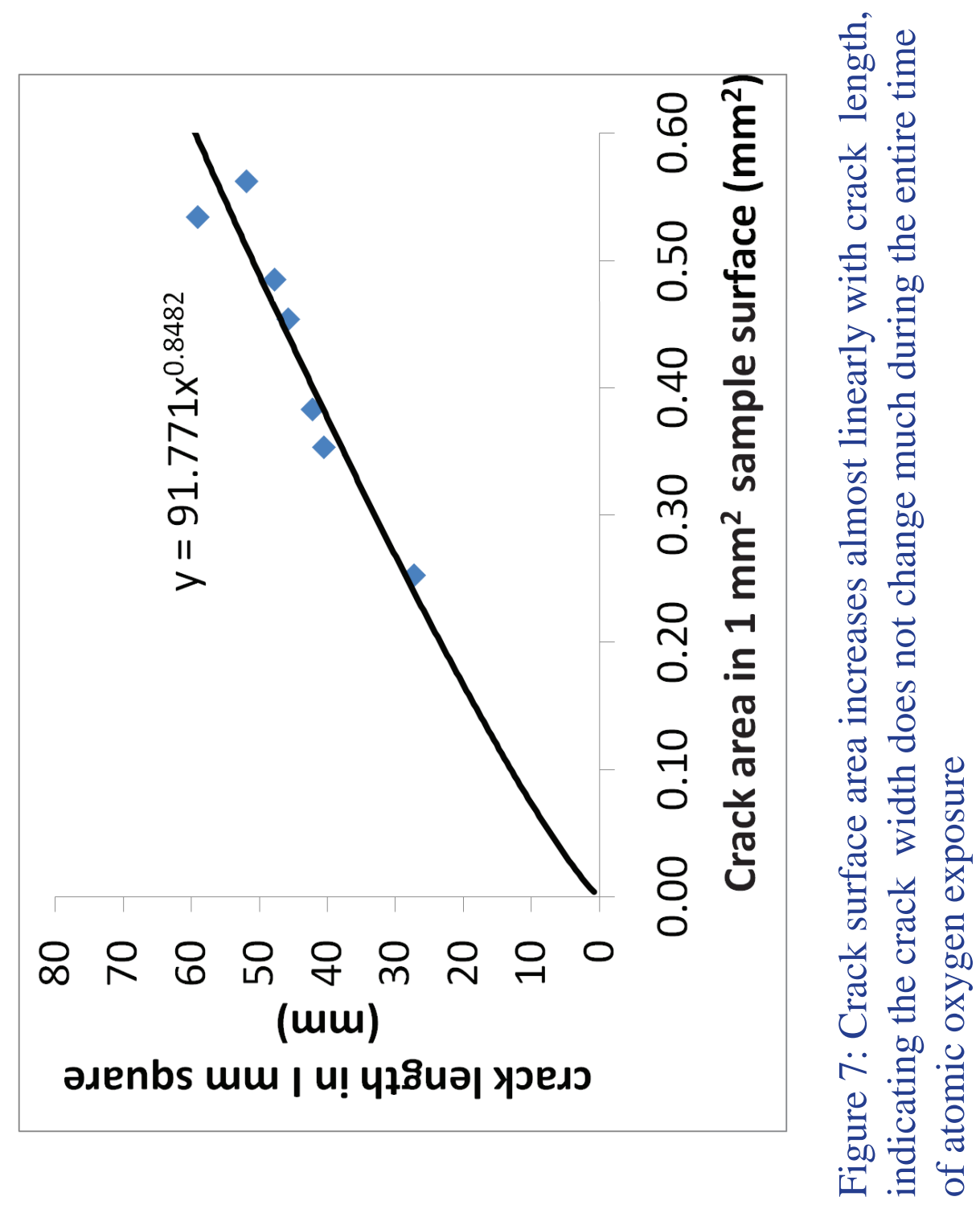




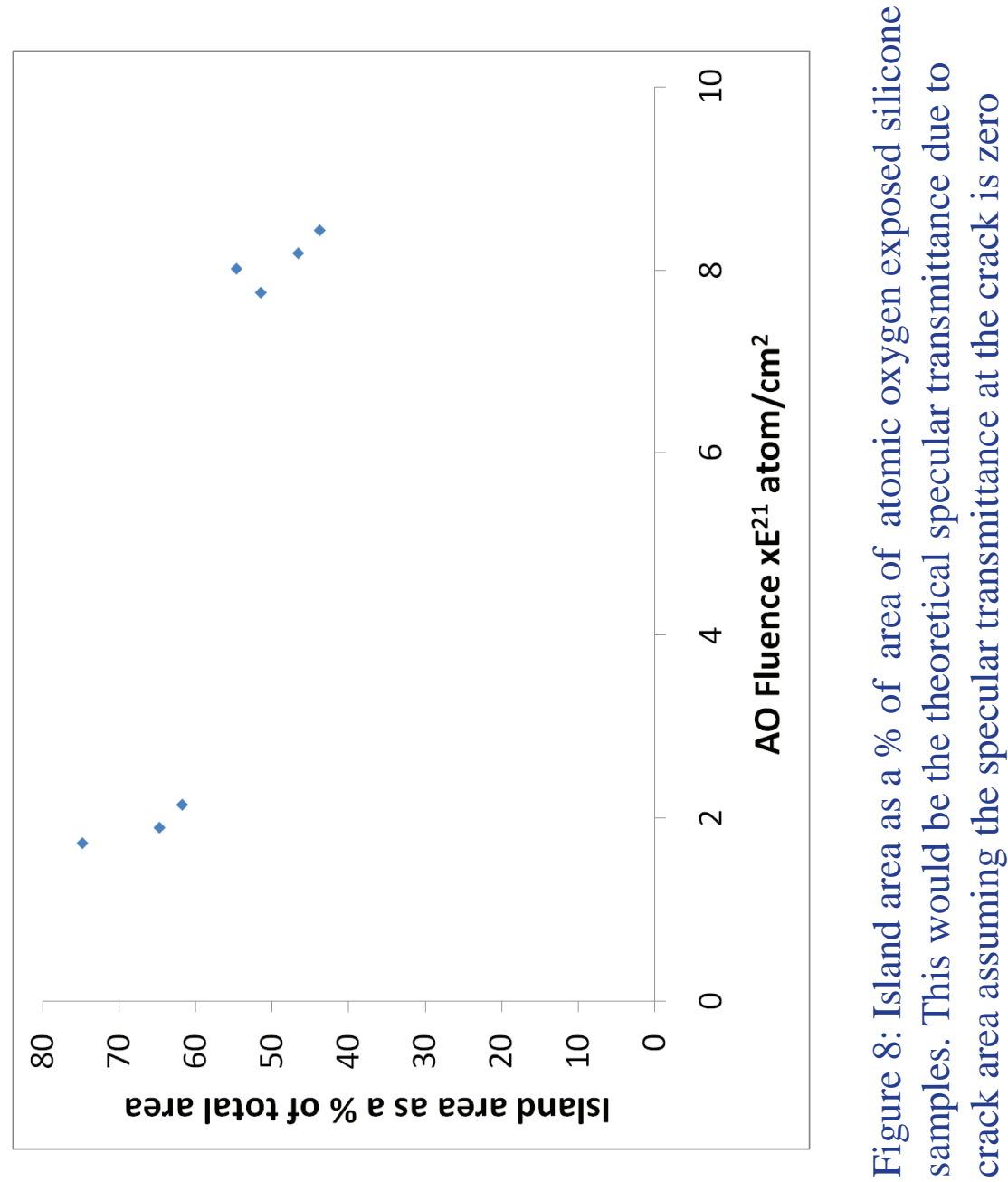



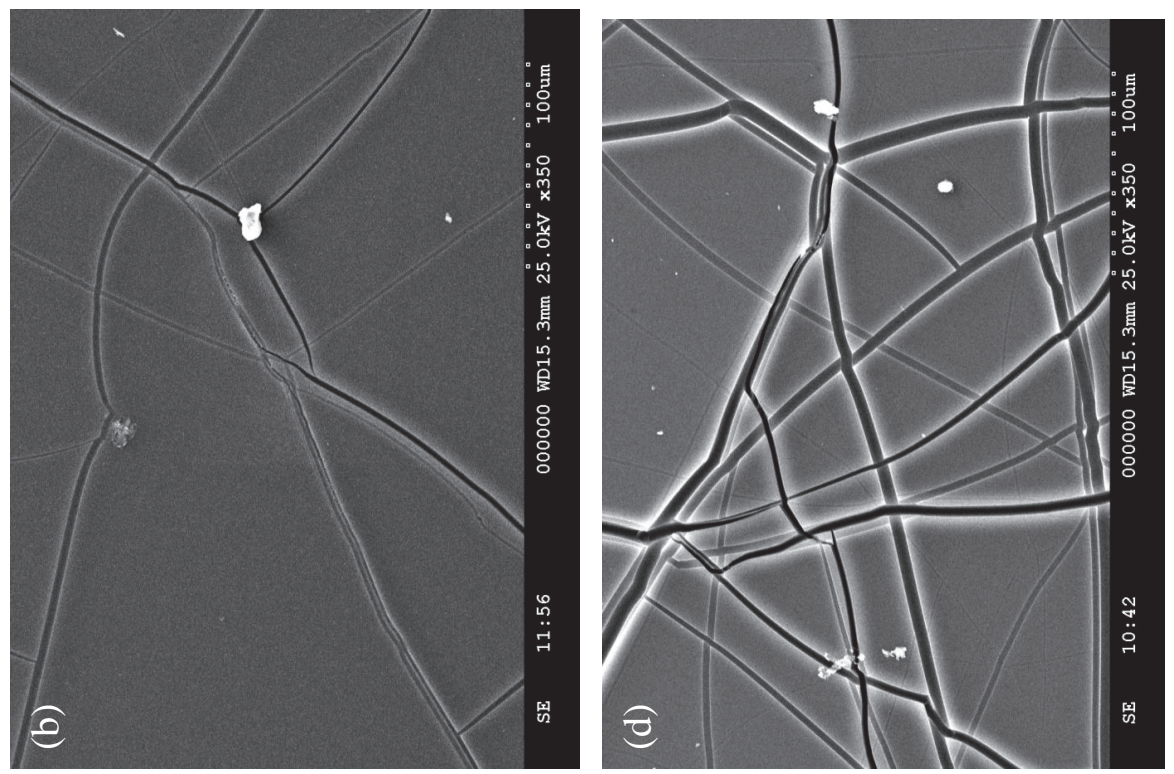

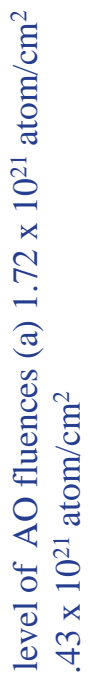
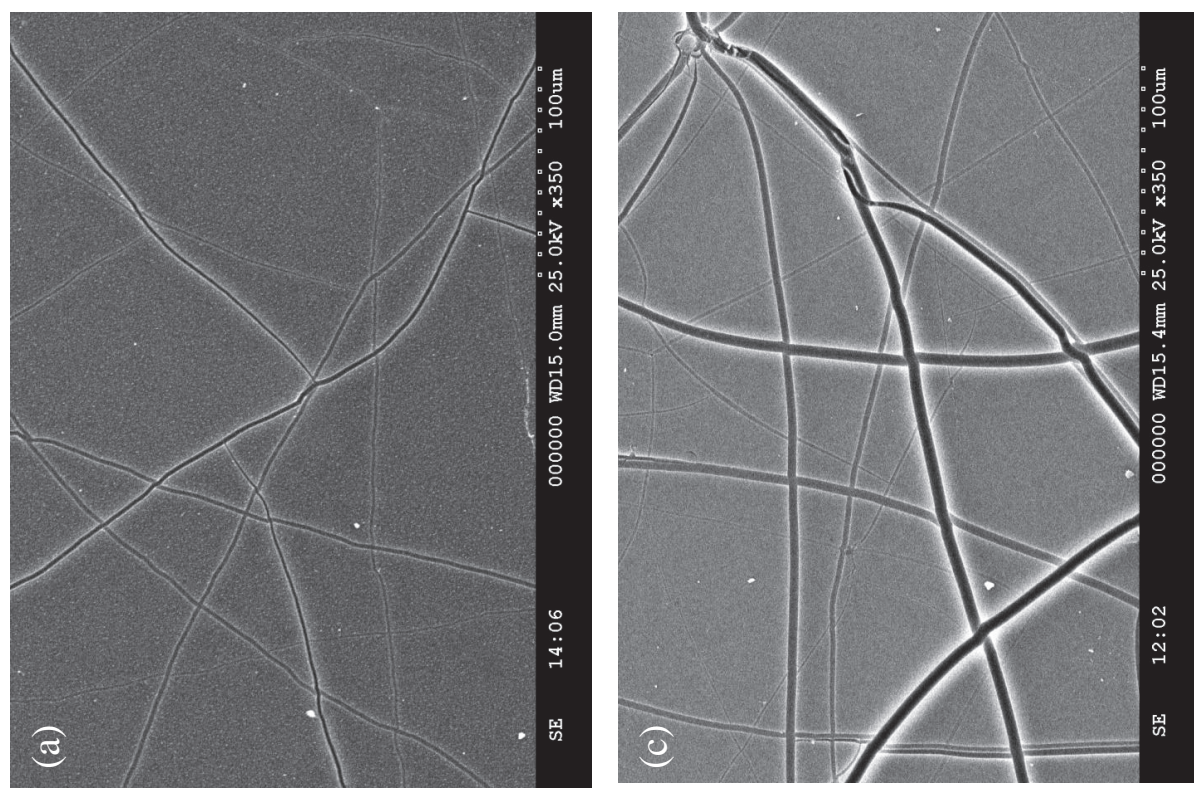
苞 ษै 몸

ชั

만음

瓷

可

पै

$\stackrel{0}{0}$

总 흠

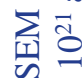

w

के

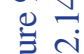

อ 


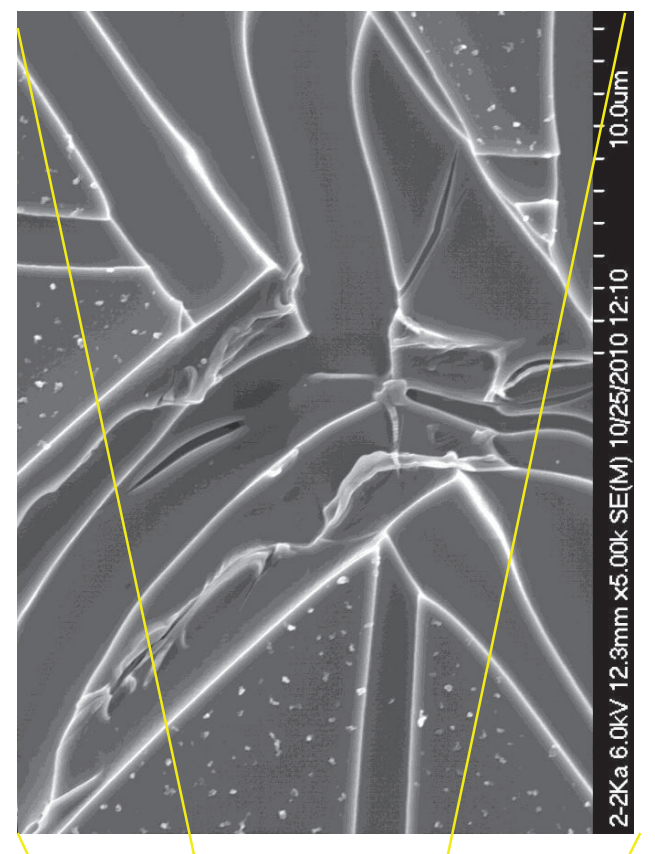

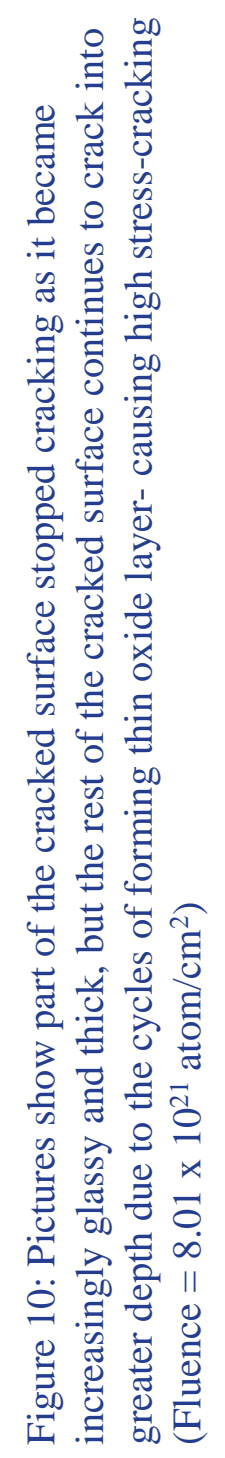



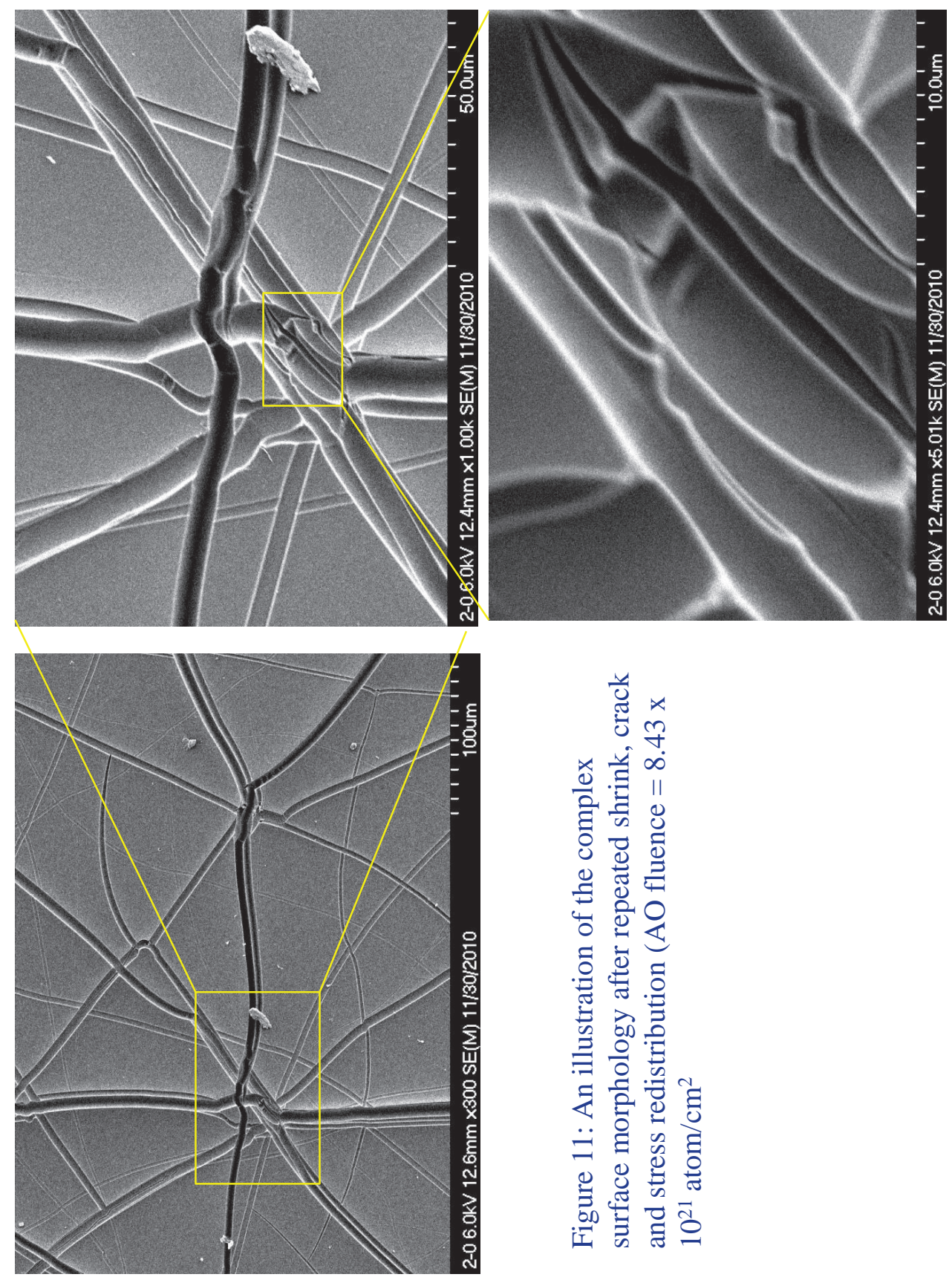


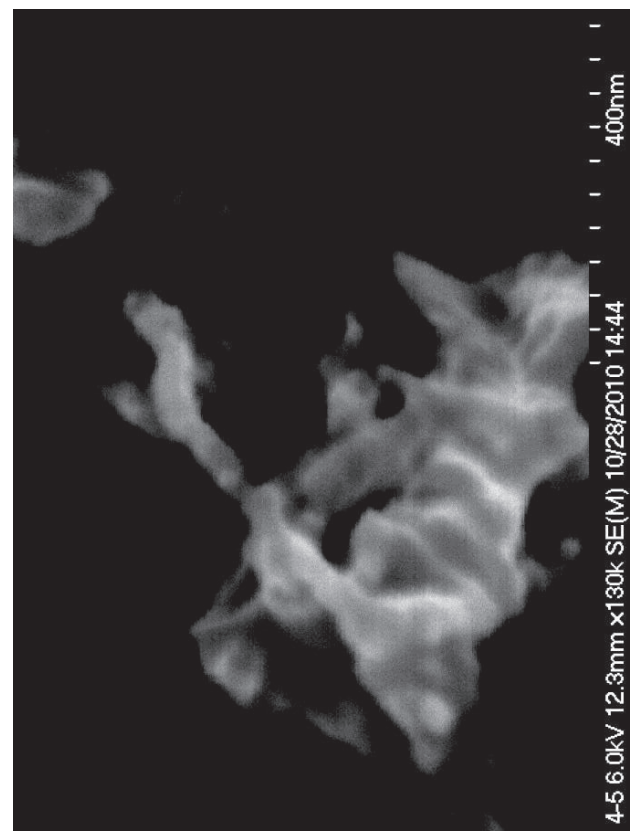

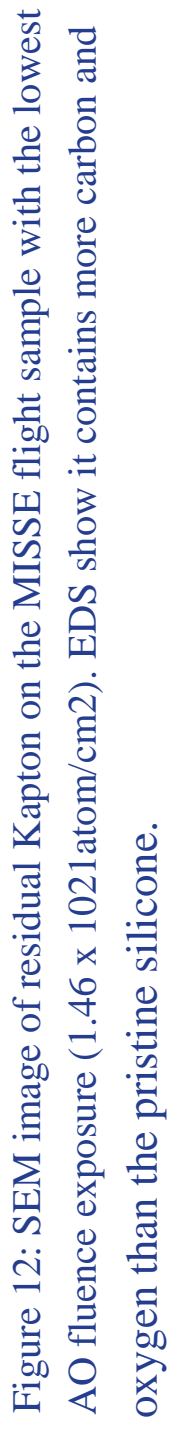

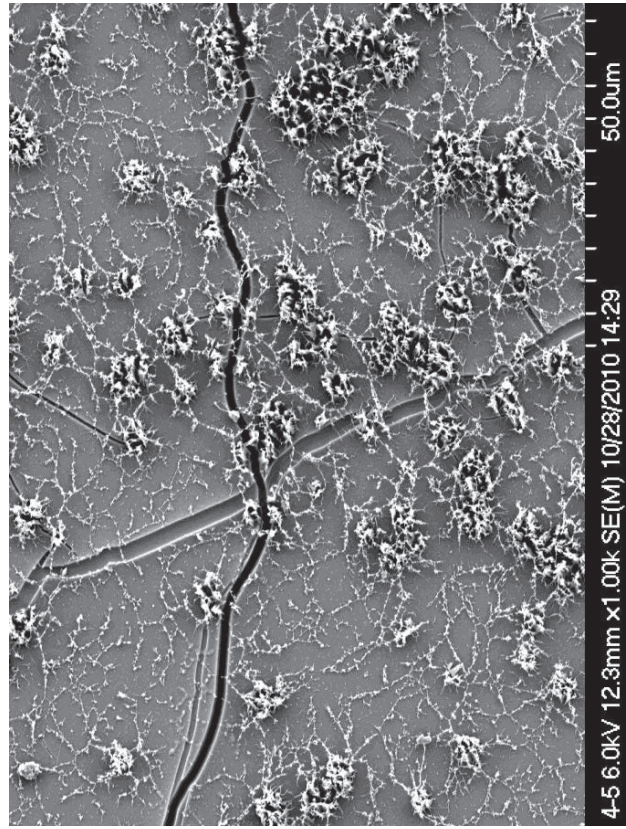



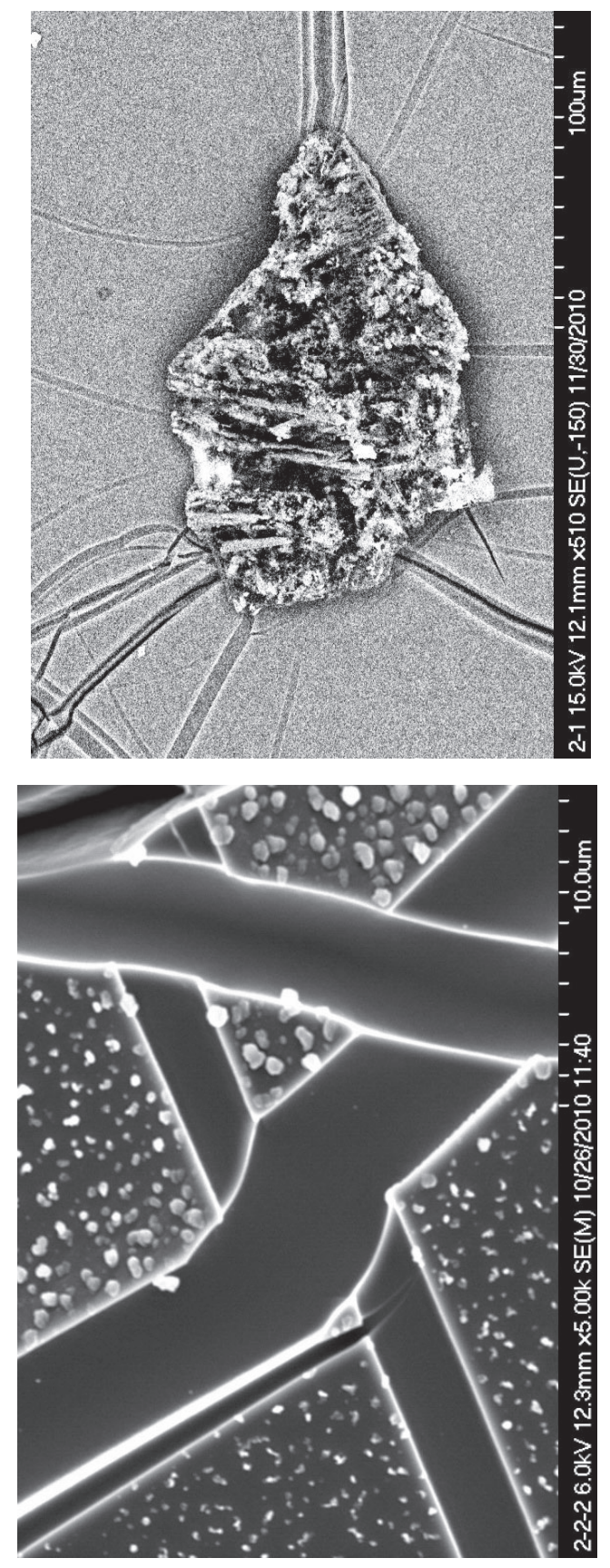

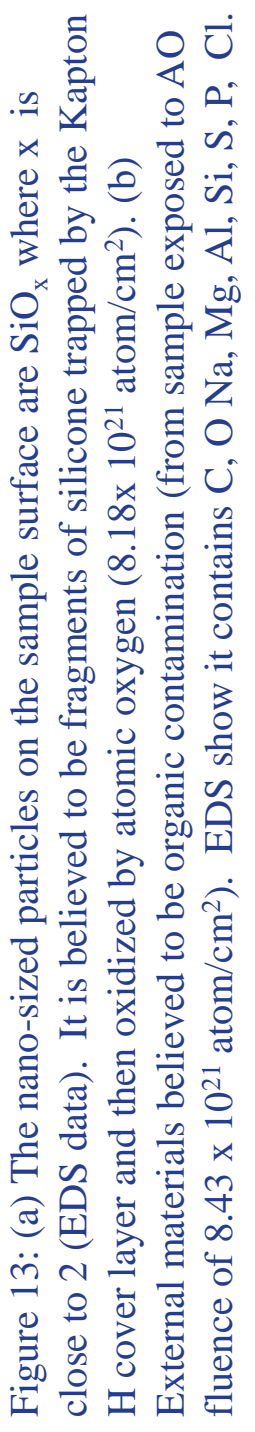





\section{Appendix A.-Optical Microscope Pictures for the MISSE2 and MISSE4 Silicone Samples}




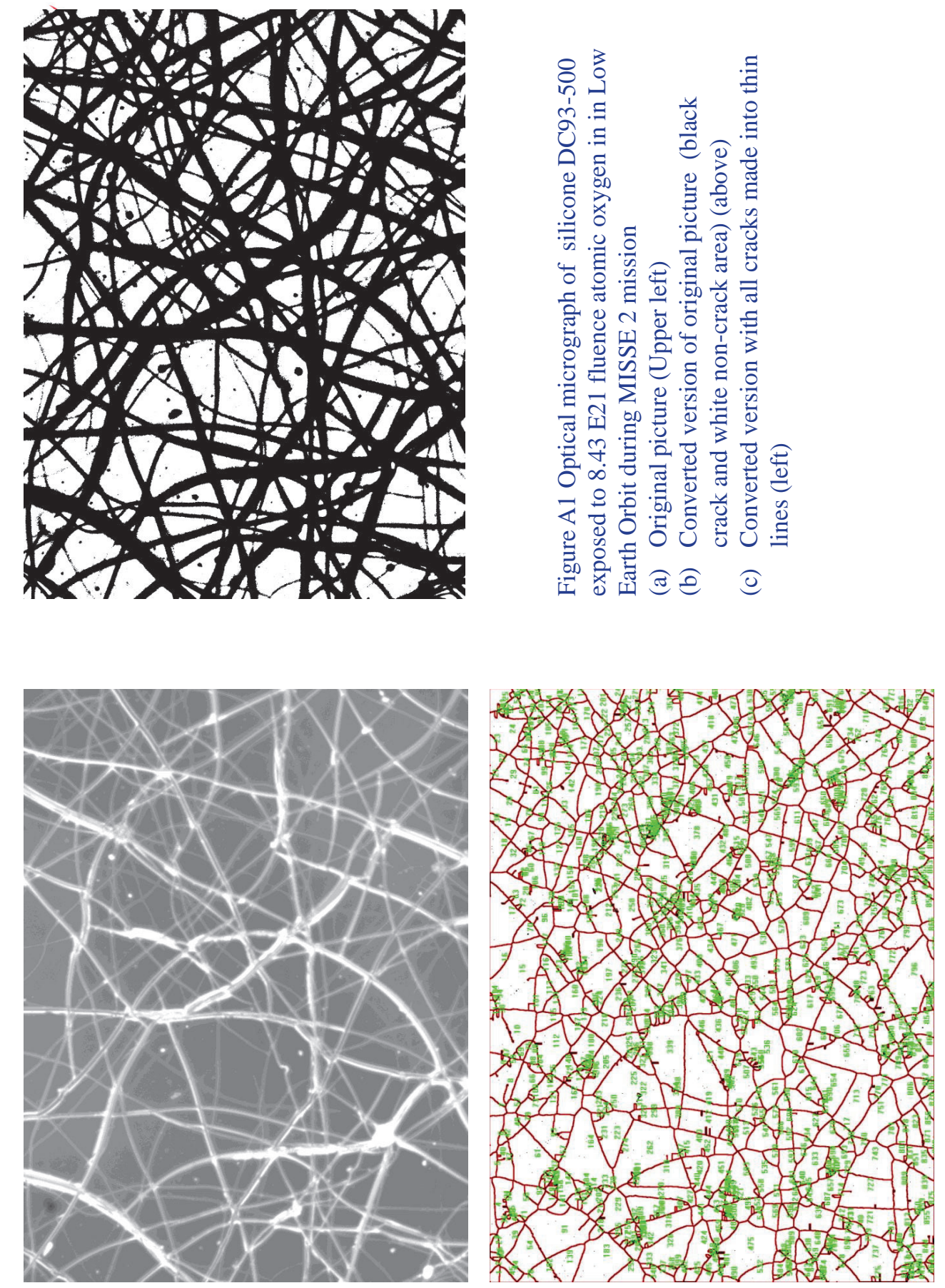

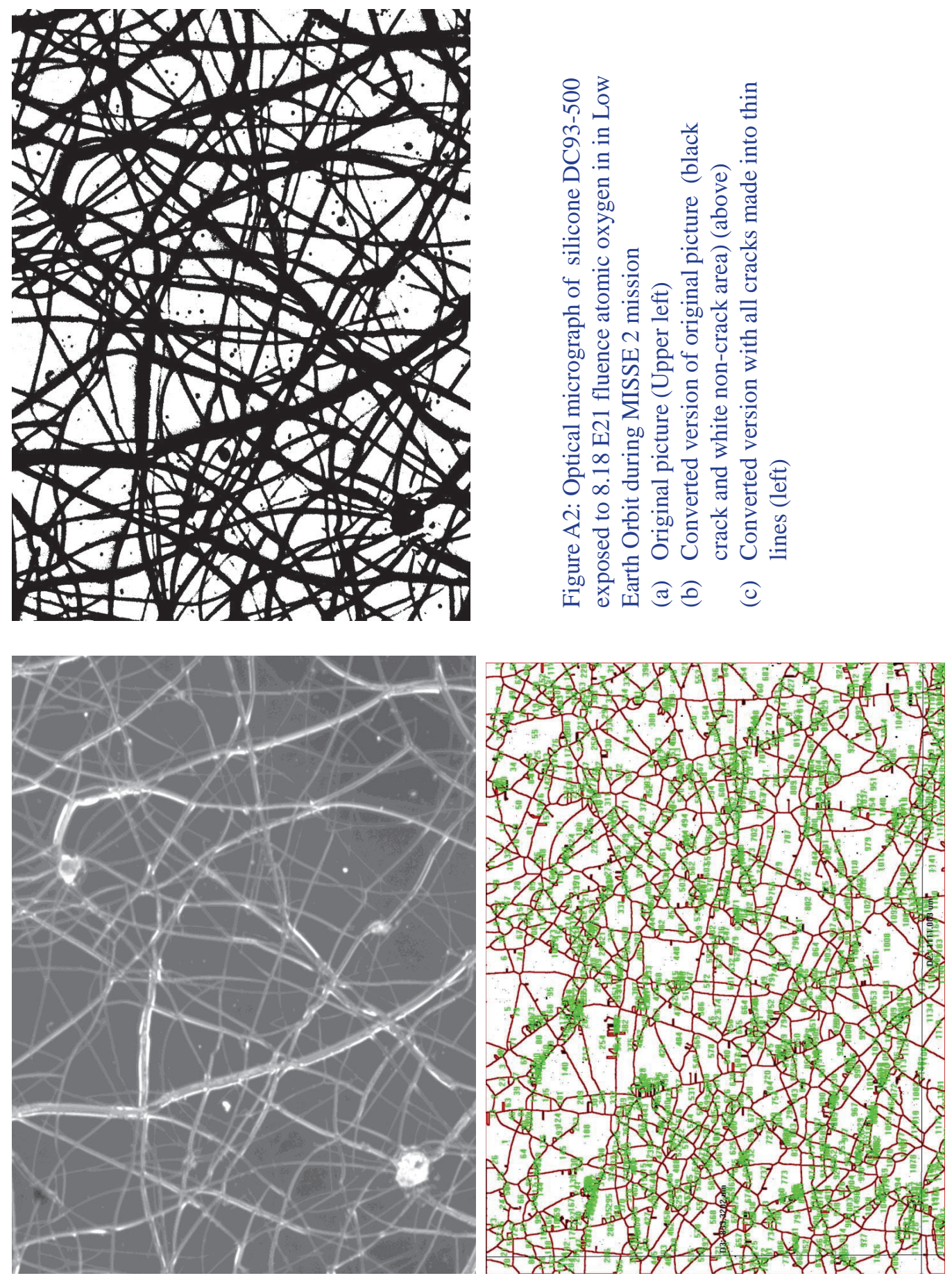


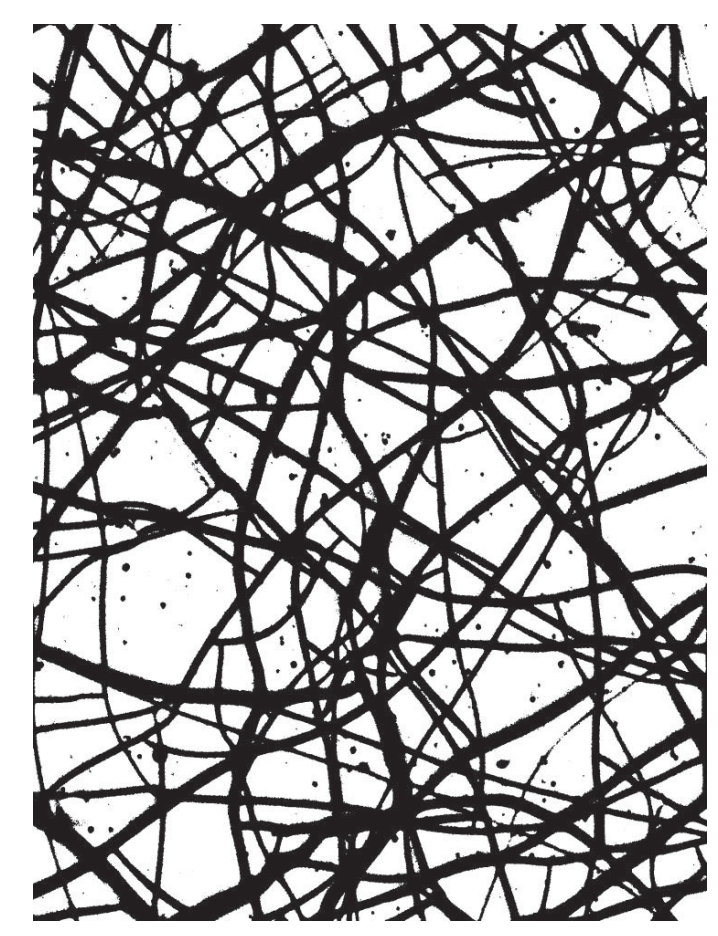

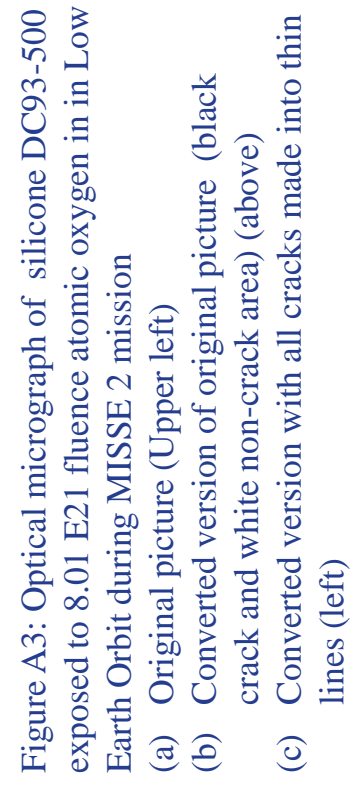
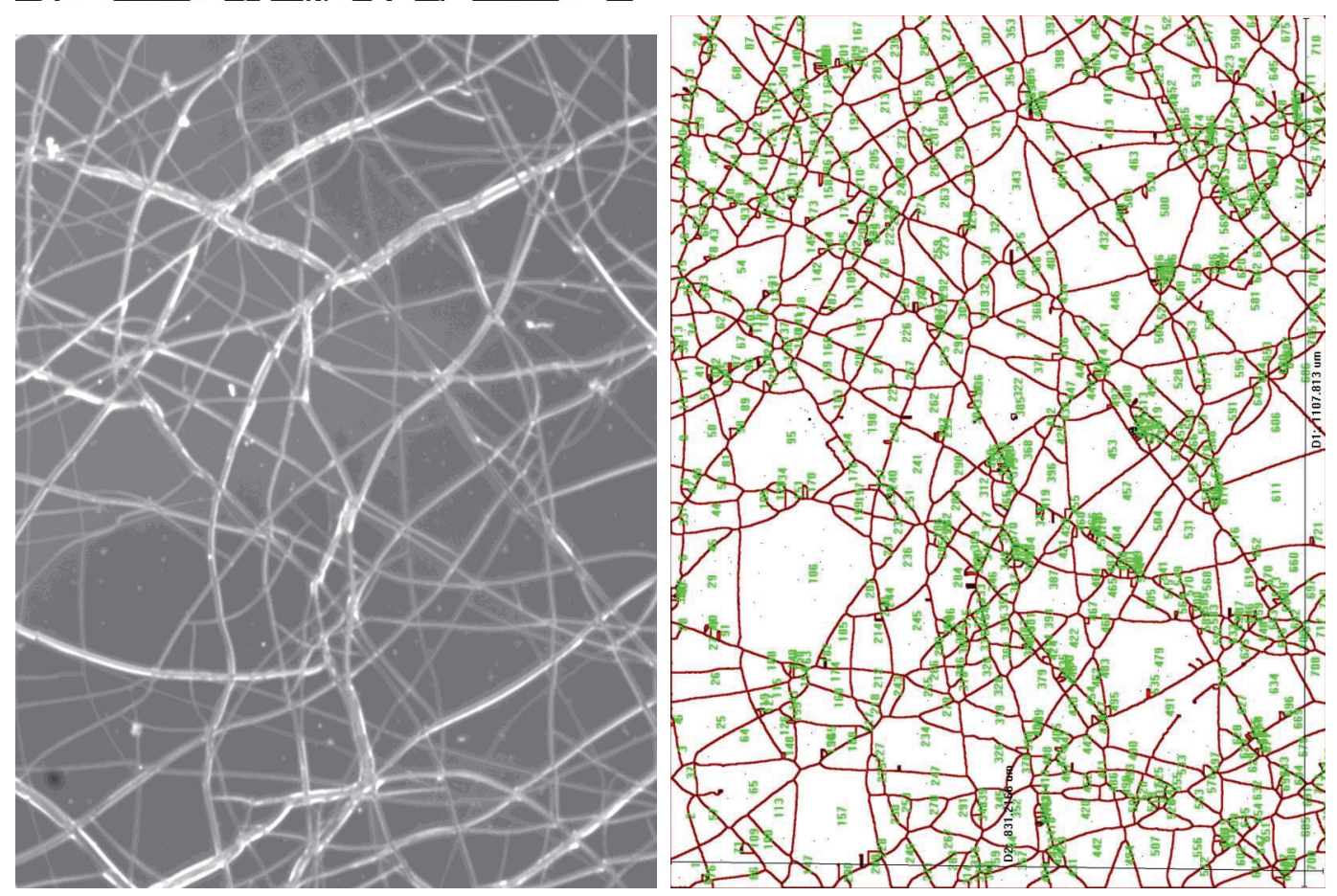


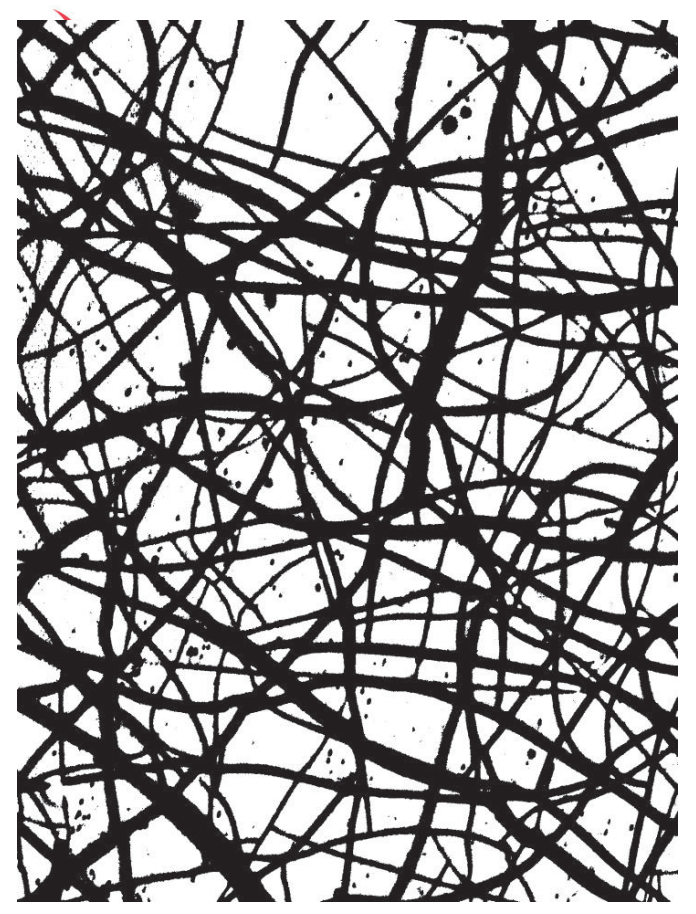

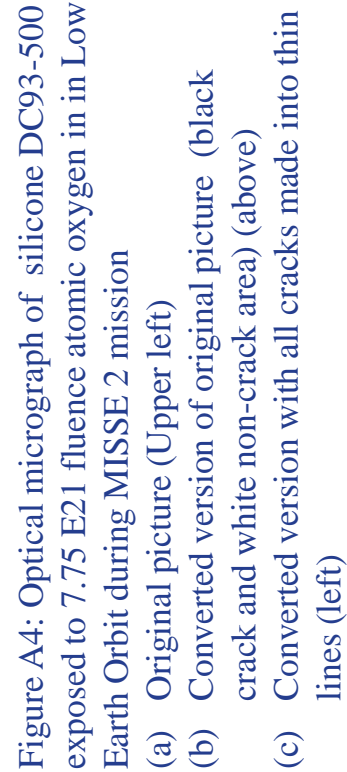
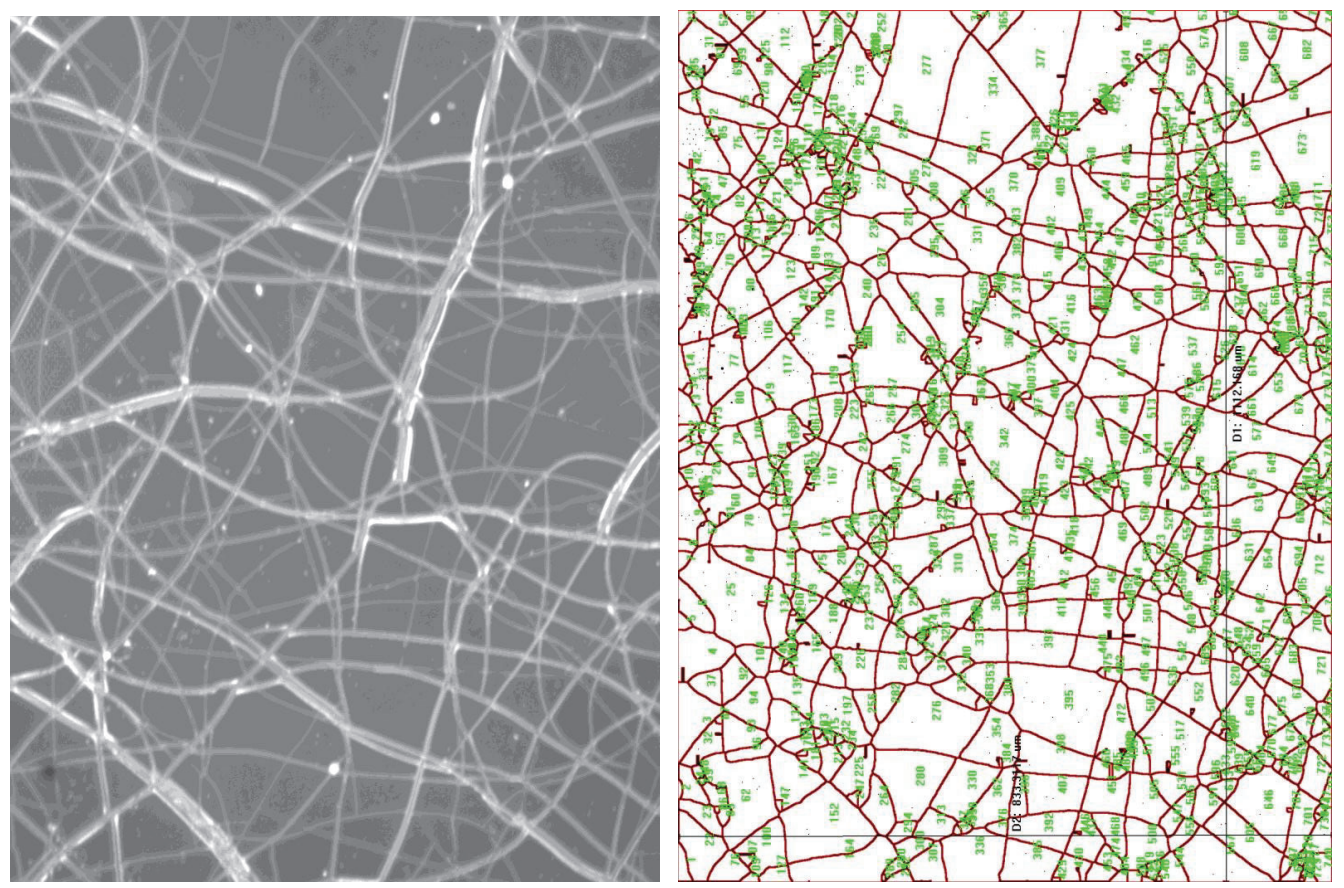

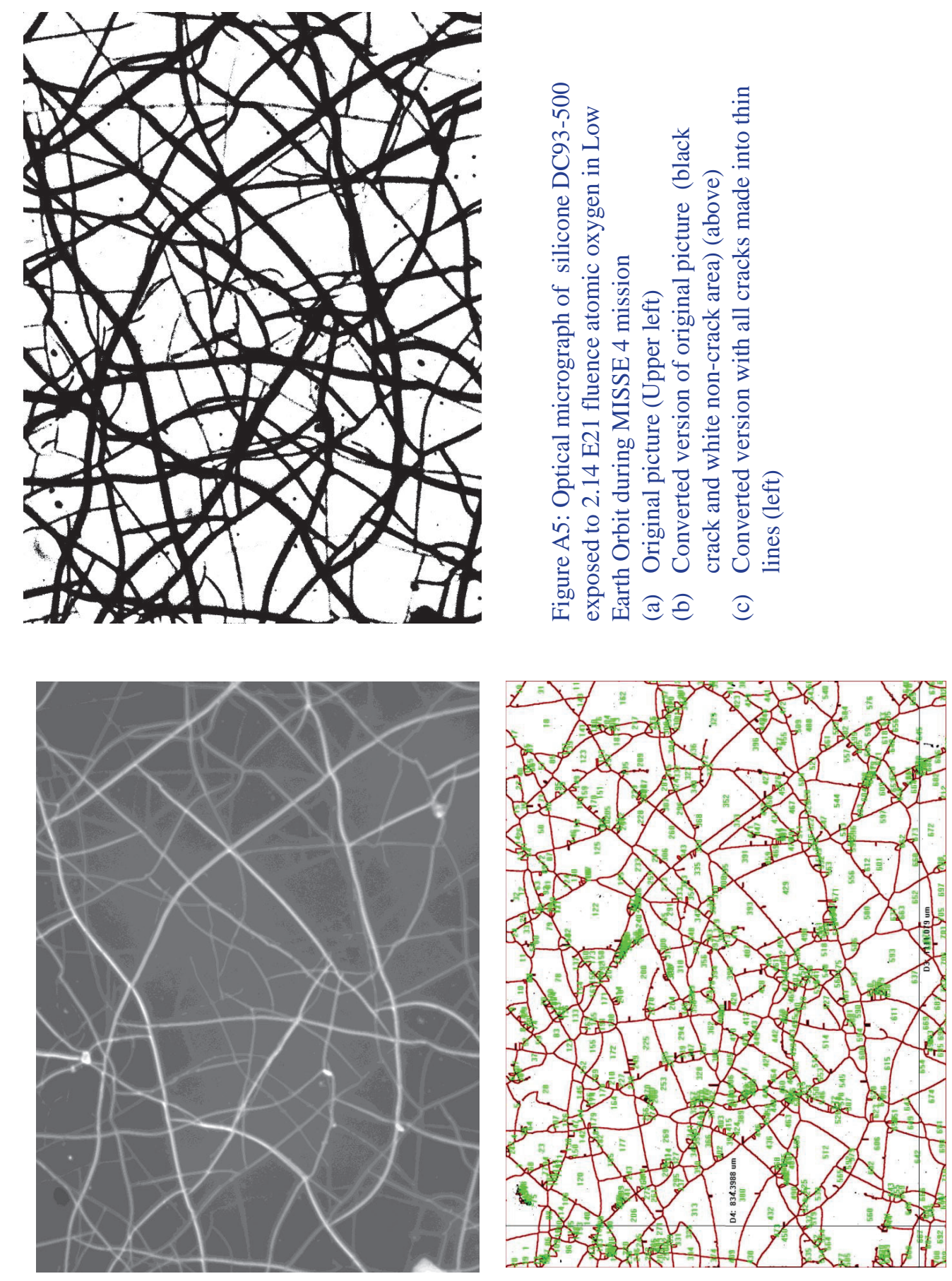


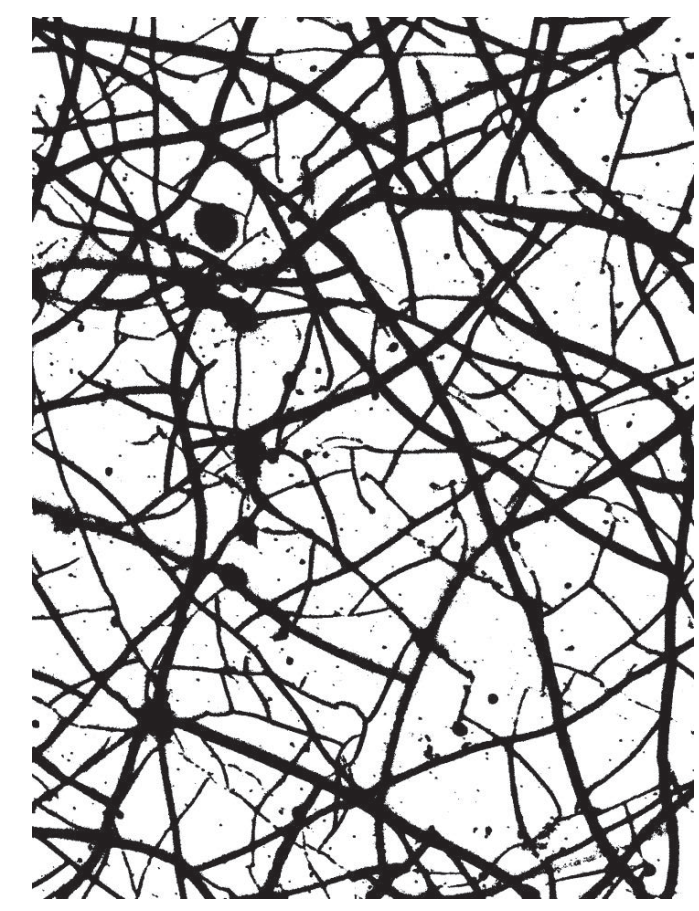

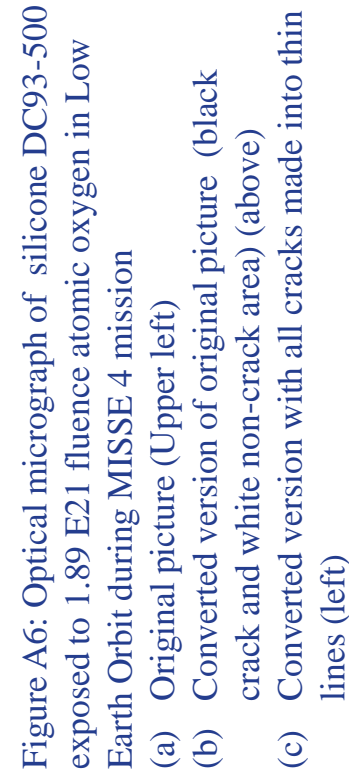
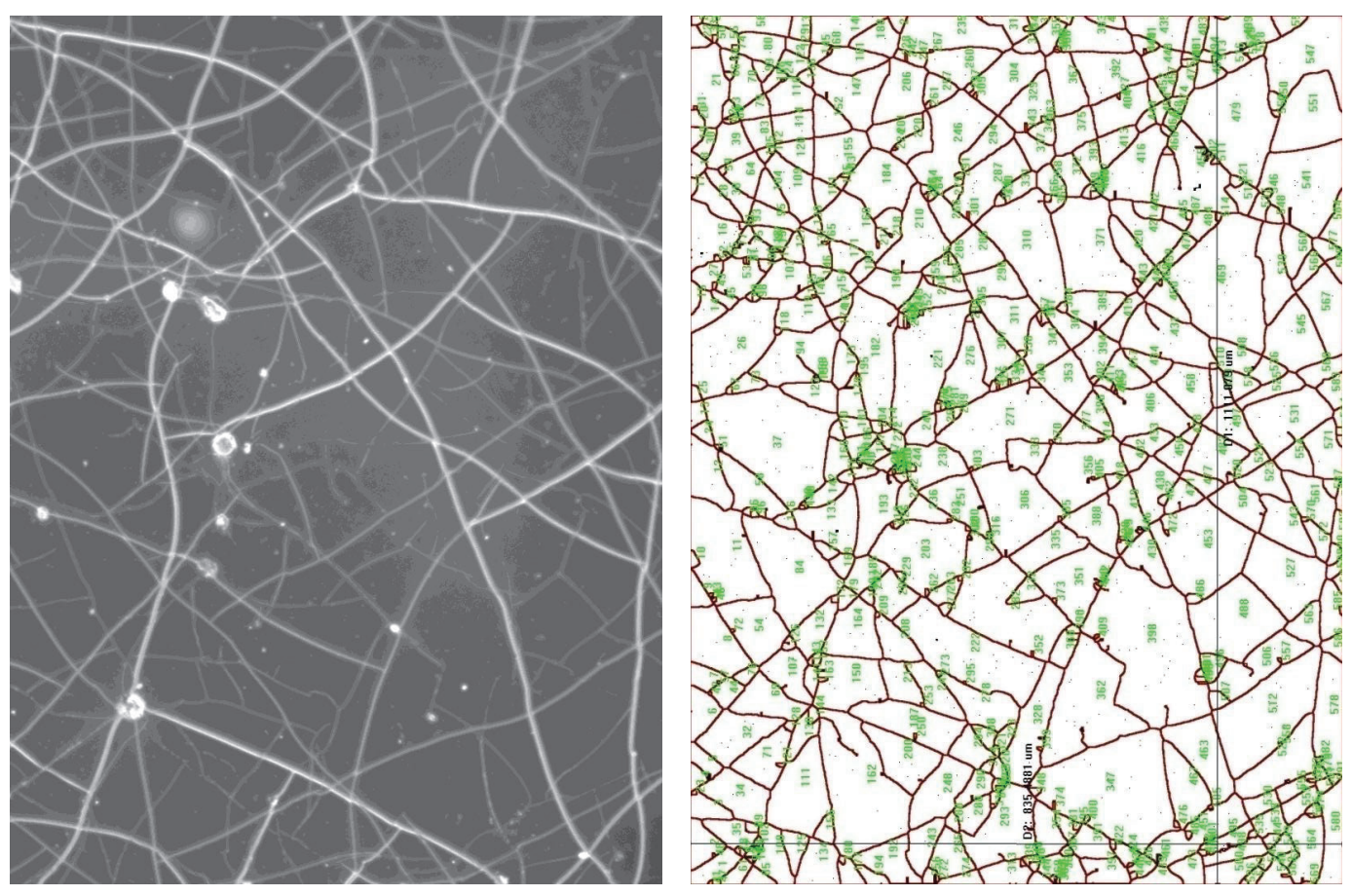

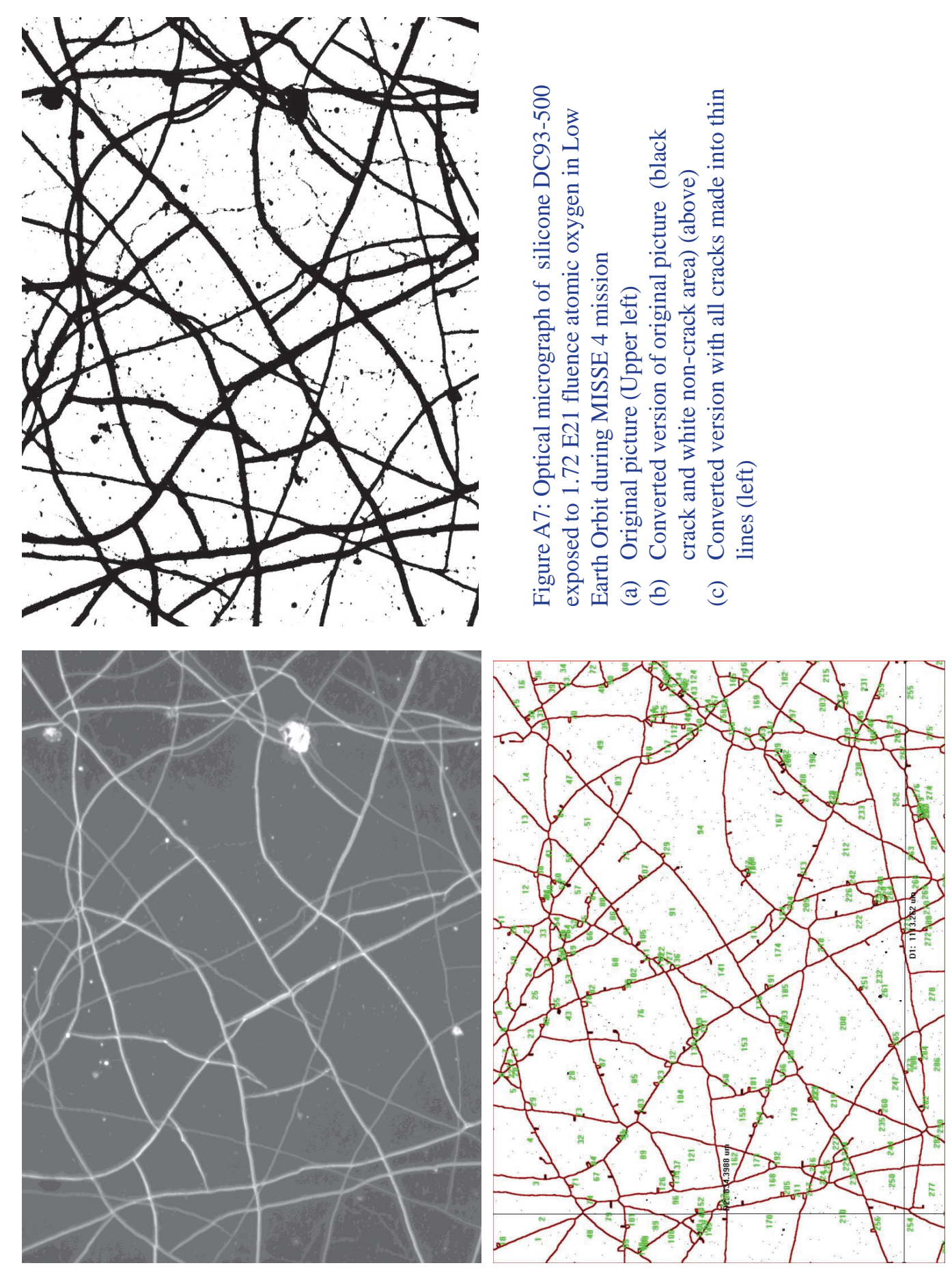

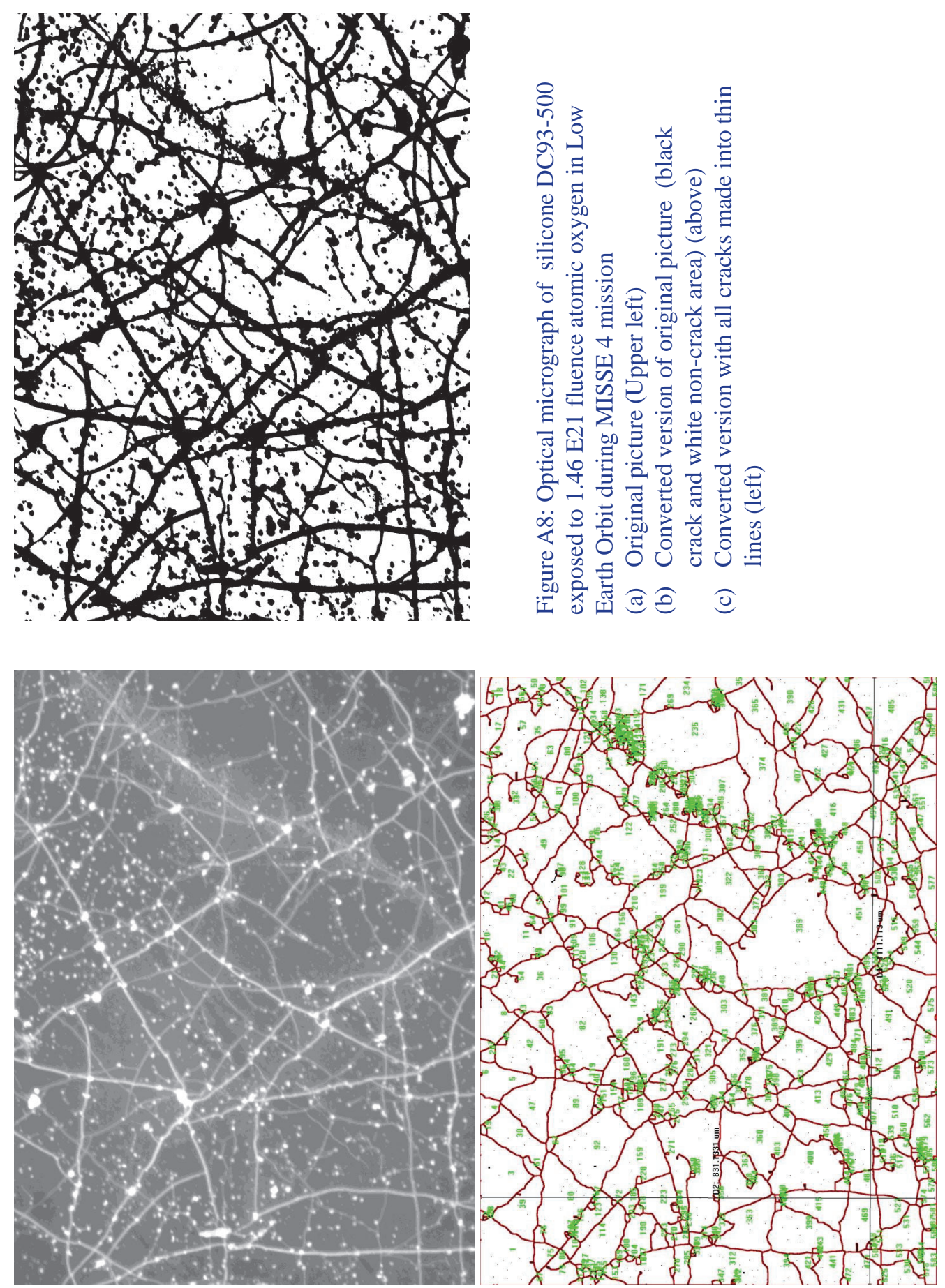


\section{Appendix B.-SEM Pictures for the Eight MISSE2 and MISSE4 Samples Exposed to Different Level of AO Fluences (x1000)}





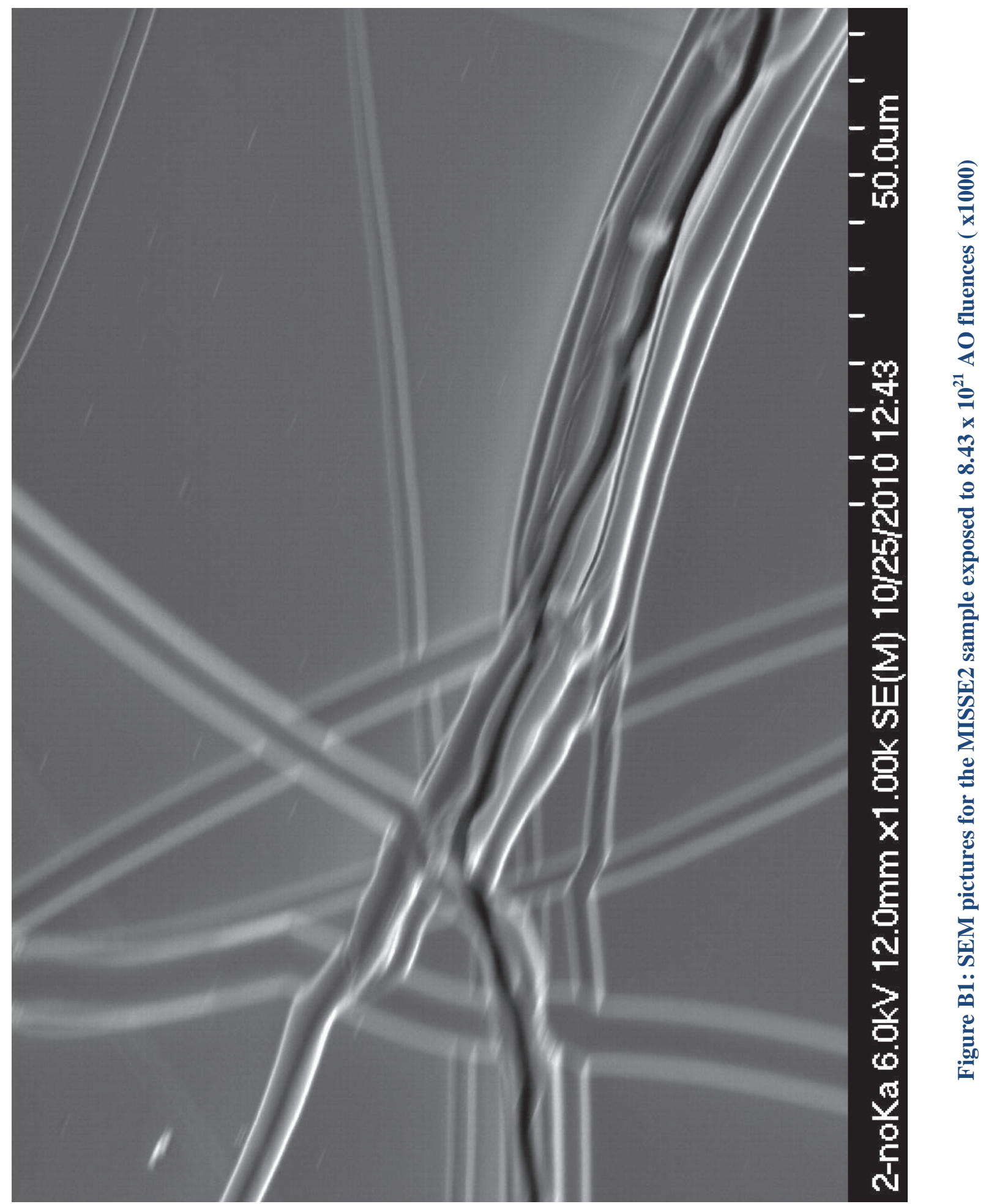




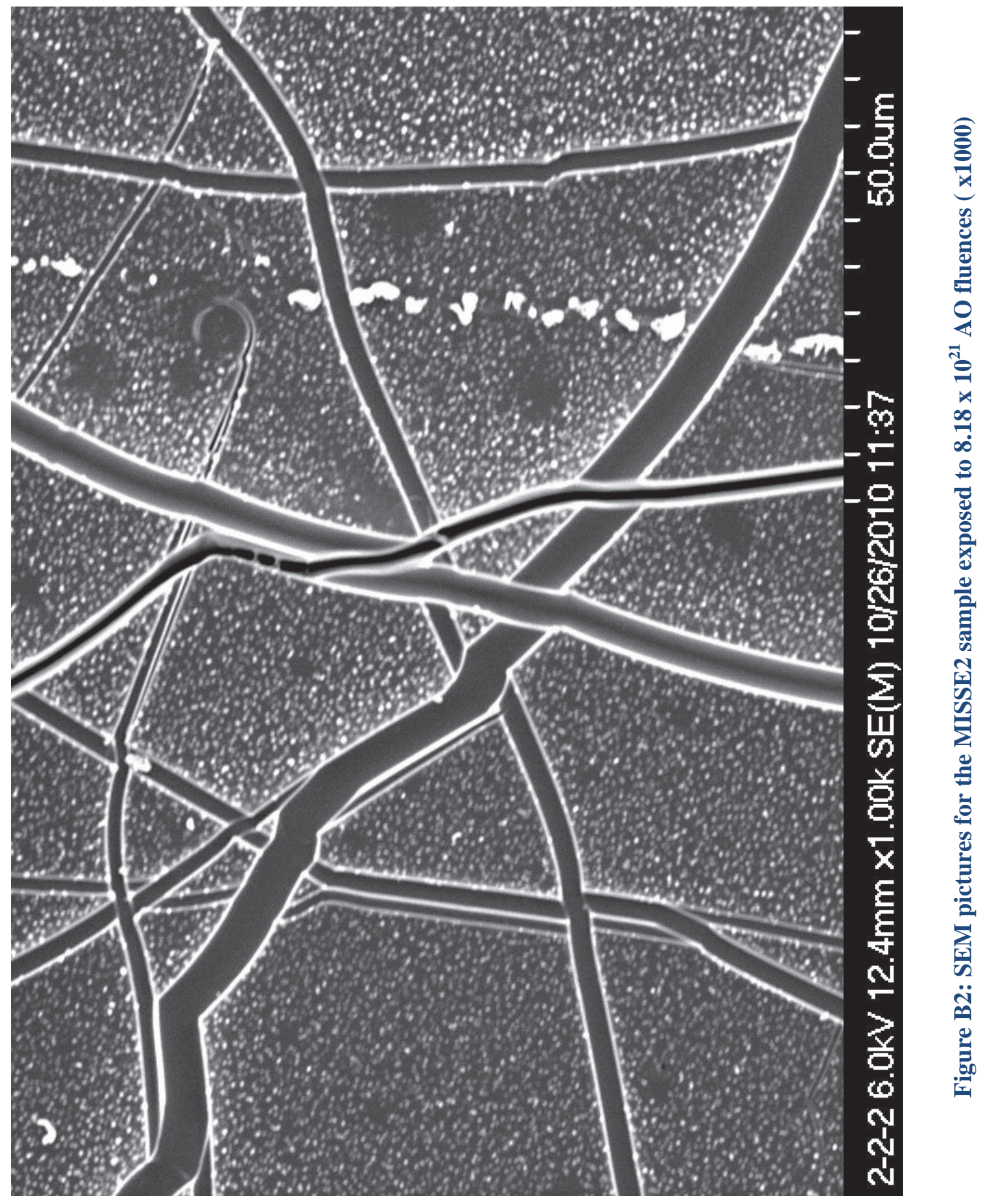




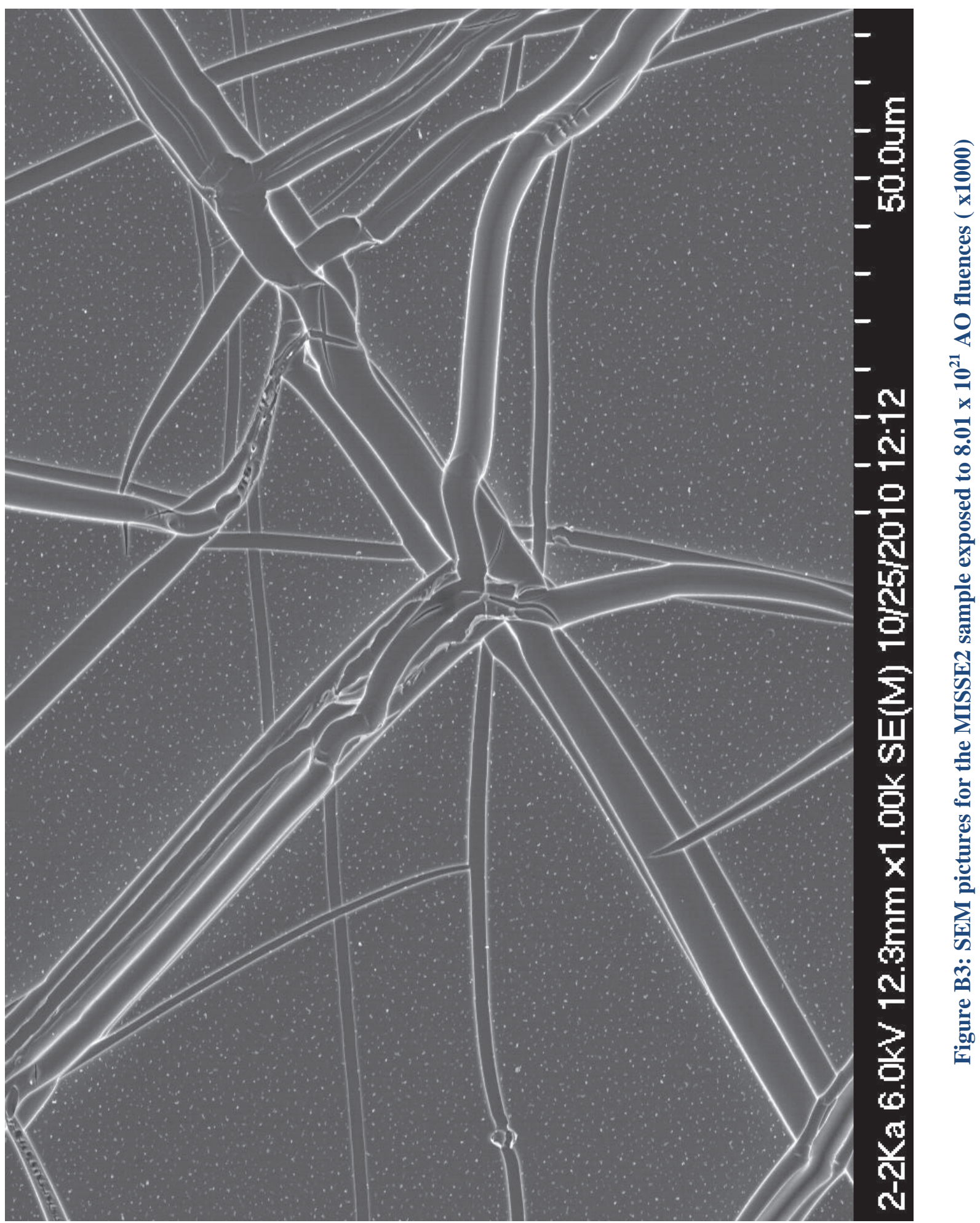




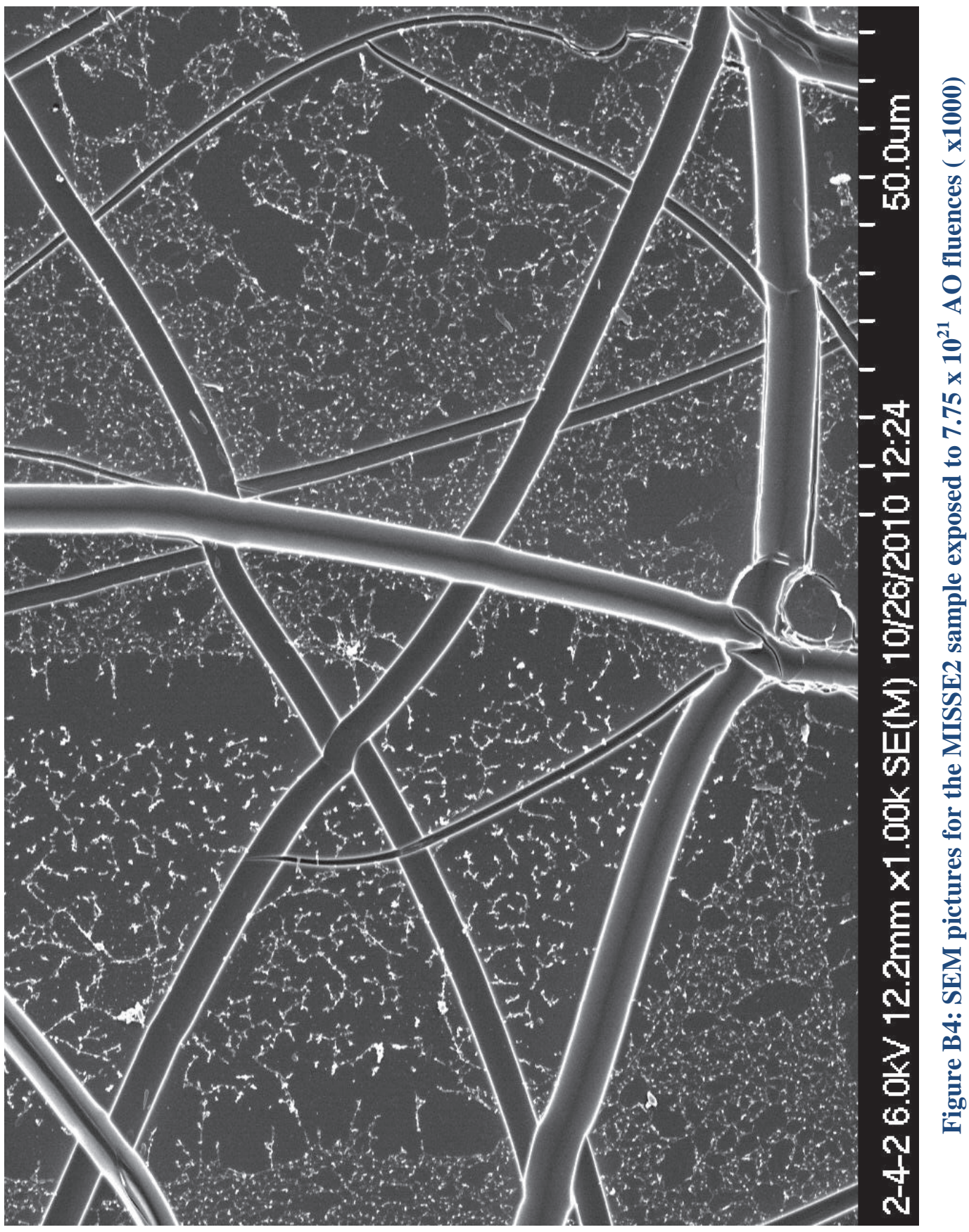




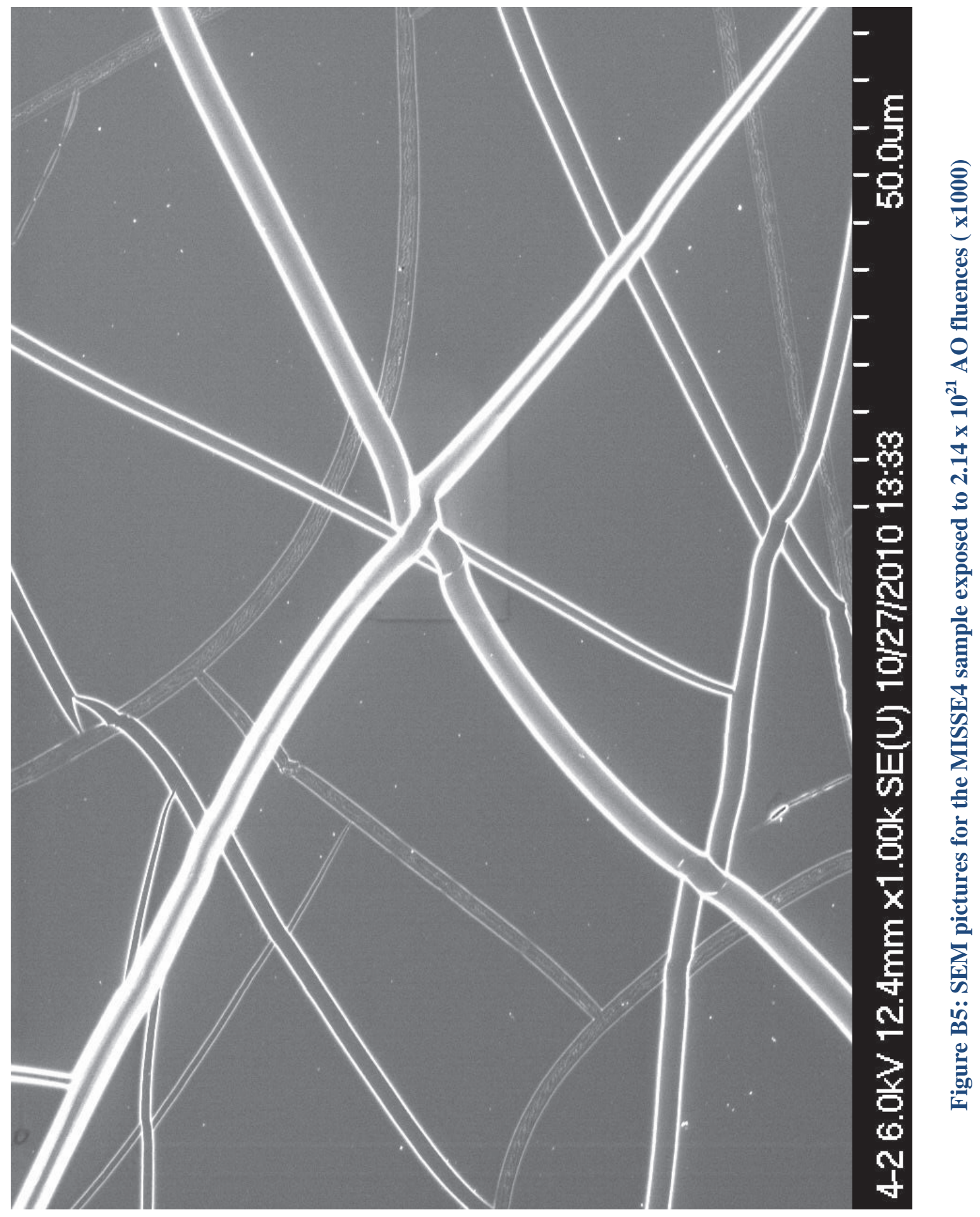




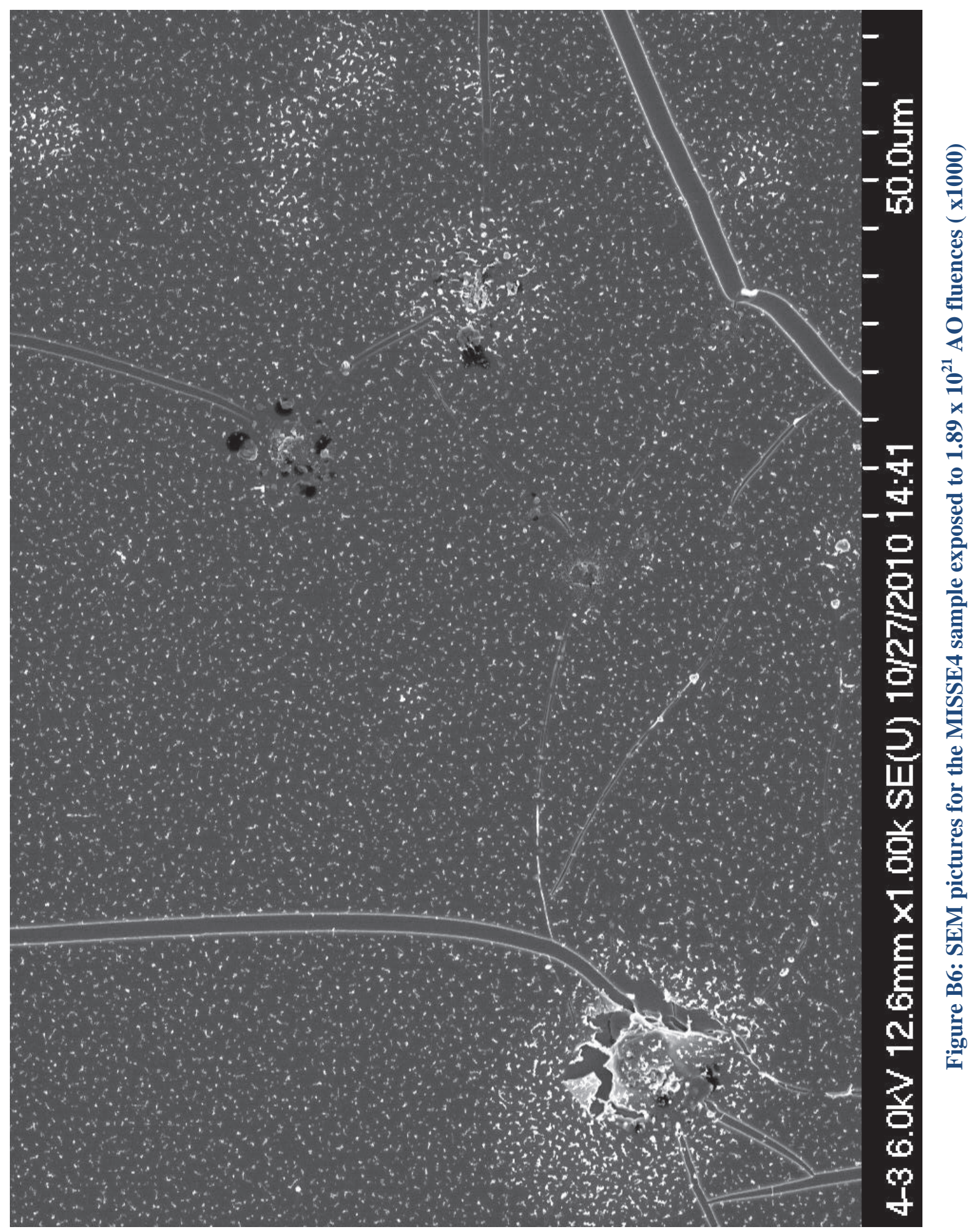




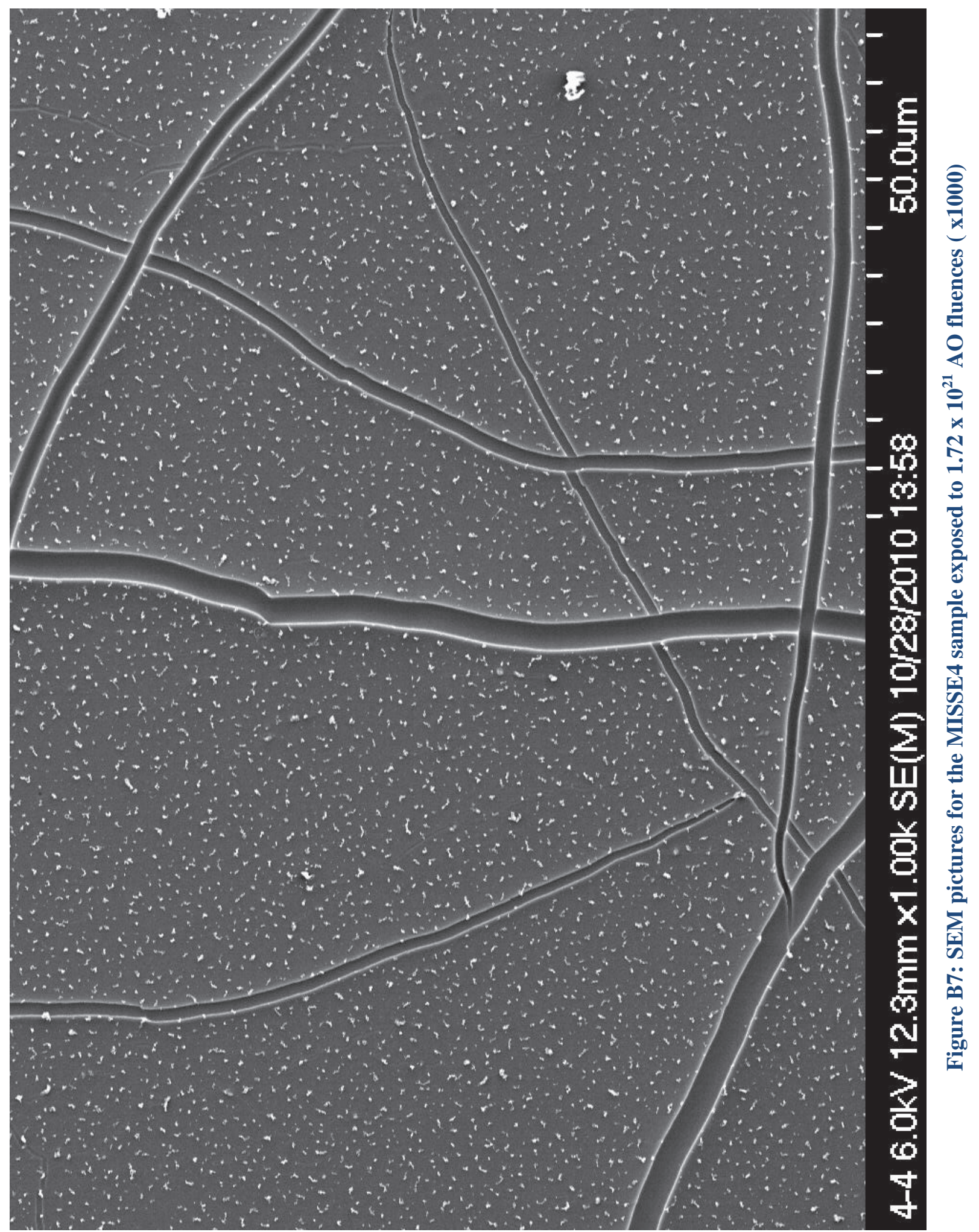




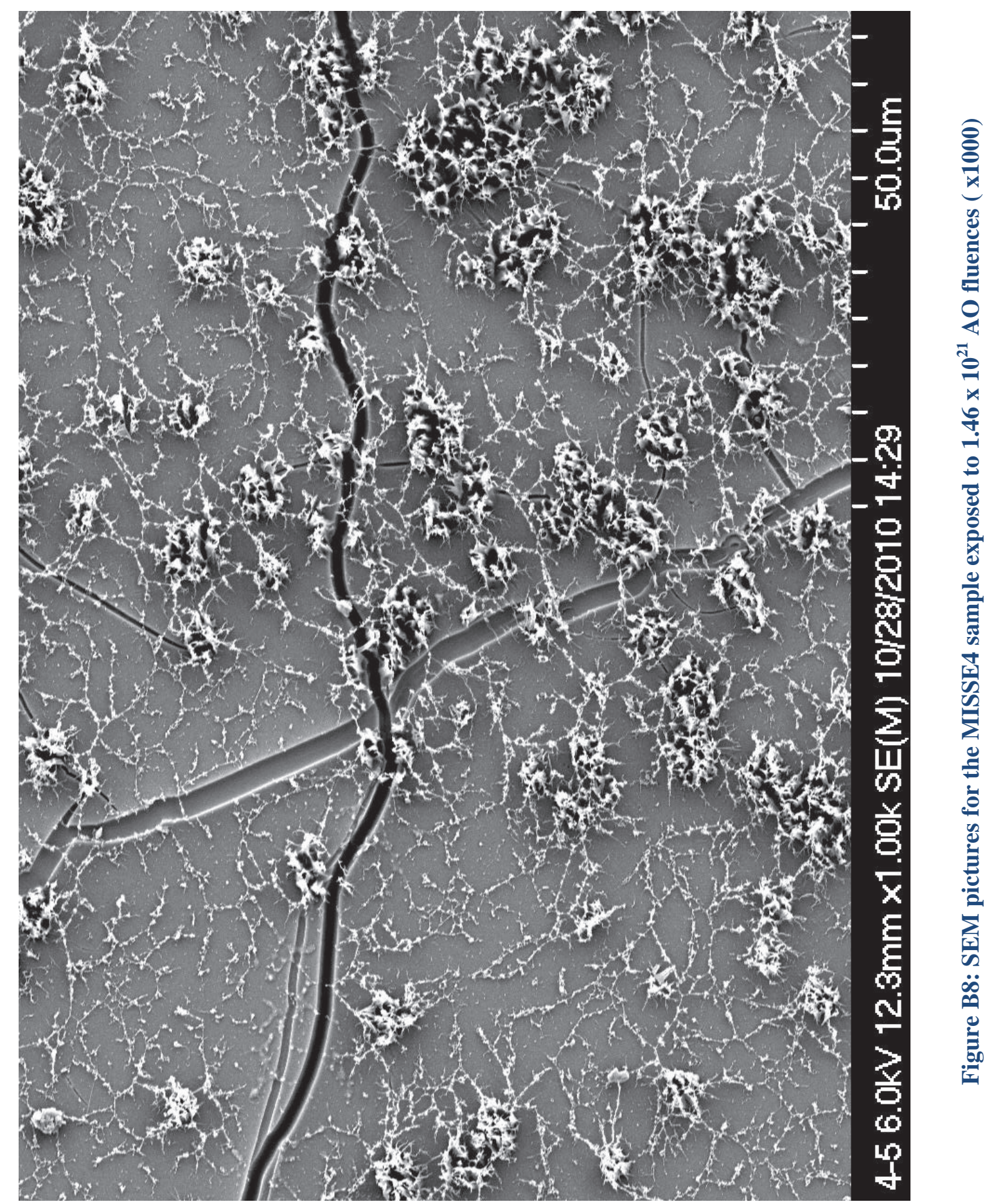




\section{Appendix C.-SEM Pictures for the Eight MISSE2 and MISSE4 Samples Exposed to Different Level of AO fluences (x5000)}





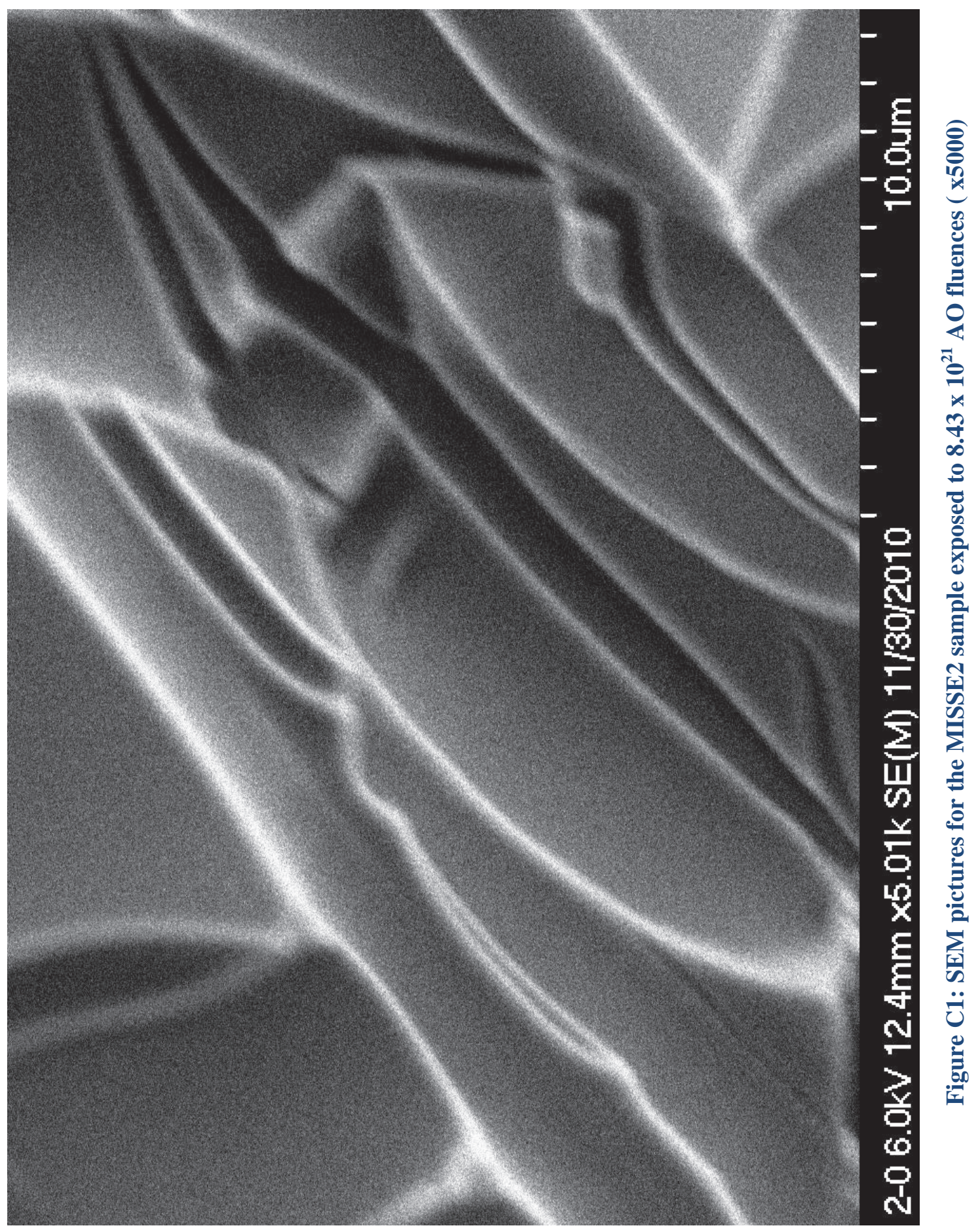




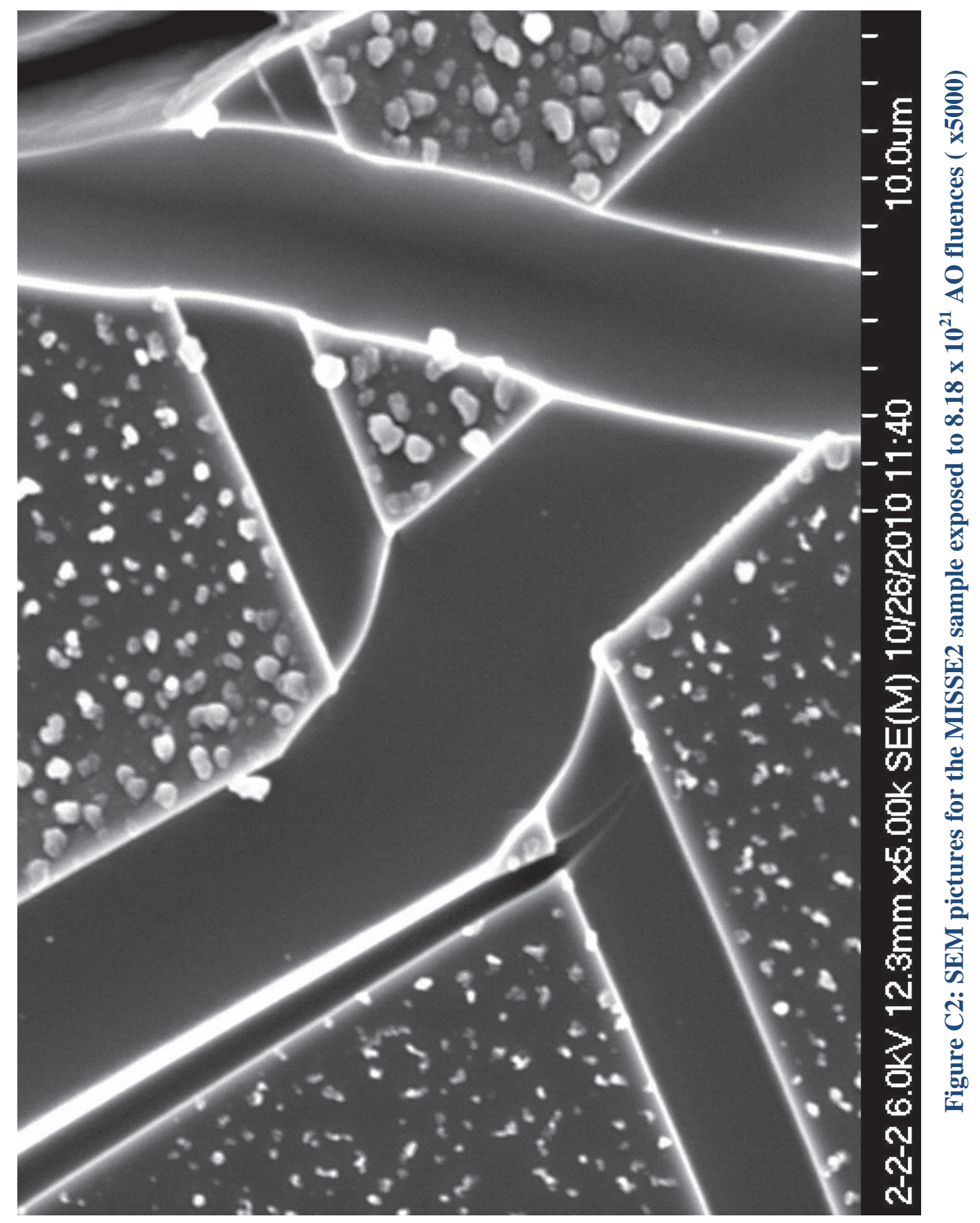




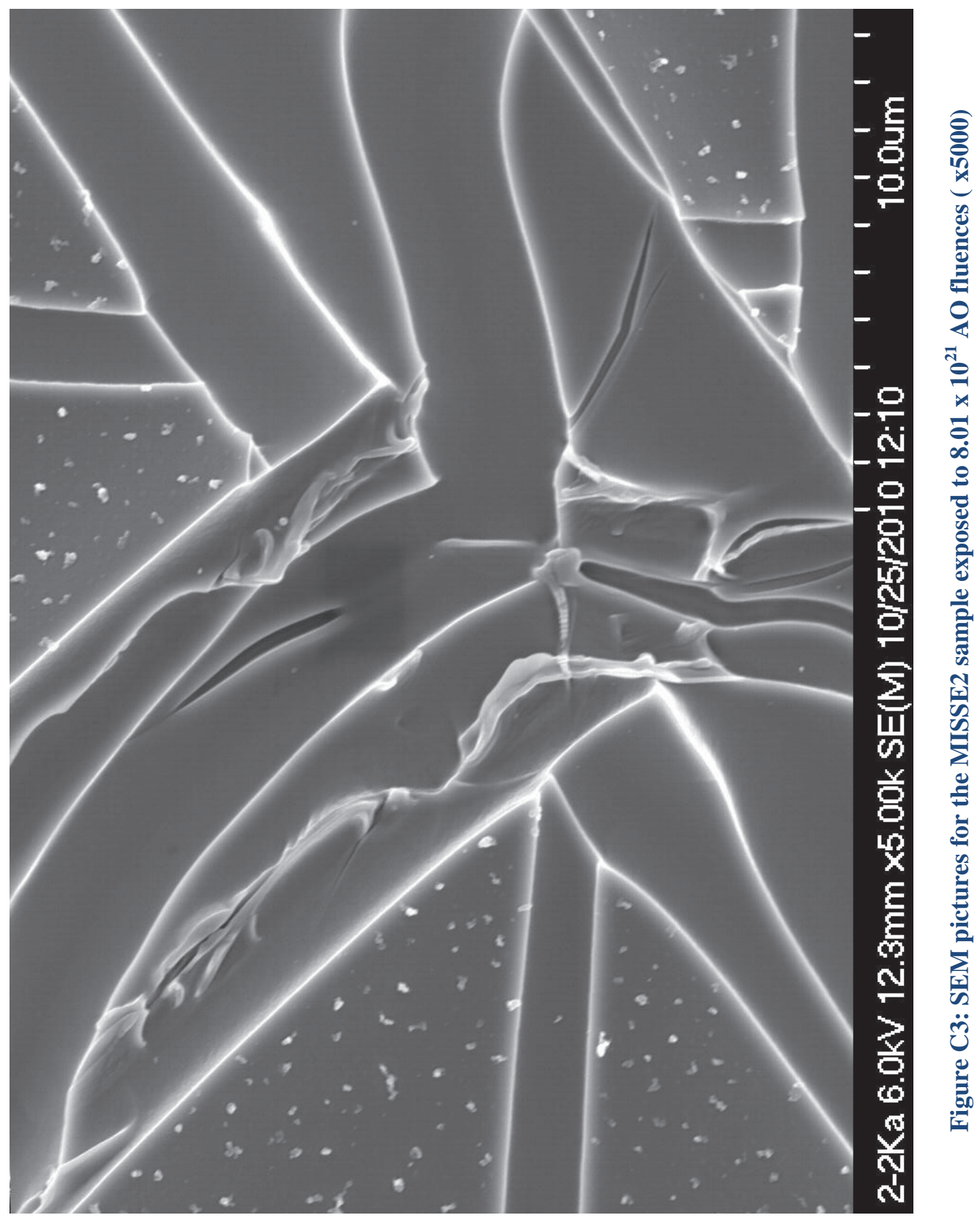




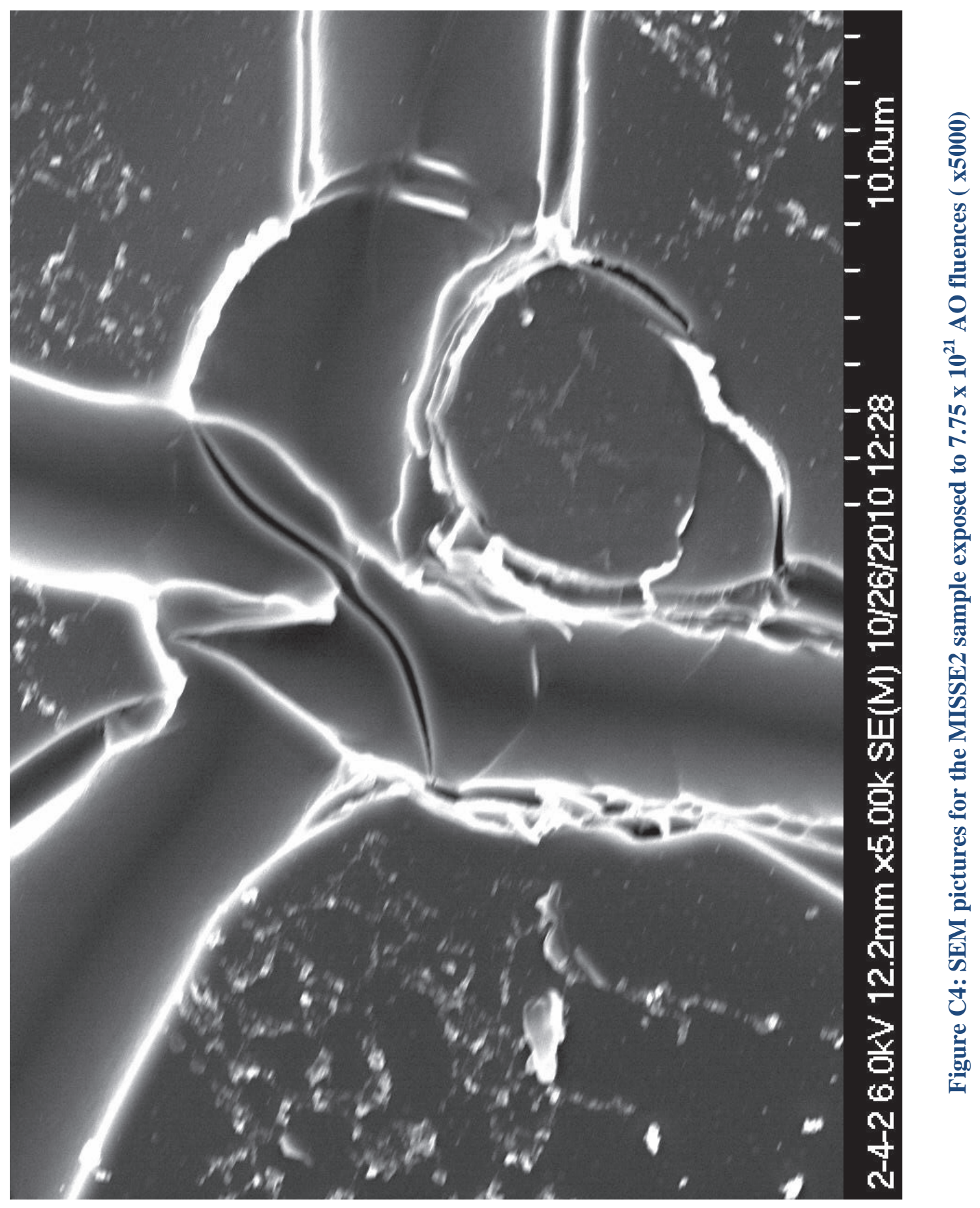




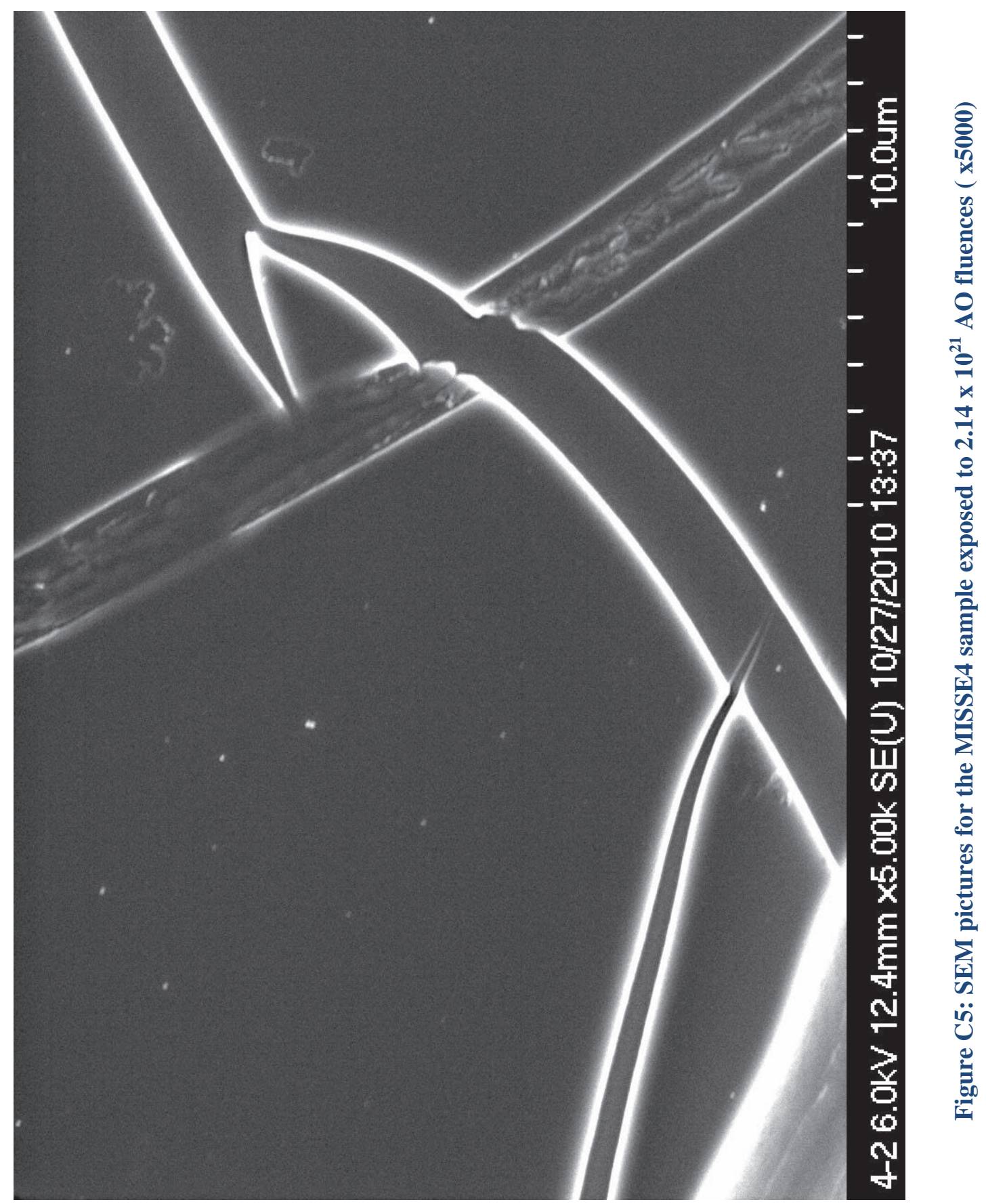




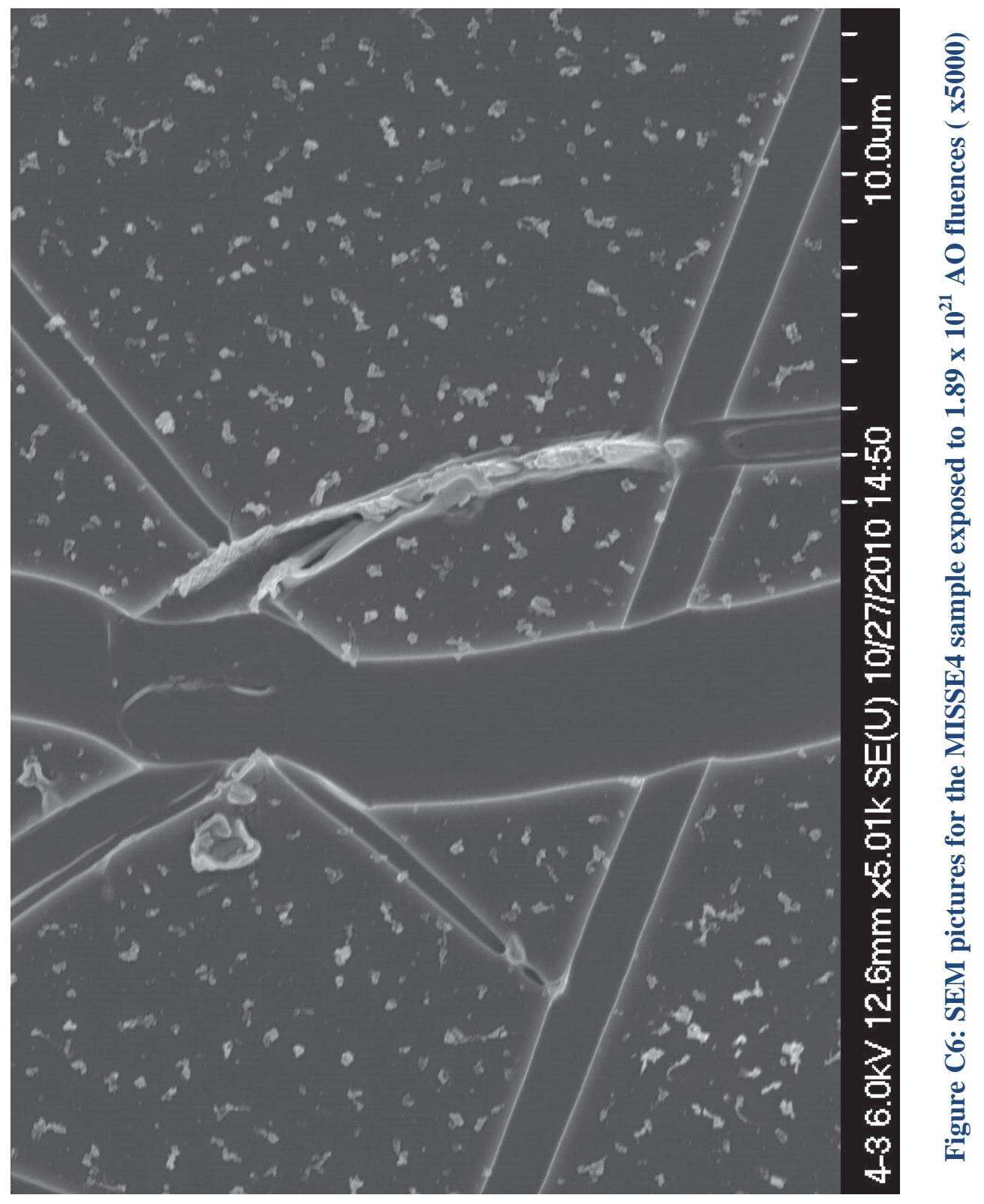




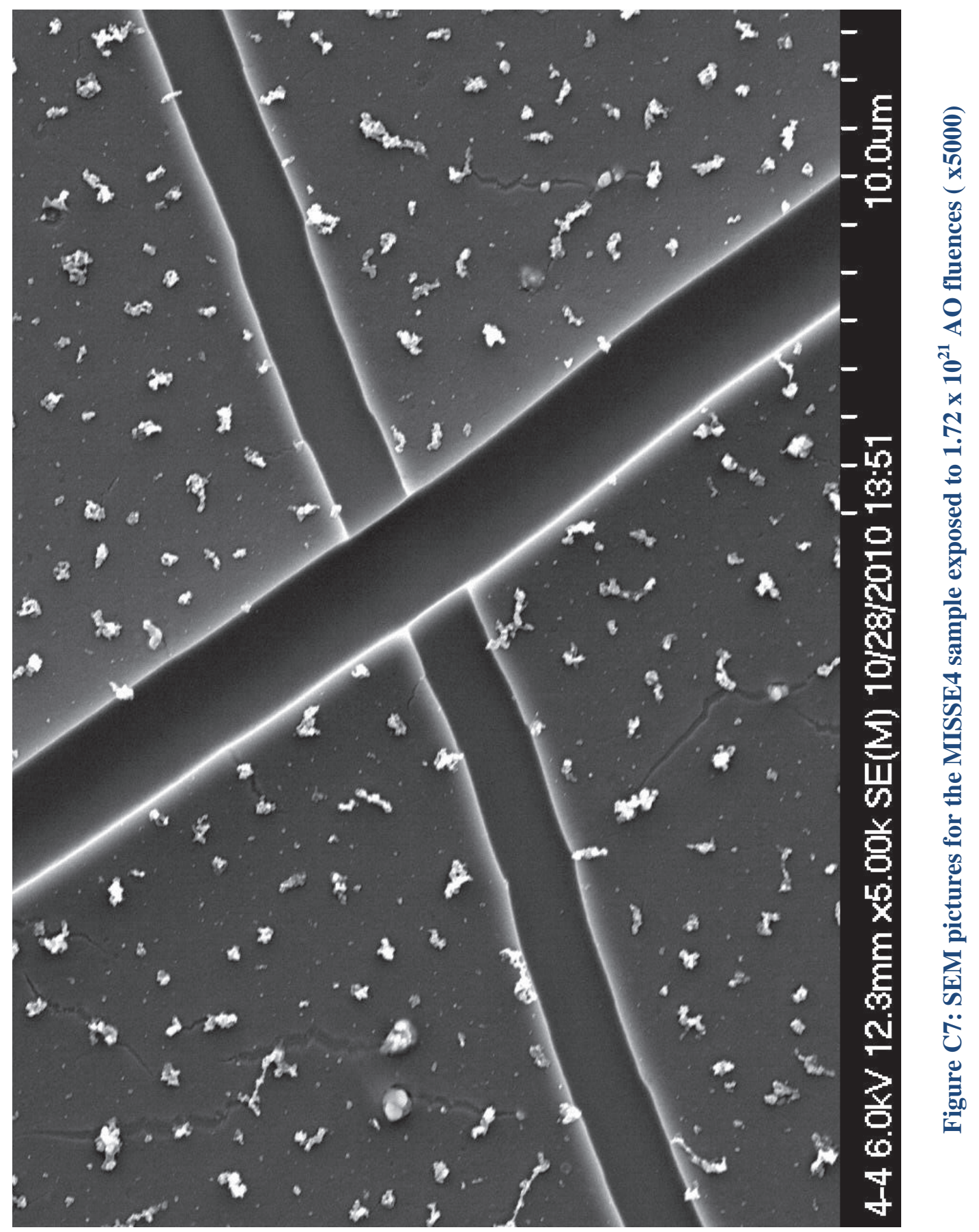




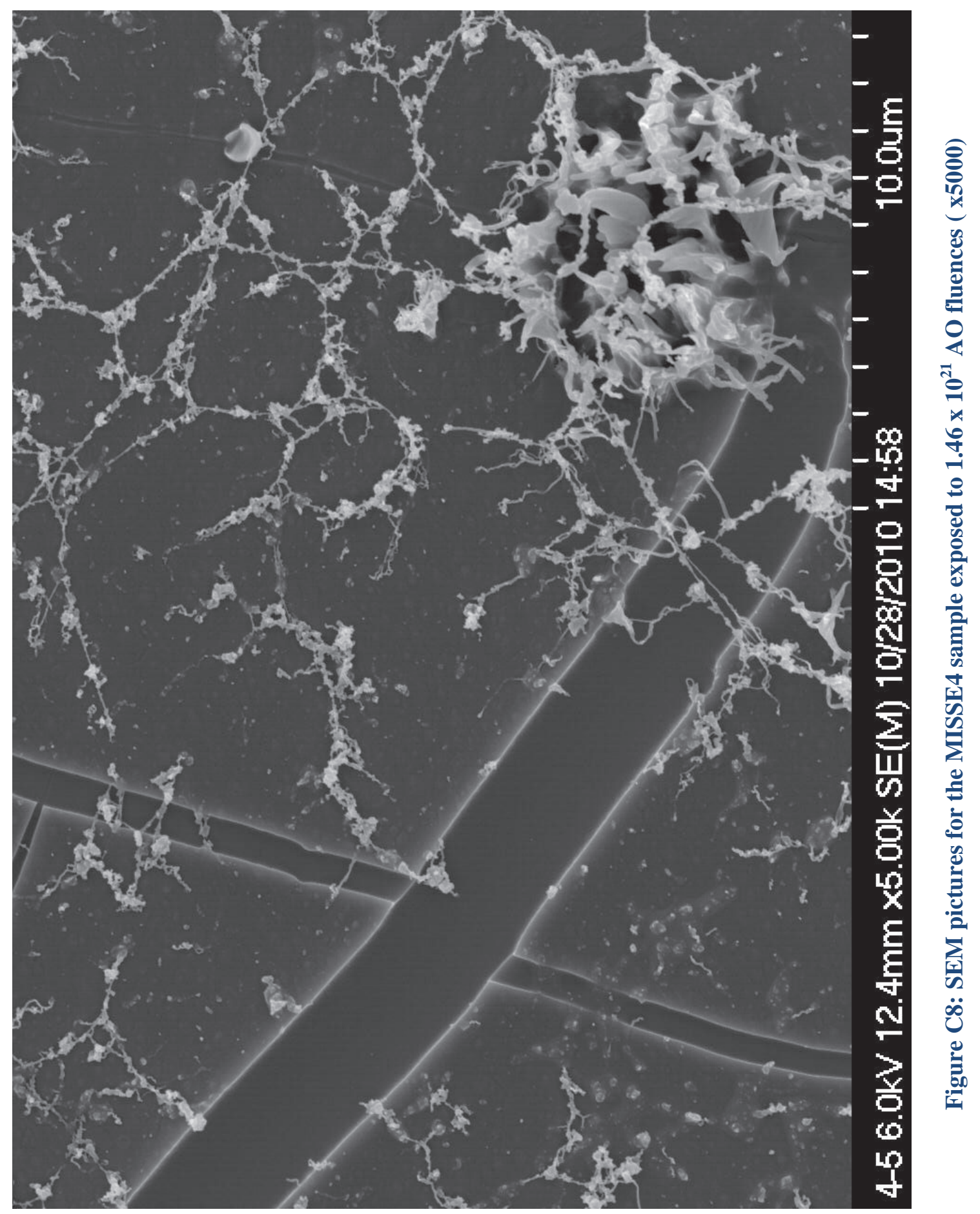




\section{Appendix D.-EDS for Pristine Silicone and the Eight MISSE2 and MISSE4 Samples Exposed to Different Level of AO Fluences}





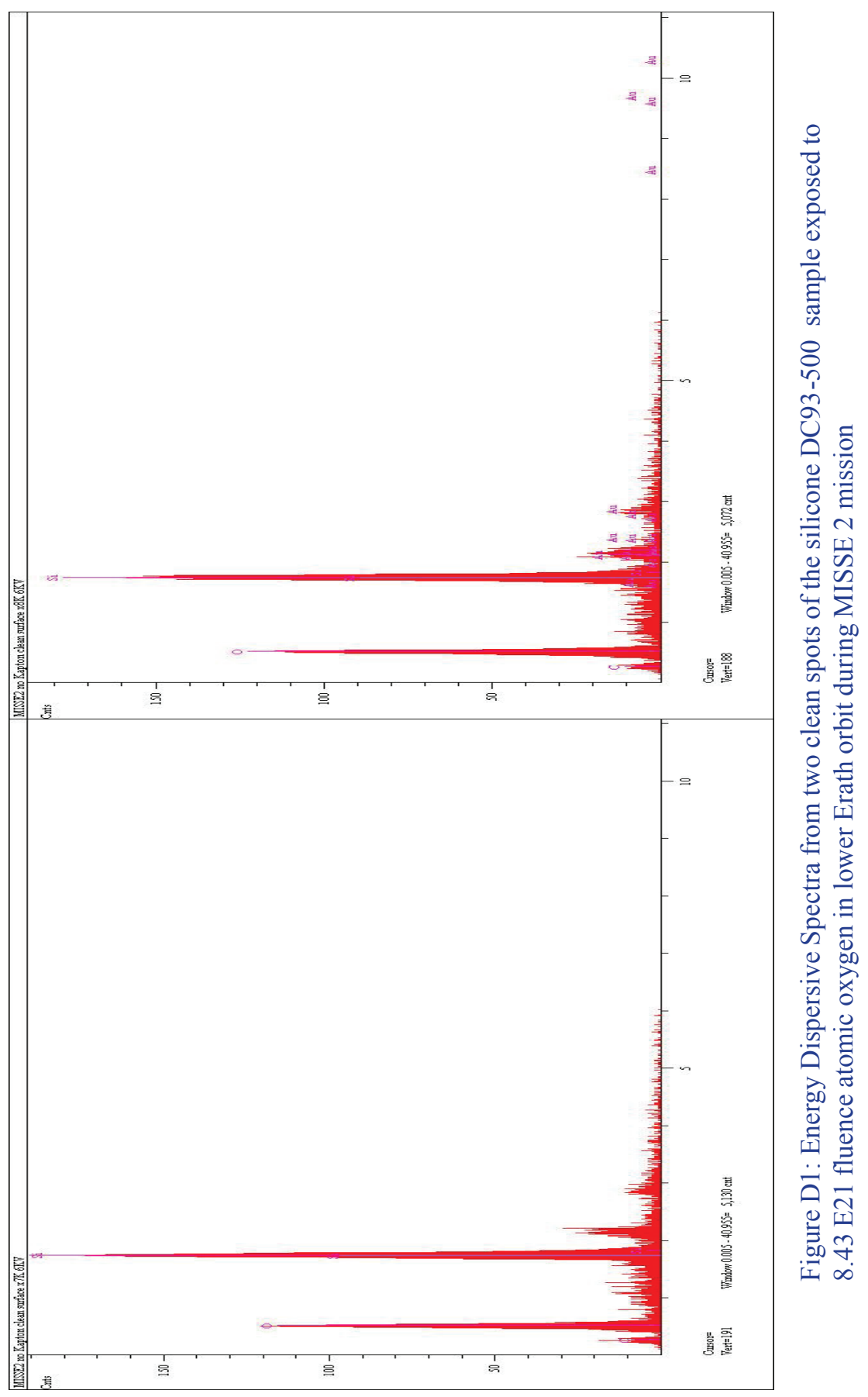




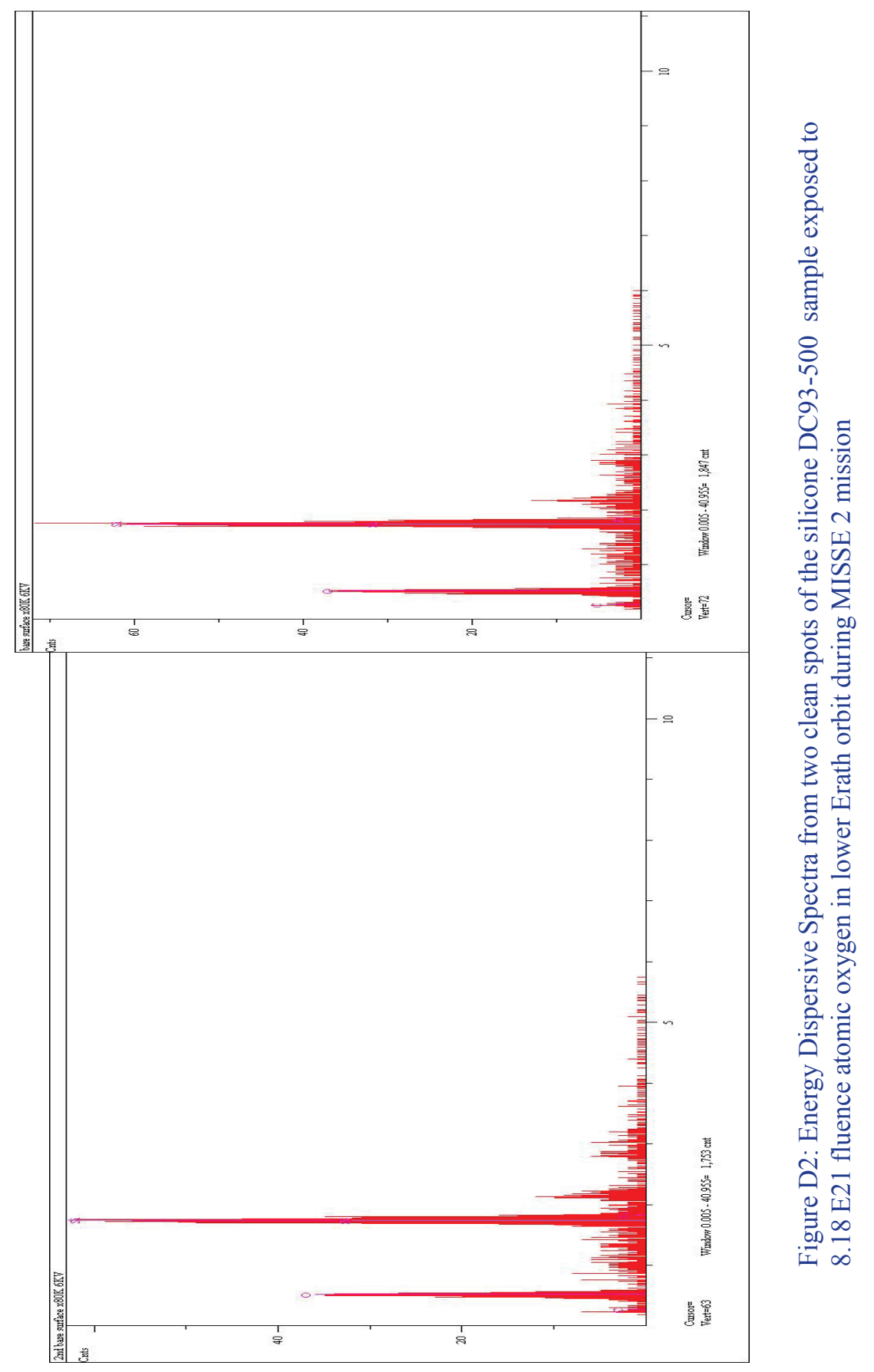




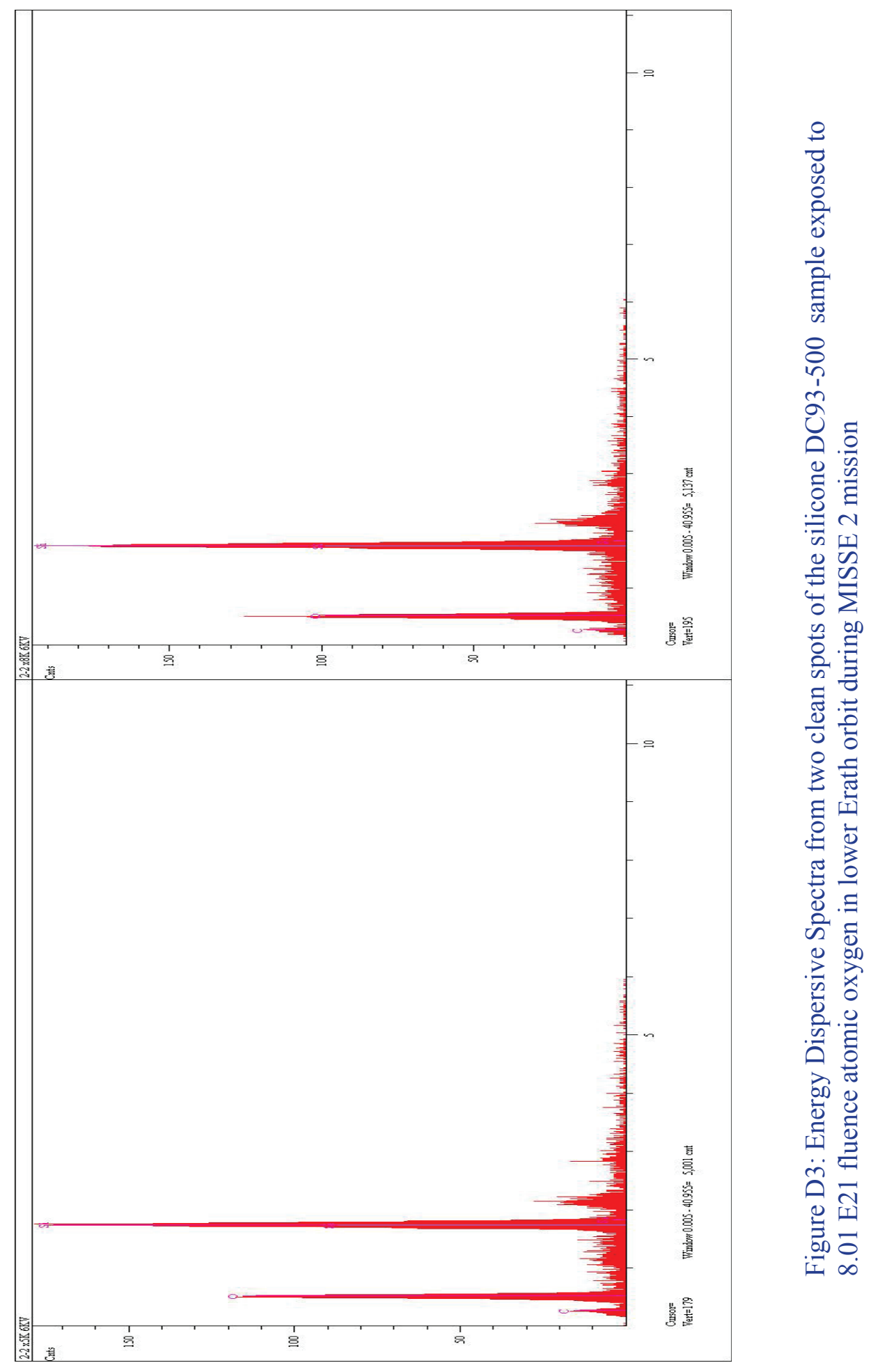




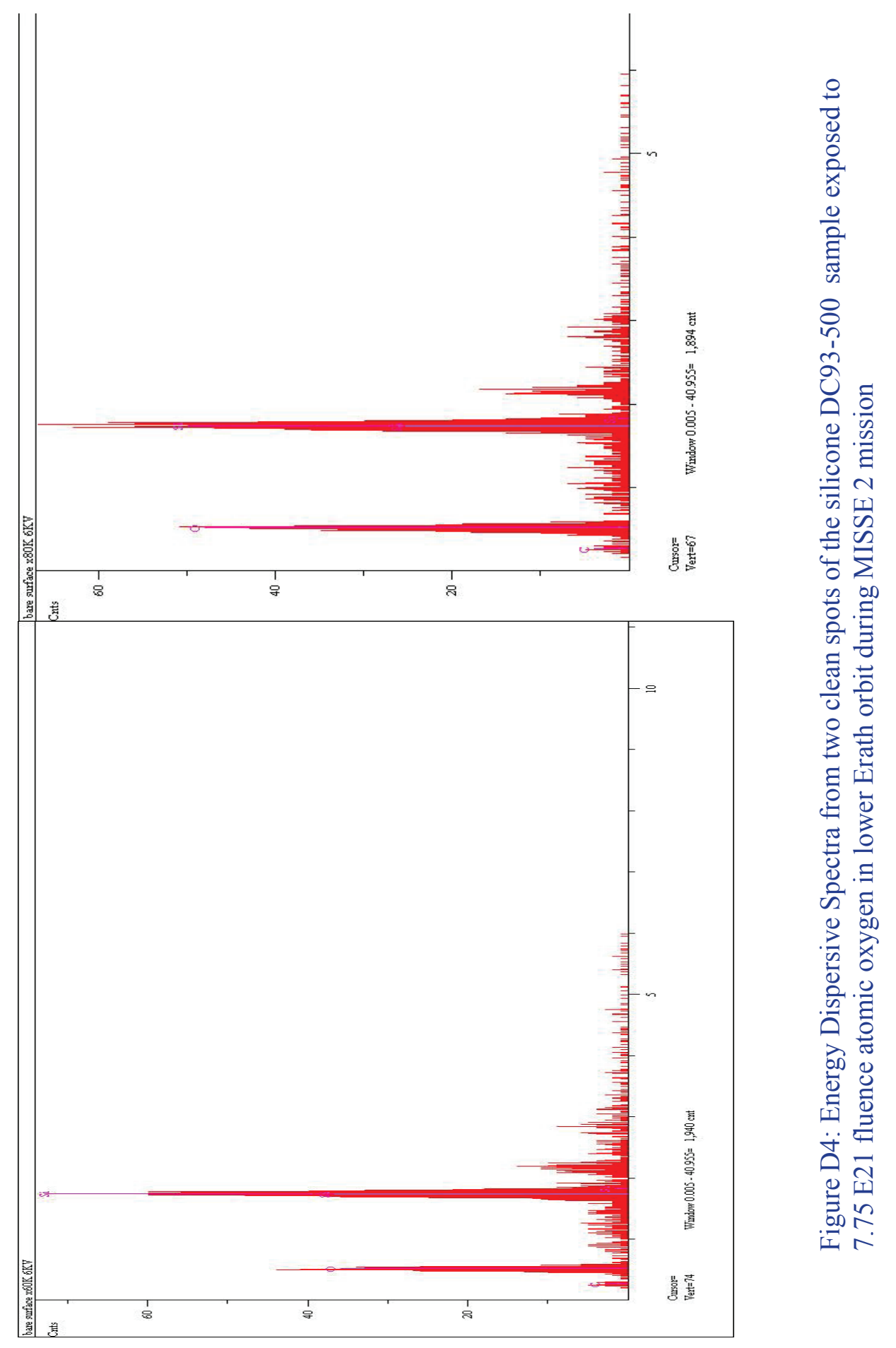




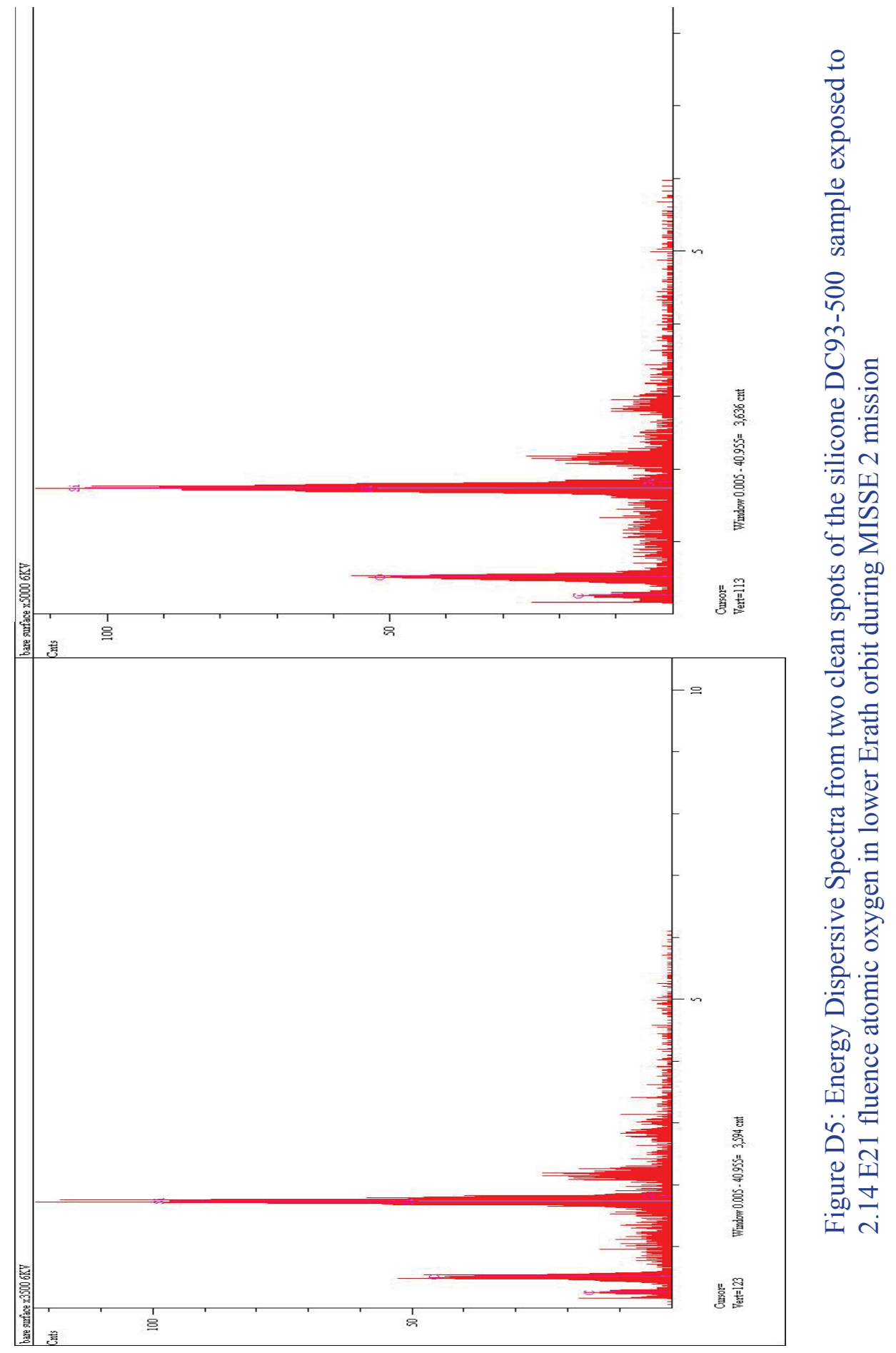




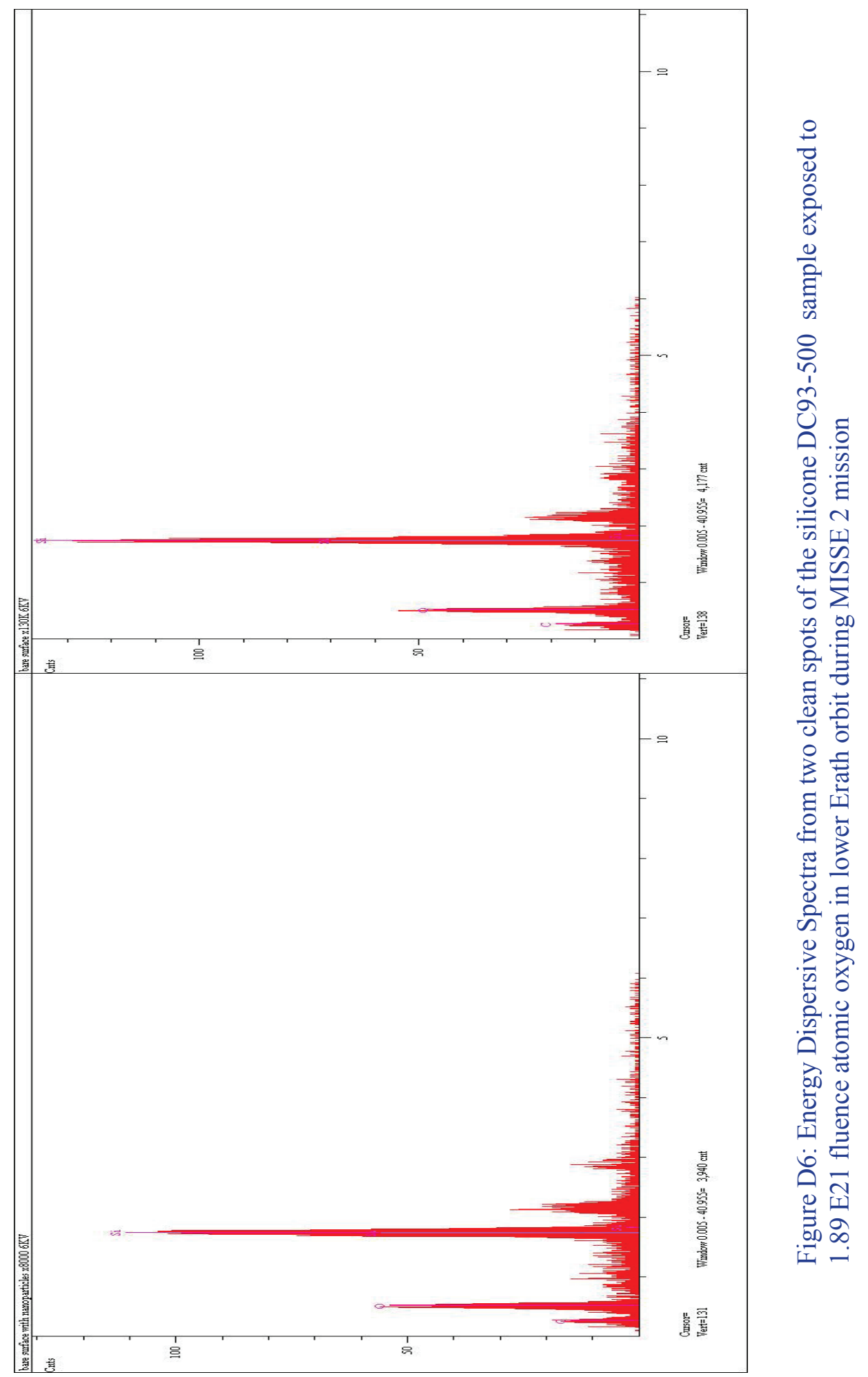




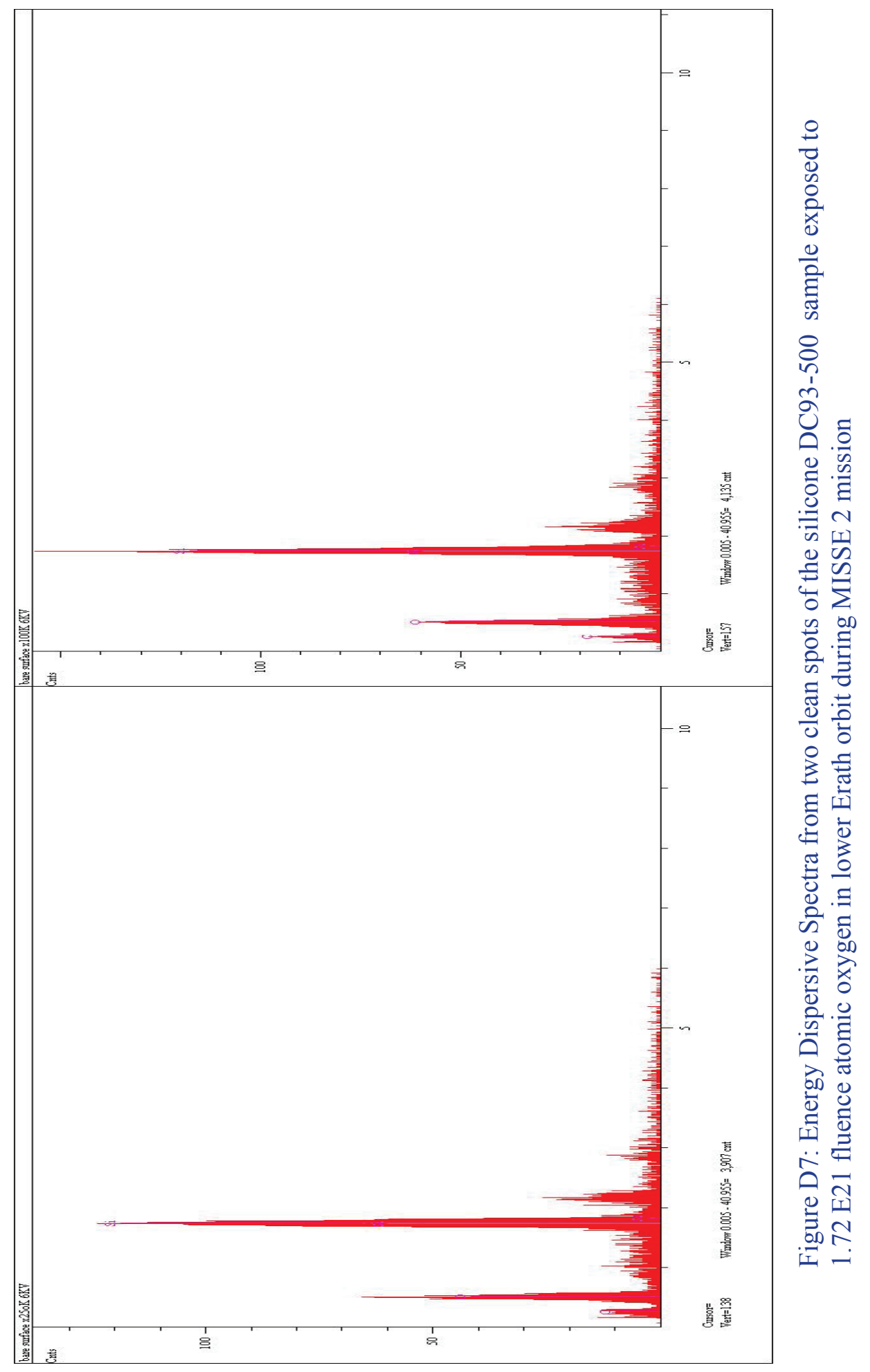




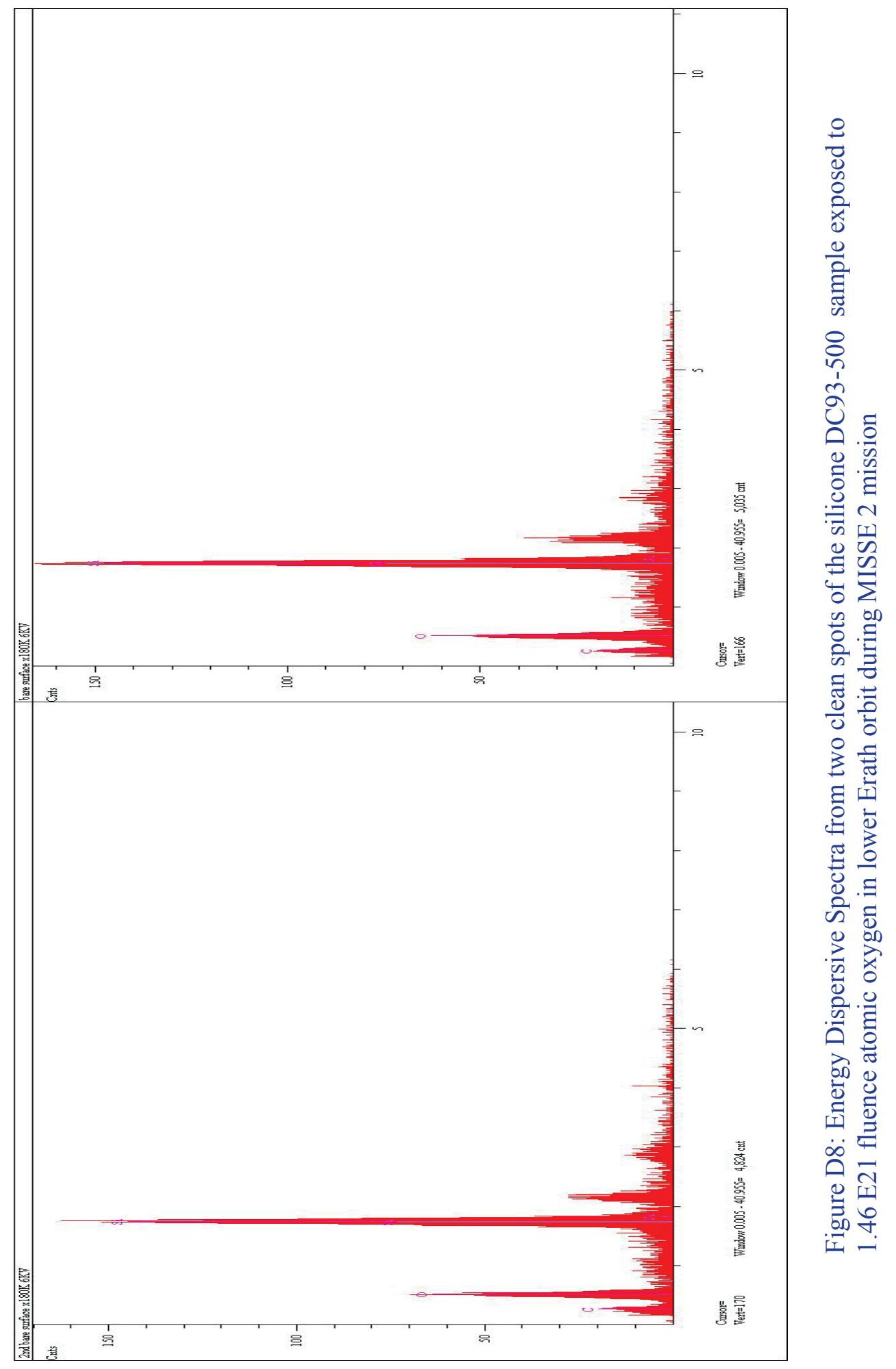




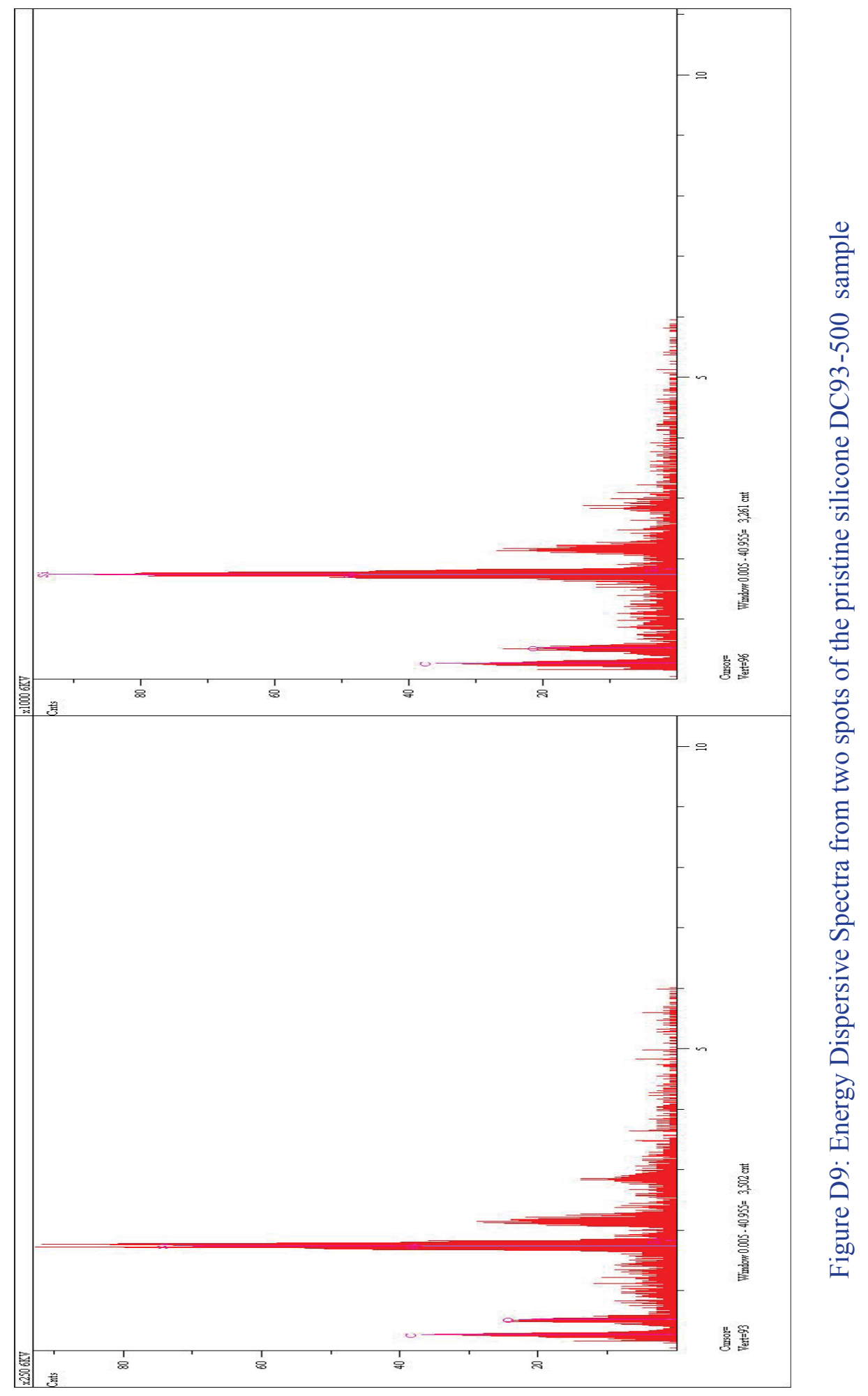





\begin{tabular}{|c|c|c|}
\hline \multicolumn{2}{|c|}{ REPORT DOCUMENTATION PAGE } & $\begin{array}{l}\text { Form Approved } \\
\text { OMB No. 0704-0188 }\end{array}$ \\
\hline \multicolumn{3}{|c|}{ 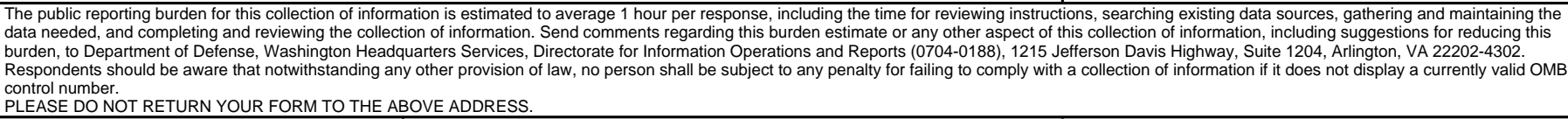 } \\
\hline $\begin{array}{l}\text { 1. REPORT DATE (DD-MM-YYYY) } \\
01-08-2012\end{array}$ & $\begin{array}{l}\text { 2. REPORT TYPE } \\
\text { Technical Memorandum }\end{array}$ & 3. DATES COVERED (From - To) \\
\hline \multirow{3}{*}{\multicolumn{2}{|c|}{$\begin{array}{l}\text { 4. TITLE AND SUBTITLE } \\
\text { Optical and Scanning Electron Microscopy of the Materials International Space Station } \\
\text { Experiment (MISSE) Spacecraft Silicone Experiment }\end{array}$}} & 5a. CONTRACT NUMBER \\
\hline & & 5b. GRANT NUMBER \\
\hline & & 5c. PROGRAM ELEMENT NUMBER \\
\hline \multirow{3}{*}{\multicolumn{2}{|c|}{$\begin{array}{l}\text { 6. AUTHOR(S) } \\
\text { Hung, Ching-cheh; de Groh, Kim, K.; Banks, Bruce, A. }\end{array}$}} & 5d. PROJECT NUMBER \\
\hline & & 5e. TASK NUMBER \\
\hline & & $\begin{array}{l}\text { 5f. WORK UNIT NUMBER } \\
\text { WBS 825080.04.02.30.17 }\end{array}$ \\
\hline \multicolumn{2}{|c|}{$\begin{array}{l}\text { 7. PERFORMING ORGANIZATION NAME(S) AND ADDRESS(ES) } \\
\text { National Aeronautics and Space Administration } \\
\text { John H. Glenn Research Center at Lewis Field } \\
\text { Cleveland, Ohio 44135-3191 }\end{array}$} & $\begin{array}{l}\text { 8. PERFORMING ORGANIZATION } \\
\text { REPORT NUMBER } \\
\text { E-18353 }\end{array}$ \\
\hline \multirow{2}{*}{\multicolumn{2}{|c|}{$\begin{array}{l}\text { 9. SPONSORING/MONITORING AGENCY NAME(S) AND ADDRESS(ES) } \\
\text { National Aeronautics and Space Administration } \\
\text { Washington, DC 20546-0001 }\end{array}$}} & $\begin{array}{l}\text { 10. SPONSORING/MONITOR'S } \\
\text { ACRONYM(S) } \\
\text { NASA }\end{array}$ \\
\hline & & $\begin{array}{l}\text { 11. SPONSORING/MONITORING } \\
\text { REPORT NUMBER } \\
\text { NASA/TM-2012-217678 }\end{array}$ \\
\hline \multicolumn{3}{|c|}{$\begin{array}{l}\text { 12. DISTRIBUTIONIAVAILABILITY STATEMENT } \\
\text { Unclassified-Unlimited } \\
\text { Subject Categories: } 18 \text { and } 27 \\
\text { Available electronically at http://wWw.sti.nasa.gov } \\
\text { This publication is available from the NASA Center for AeroSpace Information, 443-757-5802 }\end{array}$} \\
\hline
\end{tabular}

\section{SUPPLEMENTARY NOTES}

\section{ABSTRACT}

Under a microscope, atomic oxygen (AO) exposed silicone surfaces are crazed and seen as "islands" separated by numerous crack lines, much analogous to mud-tile cracks. This research characterized and compared the degree of AO degradation of silicones by analyzing optical microscope images of samples exposed to low Earth orbit (LEO) AO as part of the Spacecraft Silicone Experiment. The Spacecraft Silicone Experiment consisted of eight DC 93-500 silicone samples exposed to eight different AO fluence levels (ranged from 1.46 to $8.43 \times 10^{21}$ atoms $/ \mathrm{cm}^{2}$ ) during two different Materials International Space Station Experiment (MISSE) missions. Image analysis software was used to analyze images taken using a digital camera. To describe the morphological degradation of each AO exposed flight sample, three different parameters were selected and estimated: (1) average area of islands was determined and found to be in the 1000 to $3100 \mathrm{~mm}^{2}$ range; (2) total length of crack lines per unit area of the sample surface were determined and found to be in the range of 27 to $59 \mathrm{~mm}$ of crack length per $\mathrm{mm}^{2}$ of sample surface; and (3) the fraction of sample surface area that is occupied by crack lines was determined and found to be in the 25 to 56 percent range. In addition, average crack width can be estimated from crack length and crack area measurements and was calculated to be about $10 \mathrm{~mm}$. Among the parameters studied, the fraction of sample surface area that is occupied by crack lines is believed to be most useful in characterizing the degree of silicone conversion to silicates by AO because its value steadily increases with increasing fluence over the entire fluence range. A series of SEM images from the eight samples exposed to different AO fluences suggest a complex sequence of surface stress due to surface shrinkage and crack formation, followed by re-distribution of stress and shrinking rate on the sample surface. Energy dispersive spectra (EDS) indicated that upon AO exposure, carbon content on the surface decreased relatively quickly at the beginning, to 32 percent of the pristine value for the least exposed sample in this set of experiments $\left(1.46 \times 10^{21}\right.$ atoms $\left./ \mathrm{cm}^{2}\right)$, but then decreased slowly, to 22 percent of the pristine value for the most exposed sample in this set of experiment $\left(8.43 \times 10^{21}\right.$ atoms $\left./ \mathrm{cm}^{2}\right)$. The oxygen content appears to increase at a slower rate. The least and most AO exposed samples were, respectively, 52 and 150 percent above the pristine values. The silicone samples with the greater AO exposure $\left(7.75 \times 10^{21}\right.$ atoms/cm ${ }^{2}$ and higher) appear to have a surface layer which contains $\mathrm{SiO}_{2}$ with perhaps small amounts of unreacted silicone, $\mathrm{CO}$ and $\mathrm{CO}_{2}$ sealed inside.

\section{SUBJECT TERMS}

Silicone; low Earth orbit (LEO); Space environment; Environmental degradation; Characterization

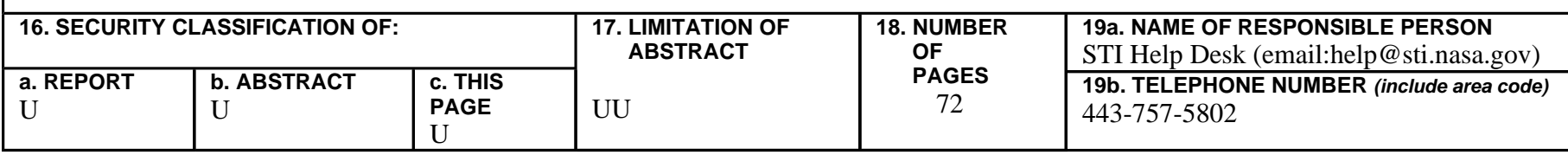


